\title{
EVOLUCIÓN DE LA SEGREGACIÓN ESCOLAR
}

\section{EN ARGENTINA}

\author{
David José Jaume * \\ Tesis de Maestría \\ Maestría en Economía \\ Universidad Nacional de La Plata
}

Director de Tesis: Leonardo Gasparini

\begin{abstract}
Resumen
El trabajo lleva a cabo un análisis empírico exhaustivo del nivel y evolución de la segregación escolar en Argentina desde el año 1992 al año 2010, centrándose particularmente en los alumnos pertenecientes a familias del $20 \%$ más pobre de la población. Con ese fin se proponen dos nuevas metodologías al estudio de la segregación: las curvas de segregación percentílicas y la utilización de micro descomposiciones. Los resultados obtenidos son alarmantes: la segregación se incrementó entre $30 \%$ y $100 \%$ dependiendo del índice y el nivel educativo analizado. Este aumento guarda una estrecha relación con los cambios en las características de las familias en el nivel primario, no así en el nivel secundario.
\end{abstract}

JEL: D63, 121, Z13.

\footnotetext{
Centro de Estudios Distributivos, Laborales y Sociales, Facultad de Ciencias Económicas, Universidad Nacional de La Plata. CONICET. Agradezco a Leonardo Gasparini por la dirección y coordinación de este trabajo de tesis; a Mariana Conte Grand, Fernando Bazán, Monserrat Serio, Emanuel Vazquez, Mariana Viollaz y a los asistentes al seminario de avance de tesis por sus valiosos comentarios y sugerencias.
} 


\section{Índice}

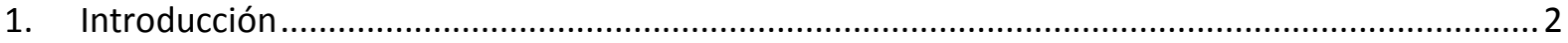

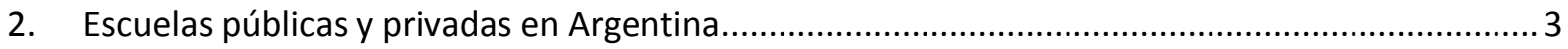

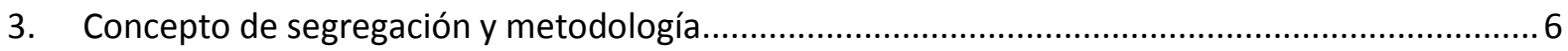

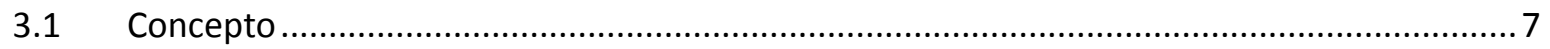

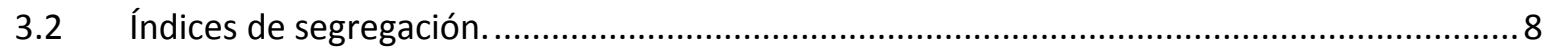

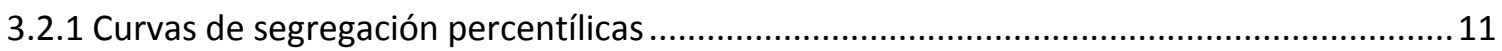

3.2.2. Curvas de segregación percentílicas de vulnerables. ....................................................... 12

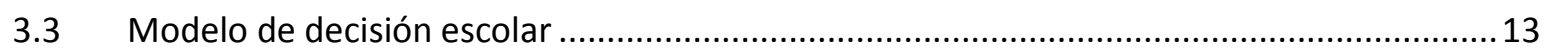

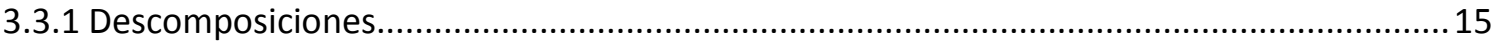

$4 \quad$ Base de datos y análisis descriptivo ......................................................................................... 16

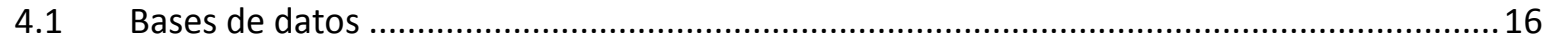

4.2 Composición socio-económica de la matrícula escolar ......................................................17

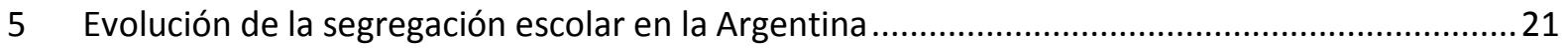

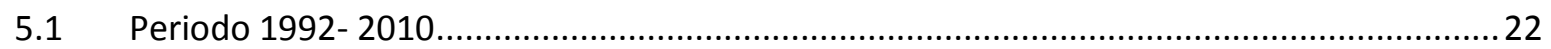

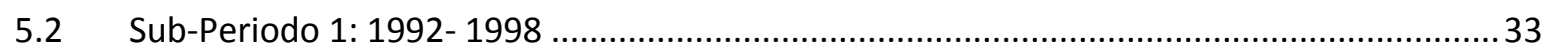

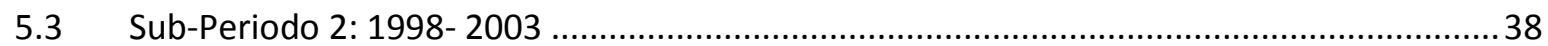

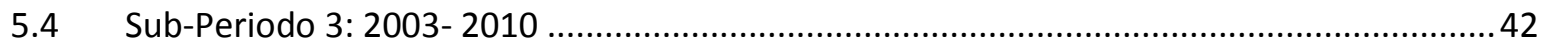

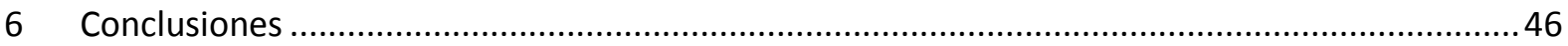

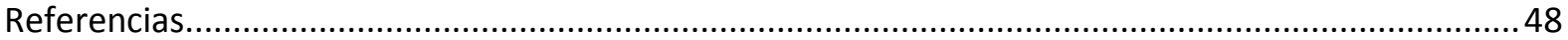




\section{Introducción}

Durante décadas la escuela pública fue considerada un pilar esencial para la cohesión social y la igualdad de oportunidades en Argentina. La escuela pública era uno de los pocos ámbitos donde personas provenientes de estratos sociales diferentes tenían un contacto directo diario y recibían un servicio semejante. Existe una percepción generalizada de que ese papel cohesionador de la educación estatal se ha ido debilitando con el tiempo, dada la creciente migración de los grupos menos carenciados desde las escuelas públicas a las privadas. Esta migración selectiva, conjuntamente con cambios en la composición socio-económica de la matrícula escolar, fueron dando forma al fenómeno de segregación escolar, por el cual los niños de distintos estratos socioeconómicos ya no se "mezclan" en la etapa educativa, al asistir a distintos tipos de establecimientos.

Si bien en los últimos años el debate sobre la segregación escolar en Argentina ha estado permanentemente presente en la opinión pública, pocos trabajos proveen de evidencia empírica sobre la evolución de este fenómeno. Gasparini, Jaume, Serio y Vázquez (2010) realizan un análisis empírico de la evolución de la segregación escolar entre escuelas públicas y privadas en la Argentina, considerando todas las encuestas de hogares disponibles. Estos autores muestran una preocupante tendencia creciente en el periodo 1992-2009, con tres sub-periodos de comportamientos bien diferenciados.

Este trabajo busca ampliar ese estudio con el fin de proveer de evidencia más robusta respecto a los cambios acontecidos en el total del periodo en general y en cada sub-periodo en particular, y se centra principalmente en la segregación de los alumnos pertenecientes a las familias del $20 \%$ más pobre de la población bajo estudio. A su vez, se realiza un aporte al análisis causal del fenómeno mediante la utilización de descomposiciones al estimar qué parte de las variaciones en la segregación escolar se deben a cambios en las características familiares de los estudiantes durante el periodo bajo estudio.

Con este fin se utilizan las Encuestas Permanentes de Hogares (EPH) de los años $1992^{1}, 1998$ y 2003 a 2010, que conforman una serie de datos comparables posibilitando estudiar de manera consistente los cambios acontecidos en estos 18 años. Los diferentes tipos de análisis utilizados proveen evidencia empírica de un aumento alarmante de la segregación escolar en la Argentina entre los años 1992 y 2010. Tanto en el nivel primario como en el nivel secundario se observa una fuerte migración de los alumnos menos carenciados desde los colegios públicos a los privados, así como significativos cambios en la composición socio-económica de la matrícula escolar. La dirección y magnitud de ambos efectos se encuentra detrás del incremento de la segregación escolar en la Argentina. No obstante, su evolución no es uniforme en todos los años analizados, haciendo interesante el análisis por sub-periodos que serán examinados por separado a lo largo del trabajo.

Además, al poner en el centro de la investigación a los alumnos considerados pobres (aquellos que forman parte de familias del $20 \%$ más pobre de la población), se observa que éstos están mucho más segregados en 2010 que en 1992 respecto de cualquier otro grupo de alumnos, especialmente de los sectores altos pero también de los sectores medios y medios-bajos. Estos resultados son robustos a diferentes definiciones de grupos de población vulnerable.

\footnotetext{
${ }^{1}$ Para este año sólo se dispone de información del Gran Buenos Aires.
} 
Finalmente, los cambios en los niveles de segregación escolar del nivel primario se deben en gran parte a variaciones en las características de las familias. De esta manera, tanto el aumento en el ingreso, en la educación de los padres, así como en otras características observables del hogar y del niño permiten explicar casi la totalidad del incremento en la segregación escolar en el periodo analizado. Por el contrario, en el nivel secundario operaron cambios más profundos en la manera en que los hogares toman las decisiones relacionadas a la escolaridad de sus miembros en edad de asistir a este nivel (no asistir al colegio, asistir a un colegio privado o asistir a un colegio público), por lo que las variaciones en estas características resultan poco relevantes para dar cuenta de los notables aumentos en la segregación escolar entre 1992 y 2010.

La principal contribución del trabajo consiste en llevar a cabo un análisis empírico exhaustivo del nivel y evolución de la segregación escolar en Argentina. Con ese fin, se proponen dos nuevas metodologías al estudio de la segregación: las curvas de segregación percentílicas y la utilización de micro descomposiciones. La primera herramienta tiene dos versiones, por un lado permite examinar la sensibilidad de los resultados a diferentes definiciones de grupos y por otro focalizarse en un determinado grupo de interés analizando su segregación respecto a varios sub-grupos restantes. La segunda herramienta busca avanzar en la búsqueda del origen del incremento en la segregación escolar, evaluando qué parte de estos cambios pueden ser explicados por variaciones en las características de las familias.

El resto del trabajo está organizado de la siguiente manera. La sección 2 discute las particularidades del sistema educativo argentino. La sección 3 presenta el concepto de segregación y la metodología utilizada. La sección 4 se descompone en dos partes, la primera presenta las bases de datos utilizadas, y la segunda analiza los cambios en la composición socio-económica de la matrícula educativa. La sección 5 muestra la evolución de la segregación escolar en la Argentina, examinando tanto los años extremos analizados (1992 y 2010) como tres sub-periodos de particular interés: 1992-1998; 1998-2003; y 2003-2010. Finalmente, las conclusiones arribadas se detallan en la sección 6.

\section{Escuelas públicas y privadas en Argentina ${ }^{2}$}

El sistema educativo de Argentina se basa fundamentalmente en principios que surgen de la Constitución Nacional, que son universalidad, gratuidad, obligatoriedad y educación común a todos los habitantes del país. Una de las finalidades de este sistema es fomentar la igualdad de oportunidades entre clases sociales y eliminar inequidades educativas entre regiones (Ley de Educación Nacional 26.206, artículo 11). A lo largo de la historia se han observado intentos de construir un sistema educativo que genere resultados de calidad independientemente de la clase social y contribuya a la igualdad de oportunidades. Desde la "obra sarmientista" cuya idea central era educar a todo el pueblo para prepararlo en el uso de los derechos humanos, estos principios se han constituido en pilares esenciales del sistema educativo argentino. Como consecuencia, las escuelas argentinas albergaron desde sus inicios alumnos de diferentes razas, culturas, nacionalidades y en particular, estudiantes de distintas clases sociales.

\footnotetext{
${ }^{2}$ Parte de esta sección está basada en el trabajo realizado por Gasparini, Jaume, Serio y Vazquez (2010).
} 
Si bien el sistema educativo argentino ha transitado por diferentes estructuras en los últimos años, en este documento se opta por trabajar con el sistema tradicional, el cual consiste en dos grandes bloques: la primaria, de 7 años de duración, y la secundaria, de 5 años. Una característica relevante a tener en cuenta es que si bien la ley obliga a los padres a que sus hijos menores se instruyan y asistan al sistema educativo una determinada cantidad de años, ellos tienen derecho a elegir libremente el tipo y clase de educación que desean para sus hijos. En la Argentina se observan dos tipos de gestión educativa: pública y privada. Ambos tipos presentan diferencias a nivel de rendimiento académico, infraestructura, docentes, etc. que influyen en la toma de decisiones de los padres sobre el tipo de educación para sus hijos.

El Operativo Nacional de Evaluación (ONE) realizado en el año 2000 ofrece un primer panorama sobre estas diferencias. Los datos relevados permiten observar que las escuelas privadas, primarias y secundarias, presentan en promedio mejores notas académicas en materias de Lengua $y$ Matemática, diferenciándose en puntaje en más de 10 puntos porcentuales. También exhiben, en promedio, una menor tasa de repitencia. En el caso de la primaria pública, el $23.4 \%$ de los alumnos ha repetido al menos una vez en comparación al 5.3\% de la escuela privada. En el caso de la secundaria pública, el $30.5 \%$ de los alumnos ha repetido, en tanto este porcentaje alcanza solamente el $11.9 \%$ en la privada. Sin embargo no es claro que esta diferencia en resultados guarde mayor relación con la gestión privada que con el contexto del alumnado en cada tipo de escuela. Marchionni, Vazquez y Pinto (2011) analizan los resultados de las pruebas PISA $2009^{3}$ realizado en Argentina y encuentran que las escuelas privadas rinden, en promedio, un $23 \%$ por encima de las escuelas públicas y estas diferencias responden esencialmente a la disímil composición socioeconómica del alumnado de uno y otro tipo de escuela.

También se evidencian diferencias respecto a la infraestructura de los colegios primarios. El $92.5 \%$ de los colegios privados poseen un edificio en buenas condiciones mientras que sólo el $62.9 \%$ de los públicos cuentan con un buen estado edilicio. El $88.9 \%$ de los privados cuentan con mobiliario en buen estado, algo que sólo el $46.5 \%$ de los públicos posee. El $93.2 \%$ de las escuelas privadas tienen aulas en buenas condiciones para los alumnos, en tanto sólo el $55.5 \%$ de las escuelas públicas poseen aulas en ese estado. Finalmente, las escuelas privadas también presentan mejor infraestructura que las públicas en lo que respecta al buen estado de la biblioteca y los libros para los alumnos.

Estas diferencias entre las escuelas públicas y privadas posiblemente ayuden a comprender parte de la dinámica reciente en la tasa de asistencia a escuelas gestionadas por el Estado. Para ilustrarla, la Figura 1 muestra la evolución histórica de la participación del sector privado en la matrícula total de alumnos desde 1894 hasta el presente, tanto en primaria como en secundaria.

En el nivel primario, se observa a principios del siglo XX una considerable reducción de la participación del sector privado en la matrícula total, producto del crecimiento del sector público en la provisión de servicios educativos. Durante la primera mitad del siglo pasado, la participación del sector privado en la educación primaria se mantuvo en niveles muy bajos (cercanos al 10\%). A partir de 1955, sin embargo, es posible observar un cambio de tendencia. La Figura 2 exhibe un aumento

\footnotetext{
${ }^{3}$ Las pruebas PISA son evaluaciones que se realizan a una muestra representativa de adolescentes de 15 años en distintos países del mundo, incluida la Argentina.
} 
en la matrícula primaria del sector privado a finales de los cincuenta ${ }^{4}$, y desde entonces este sector ha ido aumentando su participación respecto a la matrícula total. En efecto, si en 1940 sólo un $7.2 \%$ de los alumnos asistía a una escuela privada, en el 2010 este porcentaje asciende al 24.7\%, involucrando a casi un cuarto de los estudiantes.

\section{Figura 1: Participación del sector privado en la matrícula de la primaria y secundaria}

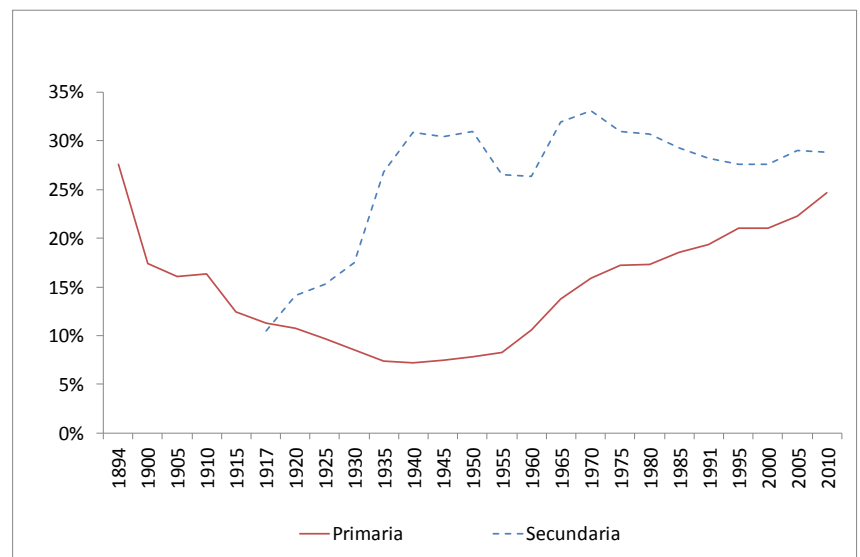

Fuente: Período 1894-1997, Morduchowicz A. et al. (2000). Período 1997-2010, Anuarios estadísticos de la DINIECE, Ministerio de Educación.

Figura 2: Matrícula de alumnos de primaria y secundaria estatal y privada, en millones

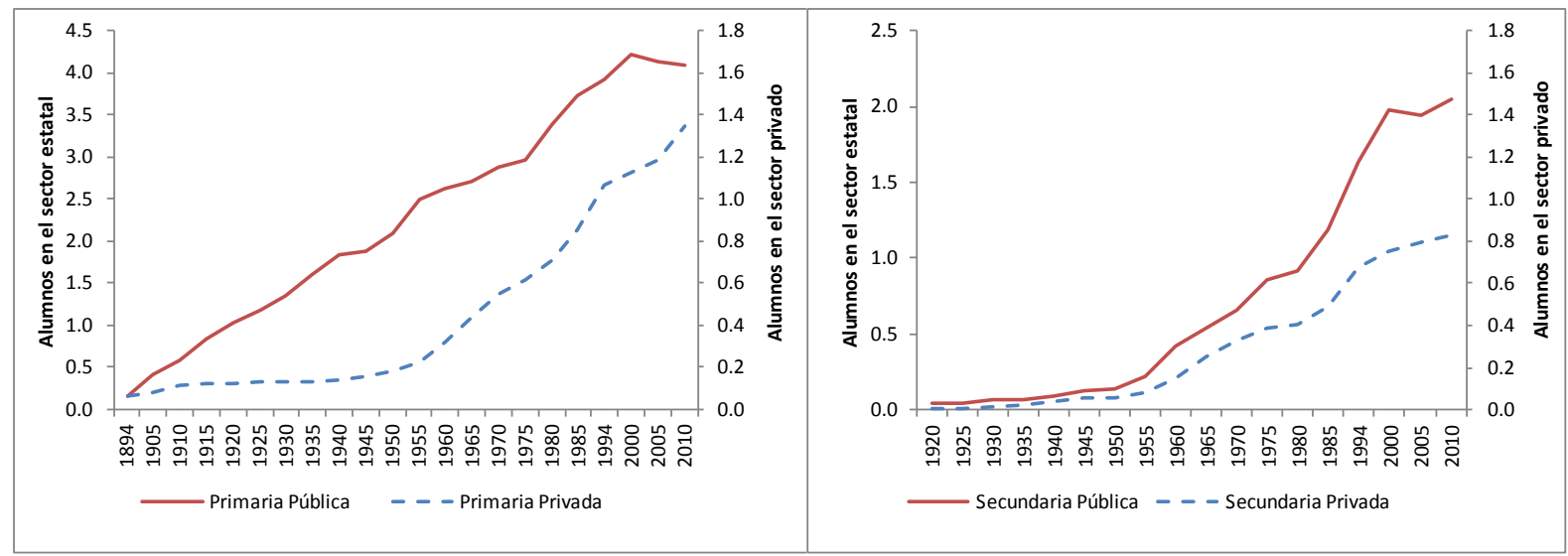

Fuente: Período 1894-1997, Morduchowicz A. et al. (2000). Período 1997-2010, Anuarios estadísticos de la DINIECE, Ministerio de Educación.

En el nivel secundario se aprecia un fuerte incremento de la participación del sector privado desde 1917 a 1940. Ese año, el porcentaje de alumnos se situó alrededor del 30\% y, desde entonces, se mantuvo relativamente estable en esos valores. La evolución durante los últimos años muestra una leve tendencia a la baja durante los ochenta y los noventa que, según Rivas, Vera y Bezem (2010), obedece a que desde el retorno a la democracia en 1983 el crecimiento en el acceso de sectores carenciados a la escuela estatal ha sido muy alto, y esto ha más que compensado el masivo pasaje al sector privado de los estratos medios y altos (que asistieron históricamente a la escuela pública). Sin

\footnotetext{
${ }^{4}$ Narodowski y Andrara (2000) indican la existencia de un decreto (Artículo 2 del Decreto $\mathrm{N}^{\circ} 12.179$ del 3 de octubre de 1960) por el cual los colegios privados podían ahora expedir credenciales educativas reconocidas como válidas por el estado, lo que equiparaba legalmente a estas instituciones respecto a las escuelas públicas. Cervini (2003) indica que existieron otros cambios importantes desde 1947 a 1960, como la sistematización e institucionalización del subsidio estatal a la educación de gestión privada, la eliminación de los exámenes finales obligatorios para el sector privado y la legitimación de la autonomía de los colegios de gestión privada.
} 
embargo, a partir del año 2000 se observa un nuevo cambio de tendencia, en el que la participación del sector privado en la secundaria crece a la par del sector público. En los últimos 10 años, por primera vez en el último siglo, la cantidad total de alumnos en las escuelas públicas cayó, en tanto la matrícula en las escuelas privadas conserva su tendencia creciente.

Como se muestra en la Figura 3, en la última mitad de la década de los ochenta el crecimiento de la matrícula respecto al año 1985 fue similar para ambos sectores educativos, tanto para primaria como secundaria. En los noventa, el sector privado muestra un mayor crecimiento que el estatal en el nivel primario, pero la diferencia se hace más notoria en los dos mil donde la cantidad de alumnos en establecimientos estatales cae mientras continuó aumentando en el sector privado. En el nivel secundario, la matrícula de ambos tipos de colegios crece a tasas similares. No obstante, durante el período 2001-2010 se encuentra que en las escuelas primarias de gestión estatal la matrícula descendió un $4.5 \%$, mientras que en la secundaria estatal aumentó $2.5 \%$. Por otro lado, las escuelas privadas exhibieron en el mismo período un incremento mucho más elevado en sus matrículas: $25.1 \%$ en primaria y $11.3 \%$ en secundaria. Este fenómeno evidencia claramente una intensificación del pasaje de alumnos del sector estatal al sector privado durante la última década.

Dada la creciente importancia del sector privado en la educación primaria, y su reciente evolución en el nivel secundario, es interesante preguntarse si esta migración desde la escuela pública a la privada ha sido uniforme en los diferentes estratos socio-económicos o si, por el contrario, las dificultades de las clases más bajas para pagar un arancel dejan a estos grupos crecientemente relegados a interactuar en la escuela pública con pares en una situación similar. Las secciones 4 y 5 exploran este interrogante. Para ello, en la sección 3 se define qué se entiende por segregación escolar y que herramientas serán utilizadas para analizar su evolución.

\section{Figura 3: Crecimiento de la matrícula de alumnos de primaria y secundaria estatal y privada}

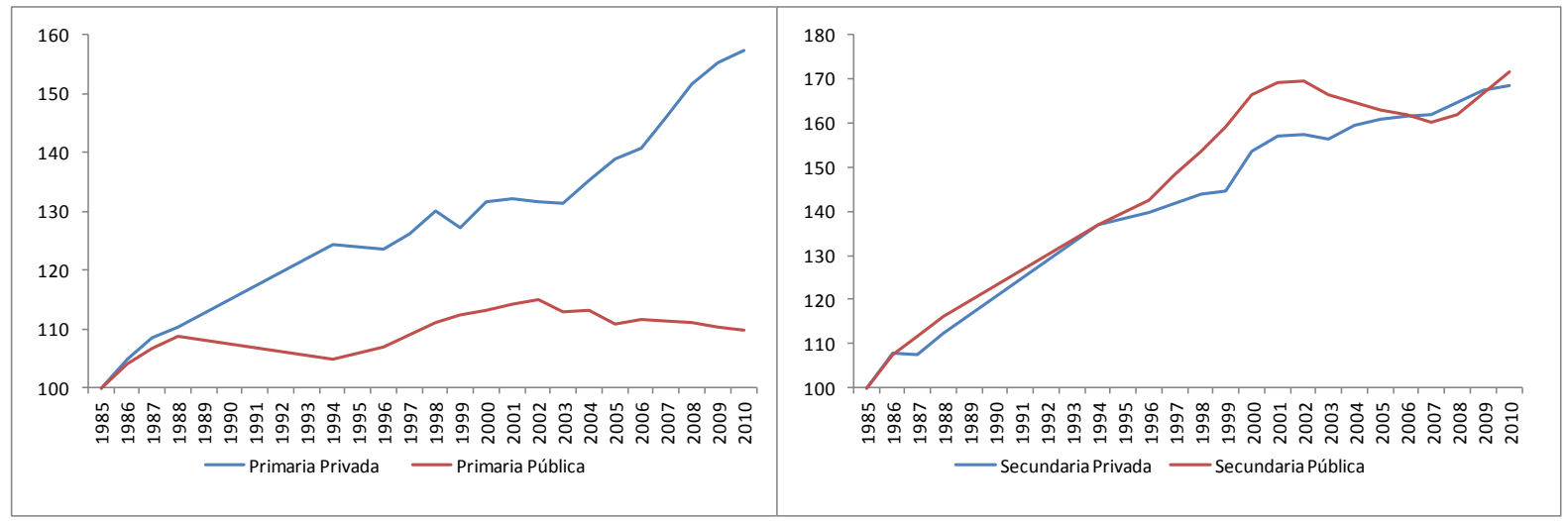

Fuente: Anuarios estadísticos de la DINIECE, Ministerio de Educación, 1985-2010.

Nota: Índice base 1985=100.

\section{Concepto de segregación y metodología}

En la primera parte de esta sección se introduce el concepto de segregación escolar. En la parte 2 se detallan primero los índices utilizados en este trabajo para medir el fenómeno. Luego se presentan las curvas de segregación percentílicas, que permiten profundizar la información provista por cada índice y que son herramientas propuestas por este trabajo para mejorar el análisis de la segregación. 
Por último, en la tercera parte de esta sección se desarrolla el modelo de decisión escolar por parte de las familias, que será utilizado luego con el doble objetivo de explorar la relación entre el percentil del ingreso familiar per cápita y la probabilidad de no asistir al colegio, asistir a un colegio privado, o asistir a un colegio público; así como realizar descomposiciones del cambio en la segregación escolar para conocer cuánto del mismo es atribuible a variaciones en las características de las familias.

\subsection{Concepto}

El concepto de segregación alude a la separación de la población en unidades de acuerdo a cierto atributo. Esta definición general implica cierta complejidad, dado que la población puede estar separada en grupos que compartan determinada cualidad de numerosas maneras. Massey y Denton (1988) proponen estudiar la segregación en términos de dimensiones que, si bien empíricamente tienden a solaparse (grupos segregados en cierta dimensión tienden a estarlo en otra), son conceptualmente distintas ${ }^{5}$.

En el presente trabajo se estudian dos dimensiones de la segregación, denominadas comúnmente similitud y exposición. La primera de ellas hace referencia a la tendencia de distintos grupos a distribuirse de manera desigual entre unidades organizativas, tales como escuelas o vecindarios. De acuerdo a esta definición, se dice que un grupo está segregado si está sobre representado en algunas unidades organizativas y sub representado en otras. La segunda dimensión, exposición, está asociada al grado de contacto potencial o posibilidad de interacción entre miembros de los distintos grupos al interior de una unidad organizacional. En este sentido, se dice que un grupo está segregado si tiene escasa probabilidad de encontrarse con miembros de los restantes grupos en la unidad organizativa a la que pertenece.

En general, la literatura se ha interesado en estudiar segregación residencial, laboral y escolar, dividiendo la población en estratos sociales (de acuerdo a atributos tales como raza, género o nivel socio-económico) e investigando la distribución de estos grupos entre barrios, trabajos o escuelas. La segregación escolar se refiere a la separación de la población estudiantil entre establecimientos educativos de acuerdo a cierta característica. En particular, en Argentina resulta relevante investigar si grupos de estudiantes de diverso nivel socio-económico se distribuyen de manera desigual (perdiendo posibilidad de interacción) entre dos tipos de establecimientos: las escuelas públicas, por un lado, y las escuelas privadas, por el otro.

Como se expuso en la sección anterior, en los últimos años Argentina ha presenciado un aumento en la importancia relativa del sector privado en la provisión de servicios educativos. Es razonable pensar que el incremento evidenciado en el porcentaje de alumnos que asisten a una escuela privada no ha sido simétrico para todos los estratos sociales, dado que las familias de menor nivel socio-económico tienen pocas posibilidades de enviar a los hijos a una escuela privada. Si esta presunción es correcta, un resultado posible es una menor interacción entre alumnos de diversas clases sociales en los establecimientos educativos, donde los alumnos de menor nivel socio-económico se relacionan casi

\footnotetext{
${ }^{5}$ Las dimensiones de segregación propuestas por Massey y Denton (1988) son: similitud, exposición, concentración, centralización y agrupamiento. Las tres últimas hacen referencia al aspecto geográfico del fenómeno, no explorado en este estudio.
} 
exclusivamente con individuos en una situación similar en la escuela pública, y la sociedad sufre las nocivas consecuencias educativas y sociales de la segregación.

Numerosas razones fundamentan la necesidad de medir el nivel y la evolución de este fenómeno. La educación se presenta en la mayoría de los debates como la gran esperanza para construir una sociedad socialmente más integrada y más equitativa (Llach, Montoya y Roldán, 1999). No obstante, la segregación escolar empobrece el rol cohesionador de la escuela como ámbito de integración social, en el que los estudiantes aprenden a convivir con personas de distinta condición económica, social y cultural. Esta pérdida contribuye a la generación de fenómenos de exclusión y desintegración en la sociedad, dado el papel que juega la escuela en la formación de grupos ${ }^{6}$. Teorías sociológicas como la desarrollada en la literatura de membrecía (Durlauf, 2006) destacan la influencia que tienen los grupos en la determinación de los resultados individuales, ya sea a través de modelos de rol o del efecto de los pares ${ }^{7}$. De acuerdo a esta teoría, los grupos cuyos miembros son determinados a través de un proceso económico o social más general, tales como los que se forman en las escuelas, pueden generar desigualdades persistentes, y éstas pueden ser más marcadas cuando hay alguna manifestación de segregación.

Parte de la evidencia empírica da cuenta que escuelas menos segregadas generan mejores resultados en los test escolares y que los alumnos que asisten a las mismas se benefician en términos de asistencia universitaria y empleo (Orfield, 2001). En relación a la equidad de resultados educativos, Llach et al. (1999) estudian los determinantes de los rendimientos en los exámenes estándar ONE 1997 realizados en Argentina, encontrando una relación positiva y significativa entre el rendimiento de los alumnos y el nivel socio-económico de los pares ${ }^{8}$. Independientemente de las razones de eficiencia y equidad que inducirían a estudiar el fenómeno, el efecto de la segregación escolar en la generación de una sociedad más integrada hace que una cuantificación precisa de su nivel y evolución en Argentina sea relevante y necesaria. Este trabajo persigue este objetivo haciendo uso de los índices de segregación más usualmente empleados y de un indicador más general propuesto recientemente por Watson (2009).

\section{2 Índices de segregación.}

La literatura de medición de la segregación ha desarrollado desde sus inicios una gran cantidad de índices. El más empleado en los estudios realizados ha sido el denominado índice de Disimilitud, que ganó notable popularidad a partir del trabajo seminal de Duncan y Duncan (1955). En los ochenta, James y Taeuber (1985) desarrollan una serie de propiedades deseables para evaluar las medidas de segregación y Massey y Denton (1988) clasifican a los índices existentes de acuerdo a la dimensión de la segregación que tratan de medir. Estos últimos autores sostienen la necesidad de medir la

\footnotetext{
${ }^{6}$ Un ejemplo para el caso argentino lo provee la Encuesta de Educación y Empleo de los Jóvenes, desarrollada conjuntamente por el CEDLAS, el INDEC y la Asociación Civil Educación para Todos en el año 2005. Según esta encuesta, alrededor de un $75 \%$ de los jóvenes entre 15 y 30 años del aglomerado de Gran Buenos Aires conoció a su mejor amigo en la escuela, lo cual ilustra el papel de la escuela en la conformación de grupos.

${ }^{7}$ Los modelos de rol sostienen que el comportamiento de un miembro del grupo está influenciado por las conductas anteriores de los miembros más antiguos. El efecto de los pares, por su parte, hace referencia a comportamientos de imitación presentes y recíprocos entre los miembros de un grupo determinado.

${ }^{8}$ Los autores determinan tres valores de nivel socio-económico de los pares: alto, medio y bajo. En el caso de la educación primaria, el rendimiento promedio de los alumnos con efecto pares alto es $60 \%$ superior al rendimiento promedio de estudiantes con efecto pares bajo.
} 
segregación con varios índices para poder captar las distintas dimensiones subyacentes del fenómeno y, además, recomiendan el uso del índice de Aislamiento como medida de exposición. Recientemente, autores como Watson (2009) avanzan en torno a índices que no dependen de la arbitrariedad del investigador para definir los grupos, explotando la información referida a ingresos.

La aplicación al presente estudio de los índices de segregación tradicionales requiere la división de los estudiantes en grupos en función de su nivel socio-económico. En base a esto, se clasifica a los alumnos en pobres y no pobres de acuerdo a si pertenecen o no al primer quintil de la distribución del ingreso per cápita familiar, y se los divide según el tipo de establecimiento educativo al que asisten (estatal o privado). El primero de los índices empleados es el de Disimilitud, que se define como:

$$
D=\frac{1}{2} \sum_{i=1}^{k}\left|\frac{x_{1 i}}{X_{1}}-\frac{x_{2 i}}{X_{2}}\right|,
$$

donde $i$ indexa en este caso el tipo de establecimiento escolar (público o privado), $x_{1 i}$ representa el número de alumnos pobres en el tipo de establecimiento $i, X_{1}$ el total de alumnos pobres, $x_{2 i}$ el número de estudiantes no pobres en el establecimiento $i$ y $X_{2}$ el total de estudiantes no pobres. Este índice capta la dimensión de similitud del fenómeno de segregación y refleja la proporción de estudiantes del grupo minoritario, catalogados en este caso como pobres, que deberían cambiar de tipo de establecimiento escolar para que exista una distribución homogénea de los mismos entre los distintos establecimientos. Sus valores oscilan entre 0 y 1 , donde 0 representa segregación nula y 1 la máxima segregación.

El segundo de los índices utilizados en el presente estudio capta la dimensión de exposición de la segregación. Se trata del denominado Índice de Aislamiento, definido como:

$$
A=\sum_{i=1}^{k} \frac{x_{1 i}}{X_{1}} \frac{x_{1 i}}{T_{i}},
$$

donde $T_{i}$ es el total de alumnos en el tipo de establecimiento $i$. Este índice puede interpretarse como la probabilidad de que un miembro del grupo minoritario (estudiantes pobres en este caso) se encuentre en un establecimiento con otro miembro de su grupo. Al captar el grado de contacto potencial de los estudiantes pobres con otros alumnos pobres, en lugar de alumnos no pobres, está afectado por la participación relativa del grupo minoritario en la población total de estudiantes ${ }^{9}$. Al igual que $D$, este índice varía en el rango de [0,1], siendo 1 la segregación máxima posible.

Una característica que se desprende del uso de indicadores desarrollados en la literatura de segregación por raza para medir segregación por nivel socio-económico, es que los grupos relevantes deben ser definidos por el investigador. Para Watson (2009), los límites entre estos grupos no son necesariamente obvios, por lo que propone una alternativa para solucionar este problema de arbitrariedad empleando el Índice de Brecha por Centiles (CGI), que constituye el tercer

\footnotetext{
${ }^{9}$ Esto no constituye una desventaja del indicador, sino una característica razonable dada la dimensión de la segregación que intenta medir. El índice $\mathrm{Eta}^{2}$, que no es más que el índice de Aislamiento con una corrección por este factor, presenta en este caso la misma evolución que los índices que captan la dimensión de similitud de la segregación (los resultados están disponibles para quien lo solicite).
} 
indicador de segregación escolar presentado en este estudio. El índice utiliza información sobre ingresos para evaluar el promedio de las diferencias percentílicas entre los asistentes a cada unidad organizativa y el percentil mediano en cada una de ellas, y se define como:

$$
C G I=\frac{0.25-\frac{1}{N} \sum_{j=1}^{N}\left|p_{j}-p_{\text {medj }}\right|}{0.25},
$$

donde $p_{j}$ es el percentil al que pertenece el estudiante $j$ y $p_{\text {med } j}$ es el percentil al que pertenece el estudiante mediano en la unidad organizacional a la que asiste el alumno $j$, escuela pública o privada. Si los estudiantes estuvieran perfectamente integrados por su ingreso entre escuelas públicas y privadas, cada unidad reproduciría la distribución general (percentiles de 0 a 1), la diferencia promedio entre una familia y la mediana en su unidad sería 0.25 , con lo cual el índice tomaría valor 0 . En el otro extremo, si los estudiantes estuvieran perfectamente segregados, cada unidad contendría en el límite individuos con el mismo ingreso y en el mismo percentil, por lo que el índice en este caso toma el valor $1^{10}$.

Los tres índices presentados (Disimilitud, Aislamiento y Brecha por Centiles) son utilizados para proveer una caracterización del nivel y la evolución de la segregación escolar en Argentina ${ }^{11}$. Cada uno de ellos puede presentar evoluciones diferentes porque se refieren a aspectos distintos de un mismo fenómeno. En primer lugar, el Índice de Disimilitud mide la forma en que se distribuyen entre tipos de escuelas públicas y privadas los alumnos pobres en relación a cómo se distribuyen los alumnos no pobres. En segundo lugar, el Índice de Aislamiento representa el contacto directo que tienen los alumnos pobres entre sí en cada tipo de establecimiento. Por último, el Índice de Brechas por Centiles es una medición global de segregación relacionada a la dimensión de similitud, pero que pondera por igual a todos los estratos económicos de la población.

Esta forma de interpretar el CGI, como una medida general, tiene implícita una ventaja y una desventaja. Por un lado, permite prescindir de la decisión del investigador respecto de la división de la población en dos grupos, por lo cual la subjetividad del investigador no juega ningún papel. Por otro lado, puede tener propiedades que no necesariamente son deseables precisamente por ponderar de la misma manera a la población de ingresos diferentes. De esta manera, es posible que el índice disminuya cuanto más segregado esté, por ejemplo, el $20 \%$ más pobre si en consecuencia el

\footnotetext{
${ }^{10}$ Nótese que en el caso de analizar únicamente dos unidades organizacionales (escuela pública o privada), no es posible que en cada tipo de establecimiento se encuentren solamente estudiantes del mismo percentil de ingresos (para lo cual sería necesario un mínimo de 100 escuelas), por lo que el índice nunca podrá tomar el valor 1. En efecto, siempre habrá alguna interacción entre estudiantes pertenecientes a distinto percentil de ingresos, de manera tal que el peor escenario posible para la definición de segregación subyacente en el CGI no es factible.

11 Además de D, A y CGI, se computaron otros índices comúnmente utilizados en la literatura (Interacción, Teoría de la Información, Atkinson, Gini, Ratio de Varianza y Raíz Cuadrada), pero como las conclusiones a partir de los resultados son idénticas a las obtenidas con D y A, no se incluyen en el presente trabajo (los indicadores están disponibles para aquél que los solicite).
} 
resto de la población se distribuye de forma más homogénea ${ }^{12}$. Por lo tanto, el resultado de este índice debe ser interpretado con cuidado, especialmente cuando el interés del estudio recae sobre un grupo determinado de la población.

Es por esta desventaja del CGI que si el investigador desea estudiar la segregación de una población específica (en este trabajo los alumnos pertenecientes al primer quintil del ingreso per cápita familiar) es necesario utilizar los índices tradicionales, como el Índice de Disimilitud y el Índice de Aislamiento, para poner en el centro del análisis a este grupo de la población. Si bien estos índices dependen de una elección subjetiva, es posible encontrar herramientas para examinar cómo cambian los resultados ante una elección diferente. La propuesta de este trabajo es realizar "curvas de segregación percentílicas", que serán definidas a continuación. También resulta relevante analizar respecto de qué grupos se encuentran más segregados los alumnos pobres, y como cambia en el tiempo esta relación. Esto último será explorado mediante las "curvas de segregación percentílicas de vulnerables", que también se presentan a continuación.

\subsubsection{Curvas de segregación percentílicas}

Con el objetivo de realizar un análisis de sensibilidad de los resultados respecto a la elección del punto de corte entre alumnos pobres y no pobres, este trabajo propone construir una curva tal que presente el valor de los índices de segregación que precisan de esta división (como los índices D y A) para cada uno de todos los posibles grupos a considerar. De esta manera se define como "curva de segregación percentílica de disimilitud" al conjunto de valores $p$ y $D(p)$ tal que

$$
D(p)=\frac{1}{2} \sum_{i=1}^{k}\left|\frac{x_{p i}}{X_{p}}-\frac{x_{[p+1,100] i}}{X_{[p+1,100]}}\right| \forall p=(10, \ldots, 90)
$$

donde $i$ indexa en este caso el tipo de establecimiento escolar (público o privado), $x_{p i}$ representa el número de alumnos con ingreso familiar per cápita iguales o por debajo del percentil $p$ en el tipo de establecimiento $i, X_{p}$ el total de alumnos con ingreso familiar per cápita iguales o por debajo del percentil $p, x_{[p+1,100] i}$ el número de estudiantes con ingreso familiar per cápita por encima del percentil $p$ en el establecimiento $i$ y $X_{[p+1,100]}$ el total de estudiantes con ingreso familiar per cápita por encima del percentil $p$. De esta manera, se obtienen 80 índices de disimilitud de acuerdo al percentil del 10 al $90^{13}$ que se tenga en cuenta como punto de corte para dividir en dos a la población analizada.

De forma equivalente se define como "curva de segregación percentílica de aislamiento" al conjunto de valores $p$ y $A(p)$ y tal que

$$
A(p)=\sum_{i=1}^{k}\left|\frac{x_{p i}}{X_{p}}-\frac{x_{p i}}{T_{i}}\right| \forall p=(10, \ldots, 90)
$$

\footnotetext{
${ }^{12}$ Cowell (2000) indica que algo similar ocurre con el índice de desigualdad de ingresos Gini por la misma razón: pondera de la misma manera a toda la población, aunque en este caso se trata de cambios distributivos y en el caso del CGI de cambios en la distribución de los distintos percentiles entre escuelas públicas y privadas.

${ }^{13}$ No se consideran percentiles inferiores al 10 o superiores al 90 debido a las pocas observaciones con que cuenta cada grupo.
} 
donde $T_{i}$ es el total de alumnos en el tipo de establecimiento $i$ y el resto de las variables se definen como en la curva de disimilitud. Nuevamente se obtienen 80 índices A de acuerdo al percentil de corte utilizado para separar en dos grupos a la población total.

Ambas curvas representan los valores de los índices de segregación para cada posible grupo de estudio en un año determinado. Existen al menos dos ventajas principales de realizar esta aproximación. En primer lugar, permite observar la sensibilidad de los índices de segregación ante cambios en la definición de grupos. En segundo lugar, es posible graficar esta curva para dos periodos diferentes y de su comparación extraer para qué definiciones de grupos aumentó la segregación, así como para cuales permaneció constante o disminuyó, entre los dos años analizados.

\subsubsection{Curvas de segregación percentílicas de vulnerables.}

Teniendo en cuenta el espíritu de la curva anterior pero con un objetivo diferente, las curvas de segregación percentílicas de vulnerables analizan la segregación de un grupo socio-económico de la población que resulta de interés (los alumnos pobres en este estudio) respecto al resto de los posibles grupos de comparación. Estos grupos pueden definirse de diferente tamaño según las preferencias del analista. En este trabajo, esta herramienta será utilizada para cuantificar la segregación de los alumnos pertenecientes al $20 \%$ más pobre de la población respecto de todos los otros grupos compuestos por 20 percentiles consecutivos de la población no pobre, como resultan ser los 60 grupos solapados pero diferentes de alumnos pertenecientes a diversos intervalos de percentiles iguales a $21-40,22-41,23-42, \ldots, 80-99,81-100 .{ }^{14}$

Se define la "curva de segregación percentílica de disimilitud de vulnerables" al conjunto de valores $p$ y $D(v p)$ tal que

$$
D(v p)=\frac{1}{2} \sum_{i=1}^{k}\left|\frac{x_{v i}}{X_{v}}-\frac{x_{[p, p+z] i}}{X_{[p, p+z]}}\right| \forall p=(v+1, \ldots, 100-z)
$$

donde $i$ indexa en este caso el tipo de establecimiento escolar (público o privado), $x_{v i}$ representa el número de alumnos del $v \%$ más pobre de la población en el tipo de establecimiento $i, X_{v}$ el total de alumnos del $v \%$ más pobre de la población, $x_{[p, p+z] i}$ el número de estudiantes con ingreso familiar per cápita en el intervalo $[p, p+z]$ en el establecimiento $i$ y $X_{[p, p+z]}$ el total de estudiantes con ingreso familiar per cápita en el intervalo $[p, p+z]$.

Por su parte, se define como "curva de segregación percentílica de aislamiento de vulnerables" al conjunto de valores $p$ y $A(p v)$ tal que

$$
A(p v)=\sum_{i=1}^{k}\left|\frac{x_{v i}}{X_{v}}-\frac{x_{v i}}{T_{(v,[p, p+z]) i}}\right| \forall p=(v+1, \ldots, 100-z)
$$

\footnotetext{
${ }^{14}$ No obstante, esta herramienta también permite realizar el mismo análisis pero poniendo el foco en otros grupos poblacionales dependiendo del objetivo del estudio, como puede ser el $15 \%, 25 \%, 30 \%$ más pobre o más rico de la población analizada.
} 
donde $T_{(v,[p, p+z]) i}$ es el total de alumnos bajo análisis (suma de aquellos pertenecientes al $v \%$ más pobre de la población y al intervalo de percentiles $[p, p+z]$ ) en el tipo de establecimiento $i$, mientras que el resto de las variables se define con en el índice anterior.

Esta herramienta es de suma utilidad para comprender el nivel de segregación del grupo vulnerable de interés respecto a diferentes grupos poblacionales, y sirve especialmente para estudiar la naturaleza de las variaciones en el análisis intertemporal. En este trabajo, el parámetro $v$ se fija en el $20 \%$ y $z$ se considera igual a 19 , de forma tal de siempre comparar en cada punto a los alumnos pobres con grupos socio-económicos alternativos que siempre comprendan el $20 \%$ de la población.

\subsection{Modelo de decisión escolar}

Como argumenta Schelling (1978), la gente se separa en muchas formas y maneras. Hay segregación por sexo, raza, religión, status socio-económico, gustos personales, etc. Los orígenes de la segregación son diversos, se puede producir por procesos deliberadamente organizados, como corolario de otros modos de segregación o por medio de decisiones de los individuos involucrados. Si las escuelas a las que asisten los ricos prohíben la entrada de los pobres, o las escuelas donde asisten los pobres prohíben la entrada de los ricos, el proceso es organizado y puede ser recíproco o de un lado. Si la segregación escolar es consecuencia de que las familias ricas y pobres viven en barrios diferentes, entonces es corolario de la segregación residencial. Por último, la segregación escolar puede deberse a decisiones de familias que, dadas sus preferencias, maximizan la utilidad respecto a las opciones escolares de sus hijos, siendo las mismas: no asistir, asistir a un colegio público, o asistir a un colegio privado.

El caso concreto de la segregación escolar por estrato socio-económico entre escuelas públicas y privadas en la Argentina parece tener su origen en el último de esos procesos, la decisión de los individuos. ${ }^{15}$ En esta sección se analiza un modelo de elección donde las características de las familias juegan un importante rol en la determinación de la decisión escolar. La estimación de este modelo persigue el doble objetivo de, por un lado, determinar la probabilidad de cada una de estas opciones en relación al percentil de ingreso per cápita familiar, y, por otro lado, permitir identificar el efecto que ha tenido sobre la segregación escolar la variación en las características de las familias.

El problema de la elección de escuela presentado anteriormente, puede ser interpretado como un modelo de respuesta multinomial (McFadden, 1984). Se asume que cada familia $i$ debe, necesariamente, optar por alguna de las siguientes opciones $j$ mutuamente excluyentes: $j=1$, no asistir al colegio; $j=2$, asistir a un colegio público; $j=3$, asistir a un colegio privado. Lo lógica de la estructura económica del modelo es la misma que cualquier maximización de utilidad (Bourguignon y Spadaro, 2005). Los agentes, en este caso las familias, simplemente escogen aquella opción que les reporta la mayor utilidad neta. ${ }^{16}$

\footnotetext{
${ }^{15}$ No obstante, es posible que la segregación residencial afecte también la segregación escolar, suponiendo que no todas las familias pueden elegir entre escuelas públicas y privadas debido al vecindario donde viven. Desafortunadamente, los datos de la EPH son insuficientes para analizar esta conexión.

${ }^{16}$ Dada la restricción presupuestaria y las preferencias, las familias escogen la opción que les reporta mayor utilidad.
} 
Se define $E_{i}$ como una variable cualitativa (Bouguignon, Ferreira and Leite, 2003) representando la elección de la familia de manera que $J$ toma el valor 1 si el niño de la familia $i$ en edad escolar no asiste a la escuela, 2 si asiste a un colegio público, y 3 si asiste a un colegio privado. La elección de las familias es representada usando el modelo estándar de maximización de utilidad interpretado en el marco de un modelo multinomial ${ }^{17}$ tal que

$$
E_{i}=j \text { si y sólo si } U_{i}^{j}=E_{j}\left(X_{i}, H_{i}\right)+v_{i}^{j} \geq U_{i}^{k}=E_{K}\left(X_{i}, H_{i}\right)+v_{i}^{k} \text { para } j \neq k
$$

Donde $E_{j}$ es la función latente que refleja la utilidad neta de elegir la opción $j$ (igual a $0,1 \circ 2$ ) para quienes toman decisiones en la familia $i$. En este caso, $X_{i}$ es el vector de las características del niño $i$ (edad y género); $H_{i}$ representa las características familiares (logaritmo del Ingreso per cápita familiar, tamaño de la familia, educación de los padres); $v_{i}^{j}$ es una variable aleatoria que representa la heterogeneidad no observada en el comportamiento de las familias. Expresando el modelo anterior en términos lineales y colapsando las características individuales y del hogar en el vector $Z_{i}$, es posible rescribir la ecuación (1) como

$$
U_{i}^{j}=E_{j}\left(X_{i}, H_{i}\right)+v_{i}^{j}=Z_{i} \beta_{j}+v_{i}^{j} .
$$

El modelo logit multinomial asume que los $v_{i}^{j}$ son independientes e idénticamente distribuidos en las observaciones de la muestra con una distribución doble exponencial $\left.\right|^{18}$. La probabilidad de que la familia $i$ elija la opción $j$ está dada por

$$
P_{i j}=\frac{\operatorname{Exp}\left(Z_{i} \beta_{j}\right)}{\sum_{j} \operatorname{Exp}\left(Z_{i} \beta_{j}\right)}
$$

Es necesario tomar una opción como referencia ya que este modelo de máxima verosimilitud sólo puede estimar diferencias entre los vectores de coeficientes $\beta_{j}$. Si consideramos en este caso $J=2$ es posible rescribir (3) como $^{19}$

\footnotetext{
17 Es posible considerar otros modelos dependiendo del proceso de toma de decisiones que se suponga. El aspecto más importante a tener en cuenta es si estas decisiones son tomadas simultáneamente o secuencialmente (Moyi, 2010). Este caso puede pensarse también como un modelo de elección secuencial donde la familia primero decide si el alumno no asiste o si asiste al colegio y, sólo en caso de inclinarse por esto último, decide si el colegio es público o privado. La literatura ha analizado las diferencias entre procesos simultáneos y secuenciales. Grootaert y Patrinos, (1999) y Post (2002) encuentran resultados similares entre ambos tipos de modelos y recomiendan utilizar modelos logit multinomiales si el orden en que se toman las decisiones no está asegurado. Por su parte, Davidson y Mackinnon (2004) indican que cuando son las mismas variables las que determinan la elección de cada una de las alternativas, es conveniente elegir un modelo logit multinomial. Es por esta última razón que se decide utilizar un modelo logit multinomial ya que no se dispone de datos a nivel escuela (como calidad educativa, distancia, costo, etc). En caso contrario un modelo probit condicional o un modelo logit anidado podría ser utilizado en el análisis.

${ }^{18}$ Este supuesto es esencial para la consistencia del modelo ya que implica IIA (Independencia de alternativas irrelevantes), que se puede evaluar a través de test. El modelo utilizado en el trabajo supera el test de SmallSiao del supuesto de IIA y los test de Wald y LR de combinar alternativas. El test de Hausman respecto a IIA no puede ser computado debido a que el modelo no cumple con los supuestos asintóticos necesarios.

${ }^{19}$ Al poseer pocas observaciones en los niños en edad de asistir a la primaria que no asisten a la escuela, el modelo al iterar no converge y es sólo por esta razón práctica que se escoge j =2 en lugar de j =1 como base.
} 


$$
P_{i j}=\frac{\operatorname{Exp}\left[Z_{i \cdot}\left(\beta_{j}-\beta_{2}\right)\right]}{\sum_{j} \operatorname{Exp}\left[Z_{i \cdot}\left(\beta_{j}-\beta_{2}\right)\right]}
$$

para $\mathrm{j}=1,3$ y $P_{i 2}=1-P_{i 1}-P_{i 3}$

Este modelo permite identificar una probabilidad de elección de no asistir al colegio, asistir a la escuela pública y asistir a la escuela privada para cada combinación posible de los factores familiares e individuales observables (ingreso de la familia y demás factores), es decir para cada estudiante $i^{20}$

\subsubsection{Descomposiciones}

En la literatura del análisis de los cambios en los niveles de desigualdad del ingreso es usual encontrar micro descomposiciones que tienen por objetivo identificar la relevancia de diferentes factores en los cambios distributivos. La metodología desarrollada por Blinder (1973) y Oaxaca (1973), extendida por Juhn, Murphy y Pierce (1993) y por Bourguignon, et. al. (1998), permite analizar en qué medida los cambios en índices de desigualdad se deben variaciones en las características individuales (efecto característica), a la manera en que afectan estas características (efecto parámetros) o a factores inobservables (efecto inobservables).

No es posible utilizar exactamente la misma metodología en este trabajo para simular que parte de los cambios en los índices de segregación escolar se debe a variaciones en las características de las familias. La principal diferencia con la literatura anterior radica en que ésta última se basa en estimaciones del nivel de ingresos laborales por el método de mínimos cuadrados ordinarios, por lo que para cada persona se obtienen estimaciones del componente del error, lo cual no es posible utilizando el modelo Logit Multinomial (notar que el parámetro $v_{i}^{j}$ que aparece en la utilidad luego desaparece en la estimación de las probabilidades que se derivan del modelo).

Por lo tanto, mientras que el verdadero valor del índice de segregación $I_{k}$ en el momento $t$ es función de las características observables, las características inobservables y los parámetros de cada individuo, tal que

$$
I_{k t}=F\left(\left\{Z_{i t}\right\},\left\{v_{i t}\right\}, \beta_{i t}\right) .
$$

No obstante, del modelo Logit Multinomial sólo es posible estimar

$$
\hat{I}_{k t}=F\left(\left\{Z_{i t}\right\}, \hat{\beta}_{i t}\right) \text {. }
$$

De esta manera la descomposición no se realiza sobre la diferencia real del índice de segregación en dos años diferentes, sino en la diferencia entre índices estimados, que puede expresarse como

$$
\begin{gathered}
D_{k t_{1} t_{2}}=\hat{I}_{k t_{2}}-\hat{I}_{k t_{1}} \\
D_{k t_{1} t_{2}}=F\left(\left\{Z_{i t_{2}}\right\}, \hat{\beta}_{i t_{2}}\right)-F\left(\left\{Z_{i t_{1}}\right\}, \hat{\beta}_{i t_{1}}\right) .
\end{gathered}
$$

Por lo tanto el modelo permite calcular el siguiente efecto:

\footnotetext{
${ }^{20}$ Los coeficientes y los efectos marginales del modelo por nivel y periodo se encuentran a disposición de quien los solicite.
} 


$$
E C_{k t_{1} t_{2}}=F\left(\left\{Z_{i t_{2}}\right\}, \hat{\beta}_{i t_{1}}\right)-F\left(\left\{Z_{i t_{1}}\right\}, \hat{\beta}_{i t_{1}}\right)
$$

Siendo $E C_{k t_{1} t_{2}}$ el "efecto características" del índice $k$ entre los años $t_{1}$ y $t_{2}$. Este efecto mide cual sería el cambio en cada índice esperado de segregación $k$ en el año $t_{2}$ si las características de las familias afectan la probabilidad de cada elección posible de la misma manera que en el año $t_{1}$. Notar que esta variación sólo es comparable con la brecha $D_{k t_{1} t_{2}}$, que representa la variación en el índice de segregación esperado $k$ entre los años $t_{1}$ y $t_{2}$. Esta descomposición se llevará a cabo para los cambios en los índices de Disimilitud, Aislamiento y CGI entre los años extremos de los periodos considerados relevantes.

\section{Base de datos y análisis descriptivo}

\subsection{Bases de datos}

Dado que el interés del trabajo radica en estudiar la forma en que se distribuyen los alumnos pertenecientes a grupos de distinto nivel socio-económico entre escuelas públicas y privadas, la medición de la segregación escolar requiere de fuentes de información que contengan dos insumos básicos. En primer lugar, es indispensable poder distinguir entre el tipo de establecimiento educativo (estatal o privado) al que asiste cada estudiante. En segundo término, es preciso contar con una medida indicativa del estrato social de cada persona, para el presente estudio se considera en este sentido al ingreso per cápita familiar.

En el caso puntual argentino sólo algunas encuestas de hogares cumplen con el requisito de insumos detallado anteriormente. Las mismas son: la Encuesta Permanente de Hogares (EPH), del segundo semestre del año 2003 en adelante; los módulos educativos especiales desarrollados para la EPH en 1992 y 1998; la Encuesta de Condiciones de Vida (ECV) 1996 y 2001; y la Encuesta de Gasto de los Hogares (EGH) 1996/1997 y 2004/2005.

El trabajo realizado por Gasparini, Jaume, Serio y Vazquez (2010) analiza por separado cada una de estas fuentes informativas. Como argumentan los autores, no es posible armar una serie perfectamente comparable en el tiempo por problemas de consistencia y comparabilidad entre encuestas. Es por esta razón que para el presente estudio se restringe el análisis a los datos provistos por las EPH, tanto en sus módulos especiales de 1992 (sólo disponible para GBA) y 1998 como su formato continuo a partir del segundo semestre del 2003 hasta el primer semestre del 2010.

Estas encuestas son realizadas por el Instituto Nacional de Estadísticas y Censos (INDEC), y son de carácter urbano representando $2 / 3$ de la población total del país. La EPH se lleva a cabo desde 1974 captando ingresos individuales y del hogar, proporcionando uno de los insumos básicos para la medición de la segregación escolar. Desafortunadamente, esta encuesta sólo empezó a preguntar en forma regular si la persona entrevistada asiste a una escuela privada o estatal a partir de su realización en modalidad continua en el año 2003. No obstante, en los años 1992 para el Gran Buenos Aires y 1998 para todo el país se realizaron módulos especiales de educación donde también es posible identificar el tipo de establecimiento al que asiste cada individuo, permitiendo por tanto contar con bases de datos comparables de inicios y finales de la década del noventa. 
La población bajo estudio se restringe a las personas entre 5 y 19 años que asisten a un establecimiento escolar primario o secundario, o que han abandonado el colegio sin finalizar el nivel secundario. Como el trabajo busca centrar la atención en la segregación escolar del grupo pobre de la población, en diversos índices utilizados en el trabajo es necesario separar a la población en dos grupos, por lo que se clasifica a los alumnos en pobres y no pobres de acuerdo a si pertenecen o no al primer quintil de la distribución del ingreso per cápita familiar, salvo que se explicite alguna definición alternativa en cuyo caso se hablará de alumnos vulnerables. Previo a la aplicación de la metodología descripta en la sección 3 , se realiza un análisis descriptivo respecto a la composición socio-económica de la matrícula escolar.

\subsection{Composición socio-económica de la matrícula escolar}

En una primer mirada al fenómeno, resulta de interés identificar la composición socio-económica de la matrícula escolar dentro de cada nivel del sistema educativo básico y cómo se distribuyen estos alumnos entre escuelas públicas y privadas. En la sección 2 se describió la evolución de la matrícula escolar total y por tipo de establecimiento de los últimos 20 años, encontrando que por primera vez en la historia argentina la cantidad de alumnos en las escuelas públicas se está reduciendo, especialmente en el nivel primario, mientras que los colegios privados continúan incorporando alumnos a sus aulas. En esta sección en particular, el análisis se centra en los datos provistos por la EPH para el GBA de 1992 y 2010. Algunos simples tabulados dan muestran un gran incremento en la participación de los alumnos pobres en la matrícula total y en las instituciones públicas, así como una importante migración selectiva de los sectores menos carenciados hacia la escuela privada.

Como se vio en la sección 2, la universalidad en la asistencia a la educación obligatoria ha sido uno de los pilares del sistema educativo argentino. En el nivel primario esta universalidad prácticamente ya se había conseguido a principios de los noventa, mientras que en el nivel secundario la asistencia estaba lejos de ser universal ya que apenas si asistía la mitad de la población en edad escolar en 1992. La Figura 4 presenta la tasa bruta de asistencia ${ }^{21}$ en el periodo 1992- 2010 para Argentina. A principios de 1992 la asistencia a la escuela primaria presentaba valores cercanos al 100\%. La asistencia pasó de ser, en promedio, 95\% en 1992 al 99\% en 2010. La brecha de asistencia entre el quintil más rico de 1992 y el quintil más pobre de ese mismo año es de 1 punto porcentual y se cierra por completo a partir del 2004. Estos valores indican que parece haberse cumplido unos de los objetivos de la educación argentina presentados en la sección 2: la universalización de la educación primaria.

Por su parte la educación secundaria muestra una evolución notable. En el mismo periodo, la tasa de asistencia pasa del 53.4\% en 1992 al 86.5\% en 2010. A su vez, al analizar por separado los diferentes quintiles de ingresos, se observa claramente que los mayores incrementos tienen lugar en los jóvenes de familias más pobres. Mientras que en 1992 la brecha en asistencia entre el quintil 5 y el quintil 1 es igual al 36 puntos porcentuales (la tasa de asistencia del $1 \mathrm{er}$ quintil es de $76 \%$ y la del 5 to quintil de 40\%) en el 2010 esta brecha se reduce exactamente a la mitad, dado el diferente incremento de la tasa de asistencia de 21 y 40 puntos porcentuales para el 1er quintil y el 5to quintil respectivamente.

${ }^{21}$ Igual a la proporción de jóvenes en edad escolar que declaran asistir a la escuela. 
Además del aumento en la tasa bruta de asistencia, la composición demográfica de cada grupo también juega un rol importante en los cambios de la composición socio-económica de la matrícula escolar. En este sentido, existen importantes diferencias en la estructura etaria de los hogares pobres respecto de los hogares no pobres, y estas diferencias se han intensificado en los últimos años. Puntualmente, en el año 2010 la población de 5 a 19 años de edad representa al 39\% de la población del primer quintil, mientras que para el resto de la población este grupo etario sólo representa el 20\% de sus integrantes; a su vez, el promedio de chicos no pobres entre 5 y 19 años pasó de 2.4 por familia en 1992 a 2 en 2009, mientras que para las familias pobres este valor se mantuvo constante en 3 chicos por familia. Este factor etario o demográfico, sumado al aumento de la asistencia, ocasiona un importante incremento de la participación de los alumnos pobres en el total de estudiantes.

Figura 4: Tasa bruta de asistencia de alumnos en edad escolar. Total Argentina.

Primaria

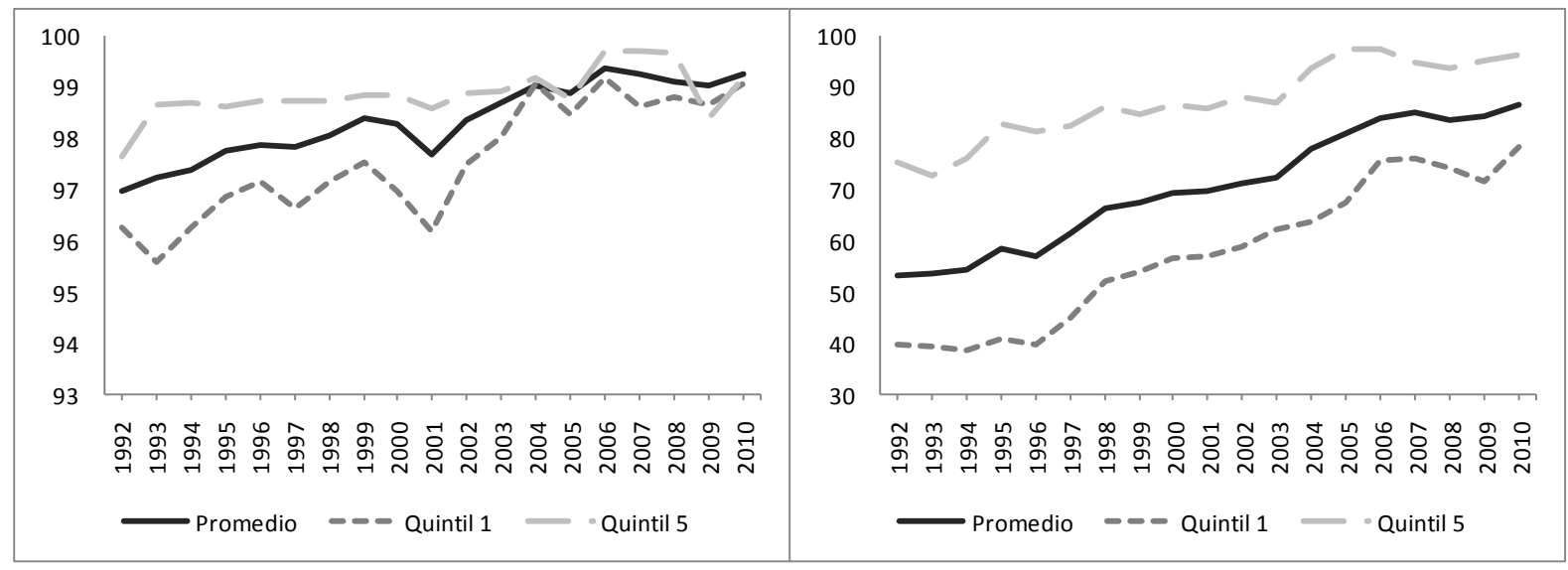

Fuente: Socio-Economic Database for Latin America and the Caribbean (CEDLAS y Banco Mundial), 2010. La tasa bruta de asistencia representa la proporción de alumnos en edad y condición de cursar cada nivel que declaran asistir al colegio respecto al total, multiplicada por 100.

En el primer bloque de la Tabla 1 se muestra, por nivel educativo, el porcentaje de alumnos pertenecientes a cada quintil del ingreso per cápita familiar en la región del Gran Buenos Aires. La participación del quintil más pobre pasa de ser del $28.4 \%$ del total de la matrícula escolar en 1992 al $36.4 \%$ en 2010 para el nivel primario, y de $19.3 \%$ en 1992 al 30.4\% en el nivel secundario. Es obvio que estos incrementos se han realizado en detrimento de la participación de los demás quintiles, principalmente los dos de mayores ingresos donde su participación conjunta disminuye 7 puntos porcentuales en primaria y 18.5 puntos porcentuales en secundaria en el periodo estudiado.

Parte de estos resultados son el reflejo de los enormes logros conseguidos por Argentina en cobertura educativa en los últimos 20 años, especialmente en el nivel secundario donde se incorpora al sistema no sólo a los jóvenes pertenecientes a clases medias y altas sino también a los más pobres. 
Tabla 1: Composición de la matrícula total, pública y privada y proporción de asistentes a la educación pública según quintil de ingreso. GBA.

\begin{tabular}{|c|c|c|c|c|c|c|c|c|c|}
\hline \multirow{2}{*}{ Quintil } & \multicolumn{3}{|c|}{1992} & \multicolumn{3}{|c|}{2010} & \multicolumn{3}{|c|}{ Diferencia } \\
\hline & Total & Primaria & Secundaria & Total & Primaria & Secundaria & Total & Primaria & Secundaria \\
\hline \multicolumn{10}{|c|}{ Composición de la matrícula total } \\
\hline 1 & 25.5 & 28.4 & 19.3 & 33.8 & 36.4 & 30.4 & 8.2 & 7.9 & 11.2 \\
\hline 2 & 23.4 & 25.5 & 18.8 & 26.5 & 26.5 & 26.4 & 3.1 & 1.0 & 7.7 \\
\hline 3 & 19.1 & 18.8 & 19.8 & 18.0 & 16.9 & 19.5 & -1.1 & -1.9 & -0.3 \\
\hline 4 & 18.9 & 15.8 & 25.5 & 13.8 & 13.3 & 14.5 & -5.1 & -2.6 & -11.0 \\
\hline 5 & 13.1 & 11.4 & 16.7 & 8.0 & 7.0 & 9.2 & -5.1 & -4.4 & -7.5 \\
\hline Total & 100.0 & 100.0 & 100.0 & 100.0 & 100.0 & 100.0 & 0.0 & 0.0 & 0.0 \\
\hline \multicolumn{10}{|c|}{ Porcentaje de estudiantes asistentes a escuelas públicas } \\
\hline 1 & 85.3 & 88.0 & 76.5 & 87.9 & 85.9 & 90.8 & 2.6 & -2.1 & 14.4 \\
\hline 2 & 74.4 & 77.4 & 65.3 & 67.9 & 63.5 & 73.5 & -6.5 & -14.0 & 8.2 \\
\hline 3 & 71.5 & 71.7 & 71.2 & 56.4 & 51.1 & 62.4 & -15.1 & -20.6 & -8.8 \\
\hline 4 & 52.0 & 53.4 & 50.1 & 40.4 & 33.7 & 48.3 & -11.6 & -19.7 & -1.8 \\
\hline 5 & 32.4 & 27.0 & 40.6 & 27.1 & 18.5 & 35.5 & -5.4 & -8.4 & -5.1 \\
\hline Total & 66.9 & 69.8 & 60.6 & 65.5 & 62.4 & 69.5 & -1.4 & -7.3 & 8.9 \\
\hline \multicolumn{10}{|c|}{ Composión de la matrícula pública } \\
\hline 1 & 32.6 & 35.9 & 24.3 & 45.3 & 50.0 & 39.8 & 12.7 & 14.2 & 15.5 \\
\hline 2 & 26.0 & 28.3 & 20.2 & 27.4 & 26.9 & 28.0 & 1.4 & -1.4 & 7.8 \\
\hline 3 & 20.4 & 19.3 & 23.3 & 15.5 & 13.8 & 17.5 & -4.9 & -5.5 & -5.8 \\
\hline 4 & 14.7 & 12.1 & 21.0 & 8.5 & 7.2 & 10.0 & -6.2 & -5.0 & -11.0 \\
\hline 5 & 6.3 & 4.4 & 11.2 & 3.3 & 2.1 & 4.7 & -3.1 & -2.3 & -6.5 \\
\hline Total & 100.0 & 100.0 & 100.0 & 100.0 & 100.0 & 100.0 & 0.0 & 0.0 & 0.0 \\
\hline \multicolumn{10}{|c|}{ Composicón de la matrícula privada } \\
\hline 1 & 11.4 & 11.3 & 11.5 & 11.9 & 13.6 & 9.1 & 0.5 & 2.3 & -2.4 \\
\hline 2 & 18.1 & 19.0 & 16.5 & 24.7 & 25.8 & 22.9 & 6.6 & 6.7 & 6.4 \\
\hline 3 & 16.4 & 17.6 & 14.5 & 22.8 & 22.0 & 24.1 & 6.3 & 4.4 & 9.5 \\
\hline 4 & 27.4 & 24.4 & 32.3 & 23.9 & 23.4 & 24.5 & -3.5 & -1.0 & -7.7 \\
\hline 5 & 26.7 & 27.6 & 25.2 & 16.8 & 15.2 & 19.4 & -9.9 & -12.4 & -5.8 \\
\hline Total & 100.0 & 100.0 & 100.0 & 100.0 & 100.0 & 100.0 & 0.0 & 0.0 & 0.0 \\
\hline
\end{tabular}

Fuente: Estimación propia según EPH 1992 y 2010.

Las consecuencias sobre el nivel de segregación sólo son directas en la dimensión de exposición, reflejada en el índice A, ya que se incrementa la probabilidad que un alumno pobre interactúe con otros estudiantes de su mismo status simplemente porque ahora representan una mayor proporción del total de alumnos. No obstante, también puede haber impactado en la dimensión de similitud a través de cambios en la distribución de los alumnos pobres y no pobres entre escuelas públicas y privadas. En el caso de los alumnos pobres, por ejemplo, si aquellos que se incorporaron al sistema son los más carenciados dentro del grupo de pobres y asisten, por lo tanto, en mayor proporción a la escuela pública, entonces aumentará en esta dimensión el nivel de segregación. En el caso de los alumnos no pobres, el efecto tiene que ver con la teoría de separación de grupos desarrollada por Schelling (1978). Bajo la hipótesis de que los padres de familias de clase media y alta prefieren que sus hijos interactúen con estudiantes de su mismo status social, con la mayor participación de los estratos más pobres en el total de alumnos, se produce una migración selectiva de las escuelas públicas a las escuelas privadas con el fin de evitar que su hijo sea parte de la "minoría" no pobre que asiste a cada escuela pública.

Teniendo en cuenta cómo se compone la matrícula escolar en la Argentina, resta analizar la manera en que se distribuyen los estudiantes de cada quintil del ingreso entre escuelas públicas y privadas, tal como refleja el segundo bloque de la Tabla 1. En el año 1992 se observa que el $66.9 \%$ del total de estudiantes asistían a un colegio público en el Gran Buenos Aires, mientras que en el año 2010 este porcentaje desciende a $65.5 \%$ para el total de alumnos, representando un cambio de sólo 1.4 puntos porcentuales en el periodo analizado. No obstante, en cada nivel educativo se observan variaciones 
importantes en la participación de la matrícula pública. Por un lado en la primaria pasa de $69.8 \%$ a $62.4 \%$, mientras que, en el nivel secundario aumenta de $60.6 \%$ a $69.5 \%$. En el primer caso la disminución es consecuencia de la migración de alumnos de los quintiles 2, 3, 4 y 5 a la escuela privada, mientras que en el segundo la migración de los quintiles 3,4 y 5 se ve más que compensada por el aumento de proporción de matrícula pública de los dos primeros quintiles, debido probablemente al mencionado aumento en la tasa de asistencia que tiene lugar en estos quintiles durante el periodo analizado.

En general, es clara la migración que se ha producido desde la escuela pública a la educación privada, principalmente en los estratos medios y altos. Desde 1992 a 2010 aumenta en 2.6 puntos porcentuales la proporción de alumnos del 1er quintil que asiste a una escuela pública, mientras que disminuye 6.5 puntos porcentuales para el quintil 2, 15.1 para el quintil 3, 11.6 en el quintil 4 y 5.4 para el quintil 5. Este comportamiento no es uniforme en los dos niveles. En el nivel primario se destaca la migración de los quintiles 2 a 5 desde la escuela pública a la privada mientras el quintil 1 se distribuye de una manera similar a 1992. En la secundaria parece haber dos efectos importantes: por un lado el aumento de la asistencia de los quintiles 1 y 2 que se matriculan en un colegio público, aumentando el porcentaje de estos alumnos que asisten a establecimientos públicos; por otro lado parece haber una migración a la escuela privada de los quintiles 3,4 y 5 , aunque claramente de menor escala que en el nivel primario.

Esta migración selectiva a la educación privada junto con los cambios en la composición socioeconómica de la matrícula, modifica sustancialmente el nivel socio-económico medio de las escuelas públicas y de las escuelas privadas. En el tercer y cuarto bloque de la Tabla 1 se observa la proporción de estudiantes que pertenecen a cada quintil de la escuela pública y privada respectivamente. En el año 1992, el 58,6\% de los estudiantes pertenecía a los dos quintiles más pobres de la población, mientras que en el año 2010 esta proporción se eleva a 72.7\%. En el nivel primario los dos primeros quintiles pasan de representar el $64.2 \%$ del total de la matrícula pública en 1992 al 76.9\% en 2010 para GBA, año en que el 50\% de los alumnos que asisten al colegio primario público provienen del $20 \%$ más pobre de la población. En el nivel secundario, el cambio es más grande pero no alcanza para equiparar la composición de primaria: el quintil 1 y 2 representan $44.5 \%$ en 1992 y $67.8 \%$ en 2010 , con una gran pérdida de representatividad del quintil 4 . Lo contrario sucede en el sector privado, donde los quintiles 4 y 5 pasan a representar una menor proporción del total de estudiantes tanto en primaria como en secundaria, pasando de $52 \%$ a $39 \%$ en primaria y del $57 \%$ al $44 \%$ en secundaria, debido al incremento en la participación de los quintiles 2 y 3.

Lo anterior también puede observarse analizando la distribución de ingresos de los alumnos que asisten a cada tipo del colegio (Figura 5). Los alumnos en escuelas públicas presentan una distribución que se encuentra claramente a la izquierda respecto de aquella de estudiantes asistentes a escuelas privadas. La línea recta representa el ingreso máximo del $20 \%$ más pobre, por lo tanto el área debajo de la función de distribución hasta dicha línea es equivalente a la proporción de estudiantes pobres que asiste a cada establecimiento. La recta prácticamente divide en dos la campana que representa la distribución de las escuelas primarias públicas, poniendo en manifiesto que cerca del $50 \%$ de los estudiantes de escuelas públicas pertenecen al primer quintil del ingreso per cápita familiar. 
Figura 5: Distribución del ingreso en escuelas públicas o privadas. Año 2010. Total Argentina. Nivel Primario

Nivel secundario
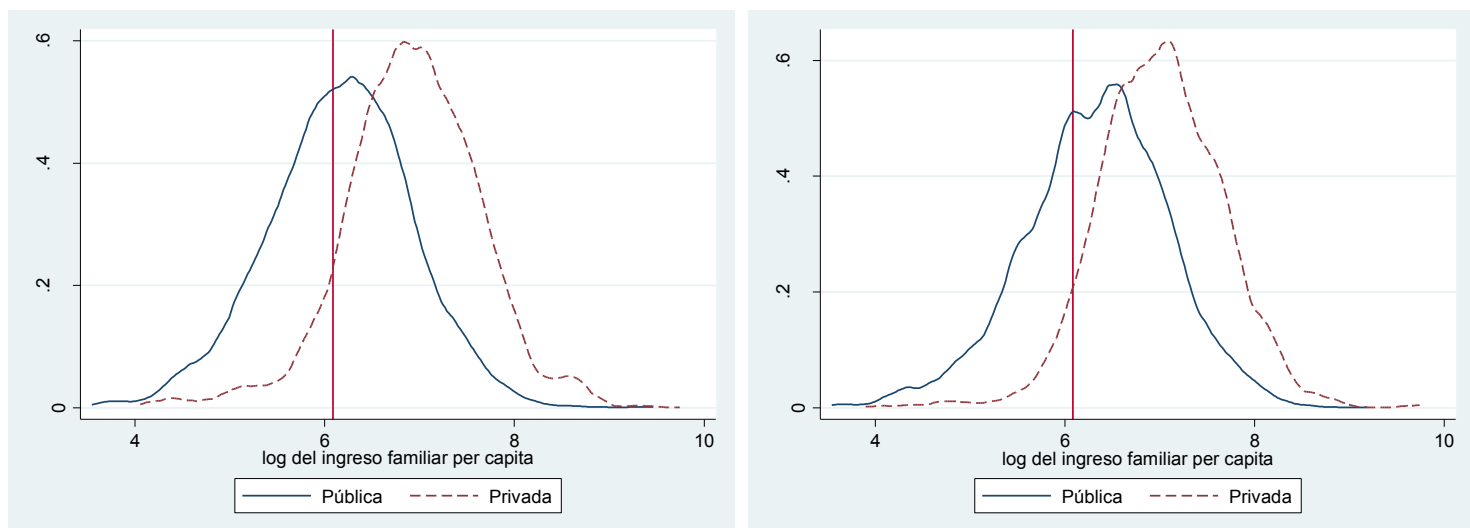

Fuente: Elaboración propia en base a EPH 2010.

Nota: Las funciones de densidad fueron estimadas por el método de Kernels epanechnikov utilizando el ancho de banda óptimo. La línea recta representa el ingreso máximo del 20\% más pobre de la población.

En resumen, los importantes cambios producidos en la composición socio-económica de la matrícula estudiantil en el periodo 1992-2010 parecen haber impactado fuertemente sobre la segregación escolar en la dimensión de exposición. Además, la dimensión de similitud también parece verse afectada aunque a través de canales indirectos como la incorporación de los más carenciados dentro del grupo de pobres y el afán de padres de clase media y alta para que sus hijos interactúen con alumnos de su mismo status. En la siguiente sección se presenta la evidencia empírica de segregación escolar en la Argentina utilizando la metodología descripta en la sección 3 de forma tal de medir de diferentes maneras el efecto sobre la segregación escolar de los cambios descriptos en la presente sección.

\section{Evolución de la segregación escolar en la Argentina}

El objetivo de esta sección consiste en presentar evidencia acerca de la evolución de la segregación escolar desde principios de los noventa hasta el inicio de la segunda década del siglo XXI. Luego se analiza de forma aislada a cada uno de los tres periodos que presentan un comportamiento diferenciado, para comprender de mejor manera qué se esconde detrás del notable aumento de la segregación escolar en el periodo 1992- 2010. En todos los casos se realizan cuatro tipos de análisis. Primero, se estudian los cambios en la asociación entre el percentil del ingreso per cápita familiar y la probabilidad de no asistir, asistir a un colegio privado y asistir a un colegio público. Segundo, se verifica la robustez y sensibilidad del valor de los índices ante cambios en la definición de grupos por medio de las Curvas de Segregación Percentílicas. Tercero, se coloca en el centro del análisis al 20\% más pobre de la población estimando su segregación respecto de varios grupos socio-económicos diferentes utilizando las Curvas de segregación percentílicas de vulnerables. Finalmente, se realiza una descomposición parcial para estimar qué parte de los cambios en los índices en cada periodo se explican por variaciones en las características de las familias. Adicionalmente, para el periodo 19922010 se presenta la evolución de la segregación escolar en la Argentina medida a través de los tres índices presentados en la sección 3. 


\subsection{Periodo 1992- 2010}

Como introducción al fenómeno de segregación escolar resulta de interés analizar la probabilidad de no asistir, asistir a un colegio público y asistir a un colegio privado a medida que aumenta el nivel socio-económico de la familia y cómo cambia esta relación en el periodo considerado. Bajo la hipótesis que la segregación se origina, al menos en parte, debido a que las personas de mayores ingresos emigran de las escuelas públicas hacia las privadas en busca de un servicio diferenciado que satisfaga sus necesidades de educación para sus hijos, el ingreso se convierte en un determinante en la elección de un colegio público o privado, afectando la probabilidad de cada uno de estos eventos (Gasparini, Jaume, Serio y Vazquez, 2010). Si bien existen otros factores que claramente influyen en la elección del tipo de colegio por parte de la familia ${ }^{22}$, el nivel de ingreso es, al menos, una condición necesaria para poder afrontar el pago de una matrícula privada. Las familias ricas pueden optar por el tipo de escuela a la que asisten sus hijos, mientras que las familias más pobres difícilmente puedan hacerlo.

Si esta idea es cierta, se puede esperar una relación negativa entre la probabilidad de asistir a un colegio público y el percentil del ingreso per cápita familiar al que pertenece cada estudiante. En contraparte, es esperable una relación positiva entre la probabilidad de asistir a un colegio privado y el percentil de ingreso. Lo anterior indicaría que mientras más pobre es la familia, mayor resulta la probabilidad de que sus hijos asistan a una escuela pública y menor es la probabilidad de que asistan a una escuela privada. Bajo este concepto la segregación escolar aumentará mientras mayor sea la influencia del ingreso en la probabilidad de asistir cada tipo de colegio. ${ }^{23}$ Para determinar esta relación, se optó por el modelo logit multinomial detallado en la sección 3. Se consideraron características del alumno y la familia al vector compuesto por: logaritmo del ingreso per cápita familiar precios constantes del 2005; edad y edad al cuadrado del alumno; género del alumno; número de miembros en la familia; aglomerado y variables indicativas del máximo nivel educativo de los padres.

Cada una de estas variables fueron elegidas considerando su potencial efecto en las decisiones escolares. Mayor poder adquisitivo de las familias resulta claramente relevante en la decisión escolar (medido por el logaritmo del ingreso per cápita familiar), debido a su efecto sobre la restricción presupuestaria de las familias. ${ }^{24}$ La edad del alumno puede ser un factor determinante, sobre todo en cuanto a la posibilidad de no asisitir al colegio. Para controlar por no linealidades de este efecto, también se incorpora la edad al cuadrado. El género resulta especialmente importante en la década de los noventa, donde el hecho de ser mujer parece estar asociado con mayor matriculación en escuelas privadas. El número de miembros de las familias busca controlar por el

\footnotetext{
${ }^{22}$ Nivel educativo de las familias, número de hijos en el hogar, género del estudiante, gustos de la familia, cantidad y calidad de la oferta educativa privada y pública, número de hermanos, lugar de residencia, etc. Como se verá más adelante, varios de estos factores son incorporados al modelo de decisión escolar.

${ }^{23}$ Notar que si la familia sólo elige entre escuelas públicas y privadas la probabilidad de un evento es igual a uno menos la probabilidad del otro evento. Sin embargo, en el modelo se tiene en cuenta la posibilidad de no asistir al colegio como una tercera opción, que resulta especialmente relevante en el nivel secundario. De esta manera, la el valor de ambas probabilidades dependerá también de la decisión de asistir o no al colegio.

${ }^{24}$ Una alternativa consiste en reemplazar el nivel del en logaritmo por variables indicativas del percentil (o decil) del ingreso. Sin embargo esta alternativa es preferida debido a que minimiza la pérdida de grados de libertad. De todas maneras los resultados son similares y están disponibles para quien los requiera.
} 
efecto de poseer una familia más numerosa en las decisiones escolares. Se considera una variable dummy por aglomerado ${ }^{25}$ teniendo en cuenta la existencia de efectos particulares en cada región (oferta de escuelas públicas y privadas, densidad de la población, entre otros). Mayor nivel educativo de los padres podría estar asociado a una mayor preocupación por el nivel educativo de sus hijos afectando las decisiones escolares, especialmente importante en referencia a no asisitir al colegio, pero también relevante en la decisión pública-privada si los padres observan calidades diferentes en cada tipo de establecimiento. ${ }^{26}$

En la Figura 6 se observa la relación entre el percentil del ingreso per cápita familiar y la probabilidad de no asistir, de asistir a una escuela pública, y de asistir a una escuela privada en el año 1992 y el año 2010 para el Gran Buenos Aires ${ }^{27}$. En efecto, la relación entre el ingreso per cápita familiar y la probabilidad de asistir a una escuela pública en el año 2010 resulta claramente negativa, así como positiva respecto a la probabilidad de asistir a una escuela privada, ya sea en el nivel primario como en el nivel secundario. Se puede apreciar que los estudiantes de familias en la cola superior de la distribución del ingreso per cápita familiar tienen bajas probabilidades de asistir a la escuela pública y altas probabilidades de asistir a una escuela privada. En sentido opuesto, es altamente probable que los estudiantes que pertenecen a las familias más pobres asistan a una escuela pública y muy poco probable que su colegio sea privado. Por ejemplo, en el año 2010 la probabilidad en el decil 10 de asistir a una escuela pública es de sólo 0.2 ( 0.8 de asistir a un colegio privado) en el nivel primario, mientras que, para el mismo año, los alumnos pertenecientes a familias del primer decil tienen una probabilidad de 0.9 de asistir a un colegio público (0.1 de asistir a privado). Respecto a la probabilidad de no asistir al colegio, esta es prácticamente nula en el nivel primario en el año 2010, como así también en el año 1992, para todos los percentiles ${ }^{28}$, pero es relevante tenerla en cuenta para el análisis del sector secundario, ya que durante el periodo estudiado ocurren profundos cambios en la probabilidad de no asistir, que aún en el año 2010 se encuentra cercana al 0.15 para los percentiles de menores ingresos, y menor aún para los estudiantes de mayores ingresos.

En relación al análisis intertemporal del periodo analizado, en el nivel primario la probabilidad de asistir a un colegio público disminuyó para todos los percentiles, pero cae más para los percentiles más altos. Como es de esperar, lo contrario sucede con la probabilidad de asistir a un colegio privado, que aumenta ligeramente para percentiles menores al 30 y fuertemente para el resto. El resultado es que en ambas curvas aumenta la pendiente (en valor absoluto) mostrando la mayor asociación entre el ingreso per cápita familiar y la elección del tipo de escuela. Notar además que en

\footnotetext{
${ }^{25}$ Menos relevante en esta sección debido a que sólo separa Capital de Conurbano. Sin embargo resulta más relevante en las secciones donde es posible analizar el fenómeno en todos los aglomerados relevados por la $\mathrm{EPH}$.

${ }^{26}$ Si bien la mayoría de estas hipótesis resultan acertadas de acuerdo a los resultados del modelo, no es el objetivo del trabajo analizar el efecto de cada variable en particular en las decisiones escolares. Lo anterior forma parte de un trabajo en proceso que se enfoca en los determinantes de las decisiones escolares. Para este informe basta con identificar primero la correlación entre el percentil del ingreso y estas decisiones, y segundo el efecto conjunto de todas las características individuales y familiares sobre las decisiones escolares.

${ }^{27}$ Generalmente se muestra la relación entre una variable de interés y el logaritmo del ingreso. No obstante, en este caso particular resulta apropiada la utilización de percentiles debido al interés en analizar la relación entre las decisiones escolares y los diferentes grupos socio-económicos.

${ }^{28}$ Por esta razón se optó por no mostrarlos en el gráfico.
} 
el año 1992 recién para los percentiles superiores al 75 era más probable asistir a un colegio privado que a uno público, mientras que en el año 2010 lo anterior ya sucede del percentil 50 en adelante.

Los cambios en el periodo considerado son bien diferentes en el nivel secundario. La probabilidad de asistir a una escuela pública apenas si es diferente para cada percentil del ingreso per cápita familiar en el año 1992, pero en el año 2010 se producen dos fenómenos interesantes: aumenta la probabilidad de asistir a una escuela pública en percentiles inferiores al 78; y se incrementa la probabilidad de asistir a un colegio privado para percentiles superiores al 20. Esto es posible debido a que disminuye en forma notable la probabilidad de no asistir al colegio en cada percentil, especialmente en los de menores ingresos. De esta manera, durante el periodo 1992 a 2010 los más pobres se incorporan al colegio público, los sectores medios se distribuyen en públicos y privados y el sector de altos ingresos se nuclea en las escuelas privadas. El incremento en las pendientes muestra que en el año 2010 el percentil del ingreso pasa a estar fuertemente relacionado con la probabilidad de asistir a cada tipo de establecimiento.

Figura 6: Probabilidad de asistir a una escuela pública, asistir a una escuela privada o no asistir. Años 1992 y 2010. GBA.

Prob. de asistir en Nivel Primario

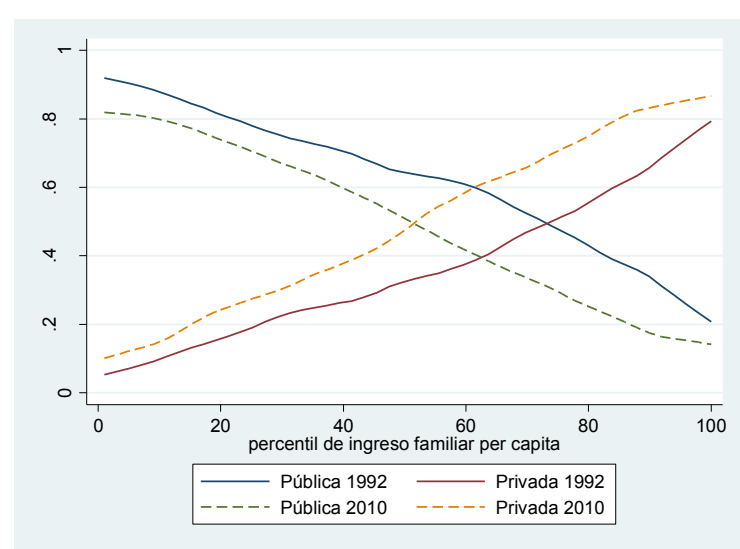

Prob. de asistir en nivel secundario

Prob. de no asistir al nivel secundario
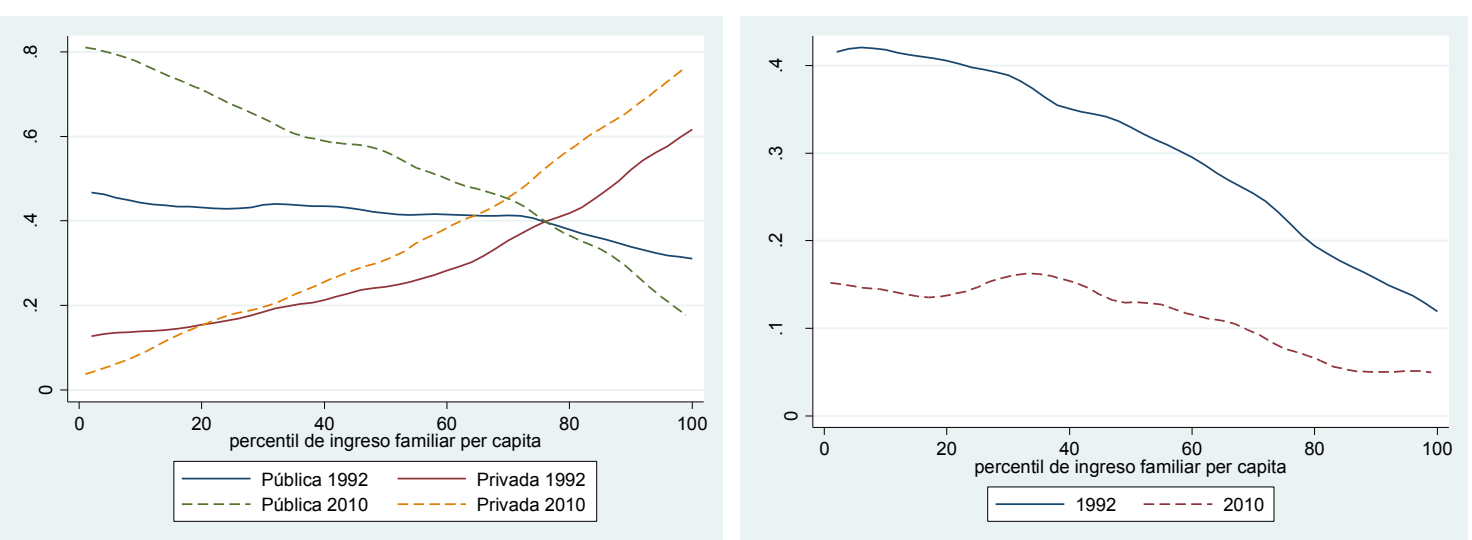

Fuente: Elaboración propia en base a la EPH 1992 y 2010.

Nota: Los gráficos surgen de predecir la probabilidad de cada evento dadas las características del individuo mediante un modelo Logit Multinomial. Luego se realiza una regresión no paramétrica con kernels para graficar la relación de estas probabilidades con el percentil del ingreso per cápita familiar.

Resulta natural vincular los cambios anteriormente descriptos en las decisiones escolares con un incremento en la segregación escolar. En el caso de la educación primaria, la mayor migración de los 
sectores altos, medios y medios-bajos hacia las escuelas privadas reflejan un claro impacto en la dimensión de similitud. En la secundaria, nuevamente la migración de los sectores de ingresos medios y altos hacia la escuela privada afectan la dimensión de similitud, pero además el fuerte aumento de la asistencia anteriormente descripto impacta directamente sobre la dimensión de exposición.

En resumen, tanto el análisis descriptivo de la sección anterior como el modelo de decisiones escolares no dejan dudas acerca de la existencia de segregación escolar por estrato socioeconómico entre escuelas públicas y privadas en el año 2010, así como el alarmante incremento de la misma durante el periodo 1992- 2010. No obstante, no proveen una medida precisa que permita cuantificar el fenómeno y su evolución en el tiempo. La forma habitual que emplea la literatura para medir la segregación consiste en el cálculo de índices de segregación (presentados en la sección 3) que permiten presentar de manera resumida diversas dimensiones de este fenómeno y realizar comparaciones, ya sea con otro periodo de tiempo, otros países o regiones u otros estudios de segregación. Estos índices resultan particularmente útiles para analizar varios periodos al mismo tiempo, o para resumir en un gráfico información de diversos grupos de comparación a través de las curvas de segregación percentílicas o las curvas de segregación percentílicas de vulnerables, presentadas en este trabajo, transmitiendo al lector toda la información disponible de forma simple y comprensible.

La Figura 7 exhibe los valores e intervalos de $95 \%$ confianza $^{29}$ de los tres índices presentados anteriormente en el periodo $1992-2010^{30}$, para el total de los alumnos, para el nivel primario y para el nivel secundario. Del análisis gráfico de la evolución de los índices de segregación se desprenden principalmente tres observaciones. ${ }^{31}$ Por un lado, la tendencia es creciente en todos los casos, indicando que la segregación escolar ha aumentado para ambos niveles cualquiera sea el índice que se utilice para medirla. En segundo lugar, la segregación escolar es superior en el nivel primario que en el nivel secundario, aunque la brecha ha disminuido en el periodo analizado. Y en tercer lugar, la evidencia empírica recopilada indica la existencia de 3 periodos de comportamientos bien diferenciados. El primer periodo, que comprende los años 1992-1998, muestra un marcado crecimiento de la segregación escolar. El segundo periodo, 1998-2003, presenta, en general, una disminución leve del nivel de segregación. ${ }^{32}$ Finalmente, en el tercer periodo, 2003-2010, es el de mayor crecimiento de la segregación escolar de los años analizados para los índices D y A, que se centran en el grupo de alumnos pobres.

\footnotetext{
${ }^{29}$ Estimados por medio de bootstrap de 200 repeticiones.

${ }^{30}$ El dato de 1992 a nivel país se obtiene extrapolando los datos del GBA a nivel país de acuerdo a su relación en el periodo 1998.

${ }^{31}$ Resultados similares son obtenidos por Gaparini, Jaume, Serio y Vazquez (2010).

${ }^{32}$ Notar que no es posible afirmar que la segregación siguió la senda que se muestra en la Figura 7, es decir que durante el periodo 1998 a 2003 los cambios podrían no haber sido uniformes. En este sentido, Gasparini, Jaume, Serio y Vazquez (2010) utilizan la Encuesta de Condiciones de Vida del año 2001 mostrando una disminución notable de 1998 a 2001, así como un leve aumento entre 2001 y 2003. No obstante, dada la incertidumbre respecto a la comparabilidad entre esta encuesta y las EPH, se optó por no utilizar esta base de datos y analizar directamente el periodo comprendido por 1998 a 2003.
} 
Figura 7: Evolución de la segregación escolar en Argentina.

Todos los niveles

\section{Disimilitud}

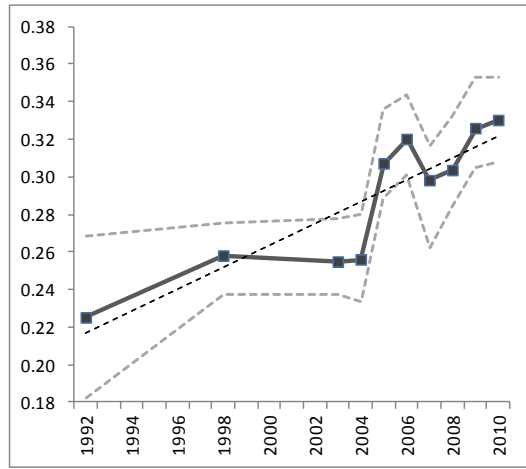

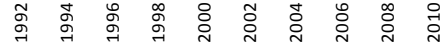

Aislamiento

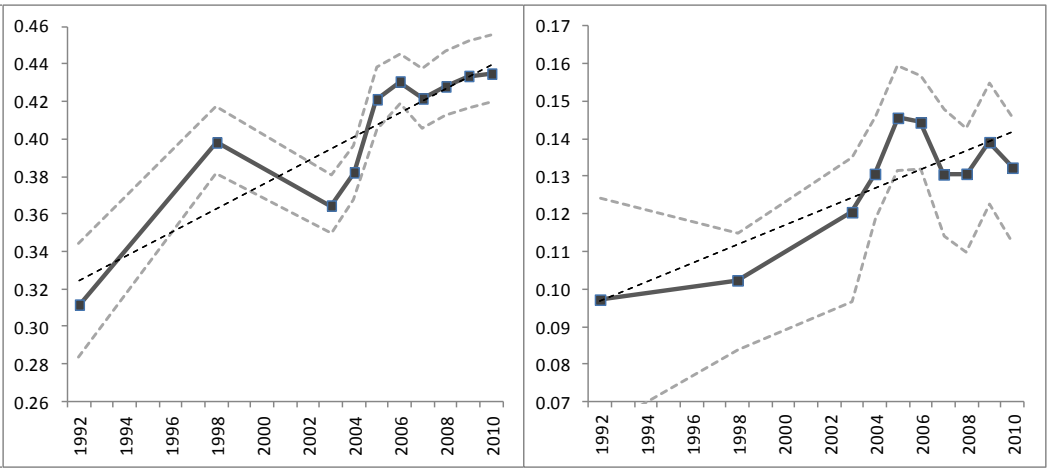

Nivel Primario

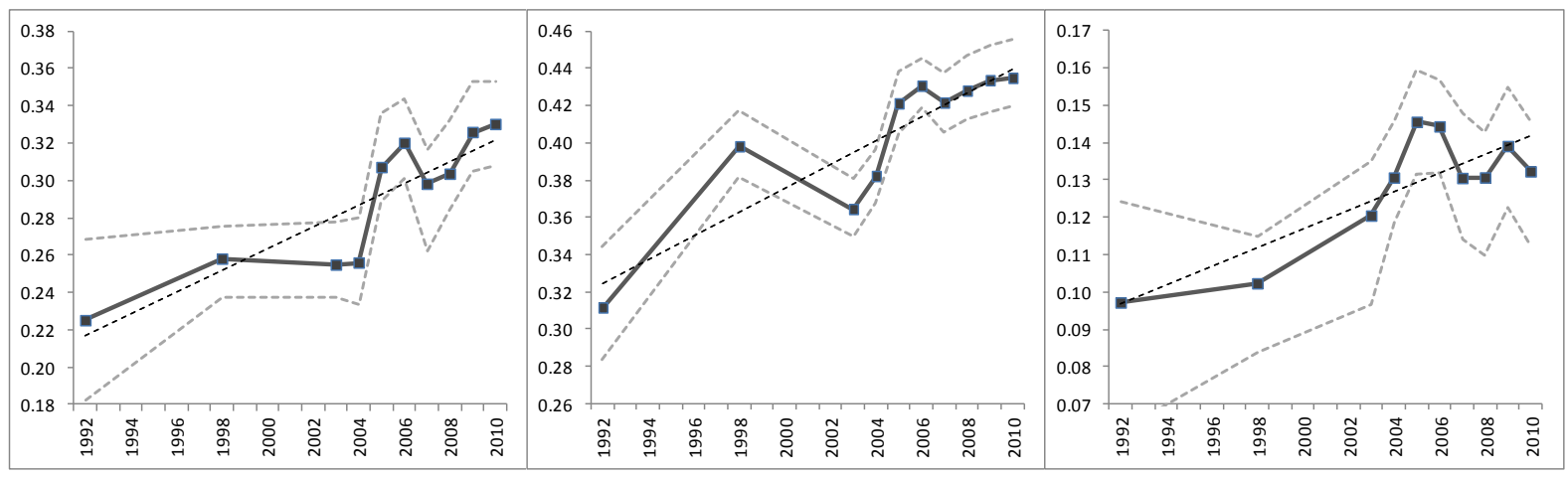

Nivel Secundario

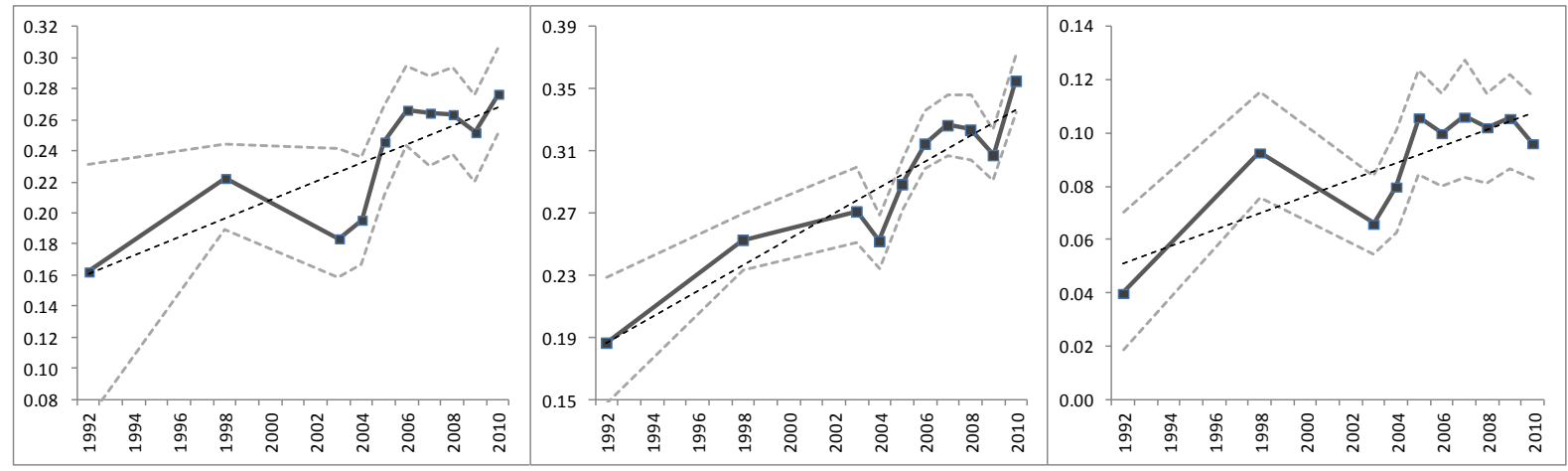

Fuente: Elaboración Propia en base a EPH 1992, 1998, 2003-2010.

Nota: Los intervalos son del 95\% de confianza y se construyen utilizando un bootstrap de 200 repeticiones.

Los cambios en los índices de segregación son notablemente grandes y estadísticamente significativos $^{33}$, especialmente a nivel secundario. La proporción de alumnos pobres que debería pasar a escuelas privadas para que éstos se distribuyan de la misma manera al resto de la población (índice D) aumenta un $47 \%$ en el nivel primario y un $74 \%$ en el nivel secundario, pasando de 0.22 a 0.33 y de 0.15 a 0.28 respectivamente. Por su parte, la probabilidad de que un alumno pobre se relaciones con otros alumnos de su mismo grupo (Índice A) presenta también importantes incrementos de $40 \%$ en primaria (de 0.38 a 0.43) y de $90 \%$ en la educación secundaria (de 0.19 a

\footnotetext{
${ }^{33}$ A excepción del CGI en el nivel primario, donde sí resulta estadísticamente significativa al utilizar intervalos de $90 \%$ de confianza.
} 
0.36). Finalmente el CGI se incrementa cerca de un $30 \%$ en primaria (pasando de 0.10 a 0.13 ) y más del $100 \%$ en secundaria (pasa de 0.04 a 0.09 ).

La necesidad de que el analista tenga que definir de antemano los grupos de pobres y no pobres en los índices D y A conducen a preguntarse si los resultados descriptos en el párrafo anterior son robustos a diferentes definiciones de pobre. En este sentido, en este trabajo se definen y utilizan las curvas percentílicas de segregación que muestran el valor de cada índice para todos los posibles grupos de nivel socio-económico a analizar (ver su definición formal en el sección 3). Las Figuras 8 y 9 presentan la curva de segregación percentílica de disimilitud (CSPD) y la curva de segregación percentílica de aislamiento (CSPA). Las mismas muestran el valor de cada índice (eje vertical) según el percentil de ingreso utilizado para separar a la población en vulnerables y no vulnerables ${ }^{34}$ (eje horizontal). Así, los valores del índice D y A de la figura 7 se correponden con el valor de los índices en el punto 20 del eje horizontal de cada año en las Figuras 8 y 9 ; y el incremento que tuvo lugar en el periodo analizado puede obtenerse como la distancia vertical entre estos puntos en cada gráfico. ${ }^{35}$

Tanto el índice de disimilitud como el de aislamiento son crecientes respecto del percentil que divide a los alumnos en dos grupos. En relación al último de estos índices, este resultado es esperable ya que el índice $A$ es sensible a la proporción de la población que se considere vulnerable al referirse, precisamente, a la interacción entre estos alumnos, que aumentará cuanto mayor porcentaje representen de la población total. Por el contrario, el índice de disimilitud, al cuantificar la diferente distribución de cada grupo entre escuelas públicas y privadas, no es afectado directamente por el aumento en la proporción de los estudiantes considerados vulnerables, y su incremento sólo se debe a que los grupos de mayores ingresos se distribuyen de forma más desigual entre escuelas públicas y privadas que el resto de la población.

Figura 8: Curva de segregación percentílica de disimilitud (CSPD). GBA.

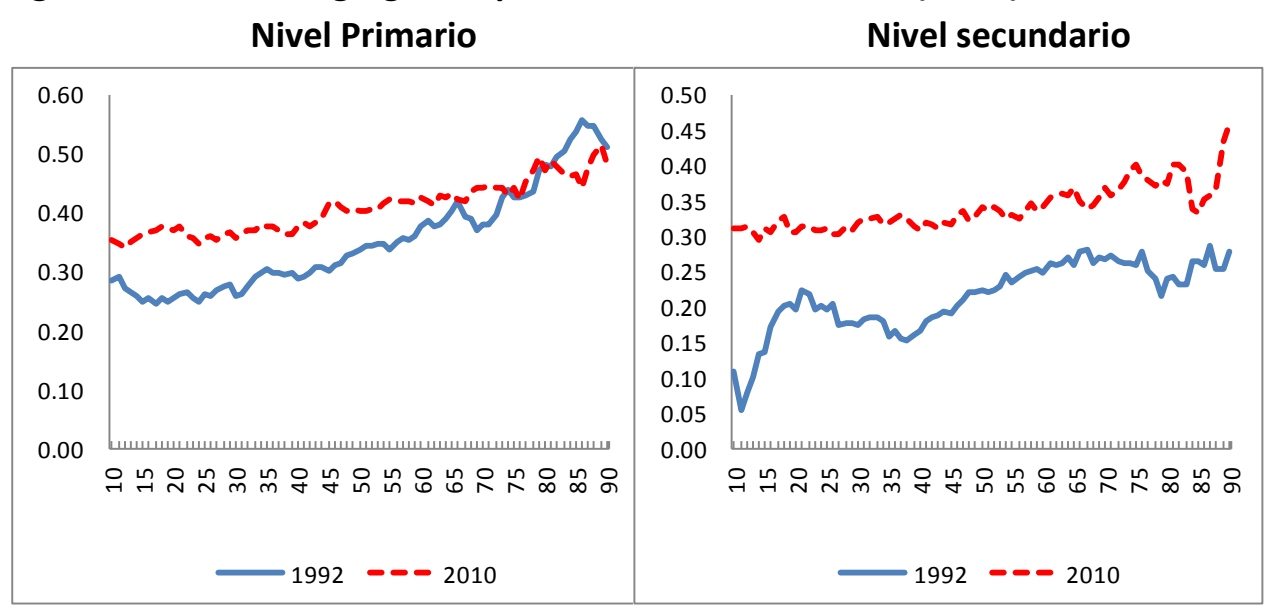

Fuente: Elaboración propia en base a las EPH de 1992 y 2010.

\footnotetext{
${ }^{34}$ En el caso particular de estas curvas la definición de pobre y no pobres no resulta acertada debido a los cambios en la composición de los grupos. En en adelante se referirá a vulnerable y no vulnerables acorde si se encuentra en un percentil anterior o posterior al punto de corte.
}

${ }^{35}$ No es exactamente igual debido a que en este caso sólo se analiza el Gran Buenos Aires. 
Figura 9: Curva de segregación percentílica de aislamiento (CSPA). GBA.

Nivel Primario

Nivel secundario

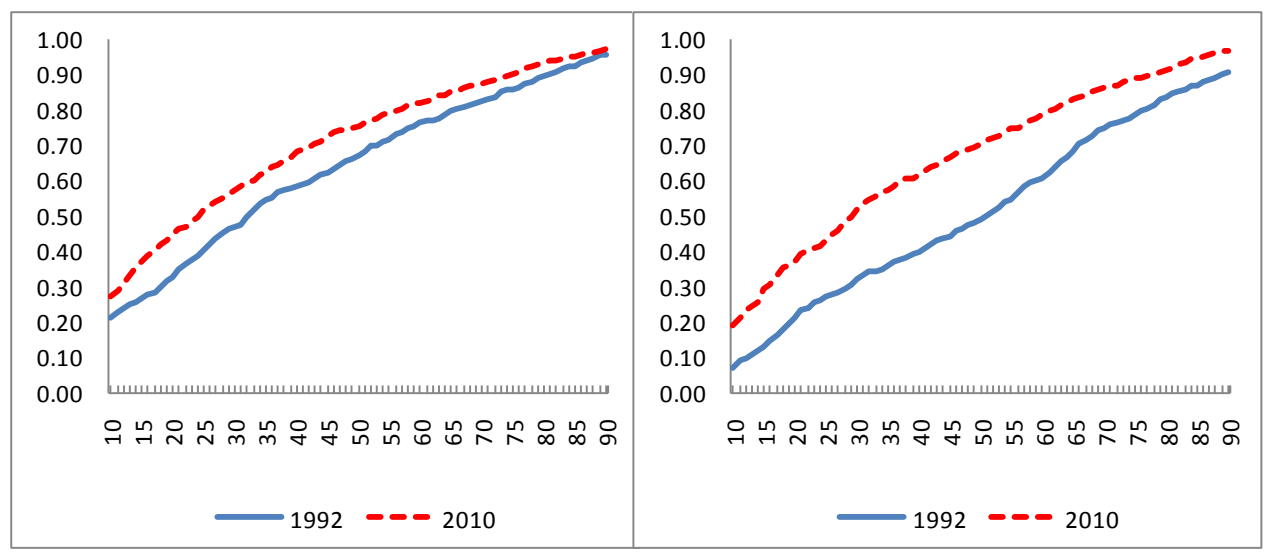

Fuente: Elaboración propia en base a las EPH de 1992 y 2010.

En las figuras se aprecia que la segregación escolar ha aumentado entre los dos periodos para prácticamente cualquier percentil de corte en la definición de grupos de vulnerables y no vulnerables, aunque con matices diferentes para cada nivel educativo. Por un lado, el nivel primario presenta un claro incremento del índice de disimilitud hasta el grupo conformado por los alumnos pertenecientes al $65 \%$ de las familias de menores ingresos, y el cruce de las curvas muestra que los alumnos de familias de menores ingresos se encuentran más segregados en el año 2010 respecto del año 1992, pero lo contrario sucede con alumnos provenientes de familias de mayores ingresos, que ahora interactúan más con el sector medio y medio-bajo de la población, y su segregación cae entre los años estudiados. Por su parte el índice de aislamiento refleja que un aumento de la segregación en la dimensión de exposición para todos los sectores pero en especial para los grupos de vulnerables compuestos por alumnos de familias con ingresos menores al del percentil 50.

Por otro lado, en el nivel secundario los incrementos son mucho más notables: tanto en la dimensión de similitud como en la de exposición la curva de segregación percentílica de 2010 se encuentra por encima de la correspondiente al año 1992. Lo anterior indica que el marcado incremento de la segregación registrado entre los años 1992 y 2010 para los alumnos del 20\% más pobre de las familias se da prácticamente para cualquiera que sea el grupo considerado vulnerable, aunque los aumentos más notables en ambos índices tienen lugar alrededor del percentil 12 en el índice $\mathrm{D}$ y el percentil 40 en ambos índices.

Si bien el objetivo del trabajo es conocer en profundidad qué sucedió con la segregación escolar en general, un objetivo más específico consiste en prestar especial atención a la segregación de los alumnos más carenciados respecto del resto, definidos los primeros, como aquellos que pertenecen al $20 \%$ de las familias más pobres. Hasta aquí es claro que la segregación de este grupo respecto del resto ha aumentado significativamente entre los años 1992- 2010, pero no es posible identificar si este proceso ha tenido lugar respecto a determinados sub-grupos en particular (como podrían ser los alumnos pertenencientes al $20 \%$ de los hogares más ricos) o si se ha dado por igual en todos los niveles socio-económicos considerados como no pobres en este trabajo. Con este objetivo se contituyen las Curvas de segregación percentílica de vulnerables tanto para el índice D (CSPDV) como para el A (CSPAV), que se muestran en las Figuras 10 y 11 respectivamente. 
Figura 10: Curva de segregación percentílica de disimilitud de vulnerables (CSPDV). GBA.

Nivel Primario

Nivel secundario

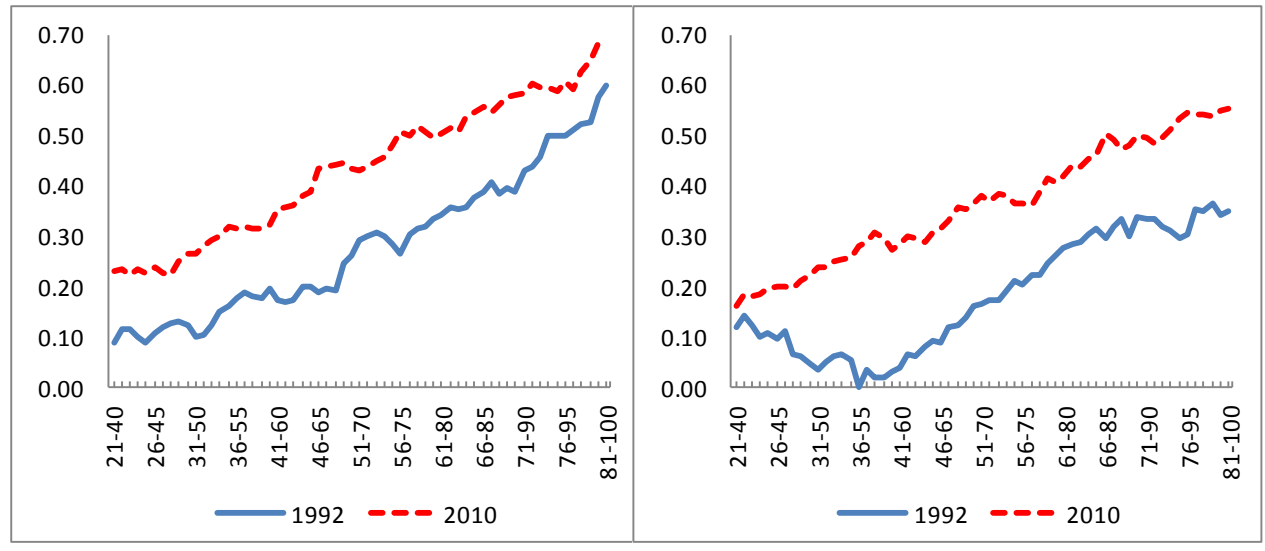

Fuente: Elaboración propia en base a las EPH de 1992 y 2010.

Figura 11: Curva de segregación percentílica de aislamiento de vulnerables (CSPAV). GBA. Nivel Primario Nivel secundario

\begin{tabular}{l|l}
0.90 \\
0.85 \\
0.80 \\
0.75 \\
0.70 \\
0.65 \\
0.60 \\
0.55 \\
0.50 \\
0.45 \\
0.40
\end{tabular}

Fuente: Elaboración propia en base a las EPH de 1992 y 2010.

Estas curvas computan el valor de los índices de segregación (eje vertical) de los alumnos considerados pobres respecto de otros alumnos pertenecientes a todos los otros posibles grupos definidos también como un $20 \%$ de la población (eje horizontal) ${ }^{36}$, es decir respecto de 60 grupos de alumnos pertenecientes a diversos intervalos de percentiles de ingreso que van desde el grupo 1: percentiles 21 a 40, al grupo 2: percentiles 22 a 41, .., hasta el grupo 60: percentiles 81 a 100. De esta manera, al desplazarse una unidad de izquierda a derecha en el eje horizontal se deja fuera del análisis al percentil más pobre del grupo anterior y se incorpora el percentil siguiente que no integraba el grupo original. Si bien la información que ofrece este gráfico tiende a solaparse ya que de grupo en grupo sólo se deja de lado un percentil y se incorpora otro, posee la ventaja de permitir observar con claridad el efecto de todos los subgrupos posibles sobre la segregación escolar de los alumnos más carenciados, poniendo a disposición del lector toda la información disponible ${ }^{37}$.

\footnotetext{
${ }^{36}$ No obstante, es posible realizar el mismo análisis pero poniendo el foco en otros grupos poblacionales dependiendo del objetivo del estudio, como puede ser el $15 \%, 25 \%, 30 \%$, etc., tanto más pobre como más rico de la población.

37 Una alternativa consiste en realizar el análisis sólo sobre 4 grupos (los cuatro quintiles que no son considerados vulnerables) pero no hay a priori ningún factor que determine que estos son los grupos relevantes de comparación. Por ejemplo, en el nivel primario resulta relevante que el mayor aumento que tiene lugar en las
} 
En el nivel primario los alumnos pobres se encuentran, por mucho, más segregados en el año 2010 que en 1992 respecto a todos los demás grupos de alumnos, tanto en la dimensión de similitud como de exposición. En la primera dimensión, el aumento es relativamente uniforme en valor absoluto para todos los grupos (0.16), a excepción de aquellos compuestos en su mayoría por alumnos del quintil más rico. Por ejemplo, el índice $\mathrm{D}$ pasa de 0.09 a 0.23 cuando se compara a los alumnos pobres respecto a los percentiles $21-40$, de 0.17 a 0.35 en relación a los percentiles 41-60, de 0.34 a 0.50 respecto de los percentiles $61-80$, y de 0.60 a 0.68 en relación con los percentiles 81100. En la dimensión de exposición a través del índice $A$, se observa un incremento menos homogéneo: Los grupos compuestos por los percentiles del 21 al 36 muestran un aumento inferior a los reportados por los grupos de alumnos del percentil 36 en adelante. El comportamiento diferencial de las dimensiones de similitud y exposición se debe a que esta última se ve afectada por los cambios en la composición socio-económica de la matrícula escolar primaria expuestos anteriormente (ver Tabla 1).

En el nivel secundario la historia es semejante, pero los cambios son aún más acentuados. En lo referido a la dimensión de similitud, los alumnos pobres se encuentran más segregados respecto a todos los grupos de comparación utilizados, especialmente los estratos medios. Así, el índice D pasa de 0.12 a 0.16 respecto de los alumnos pertenecientes a los percentiles $21-40$, de 0.04 a 0.29 respecto de los percentiles 41-60, de 0.28 a 0.42 en relación a los percentiles $61-80$, y de 0.35 a 0.5 respecto los percentiles 81-100. En la dimensión de exposición sucede algo parecido, pero se acentúan las diferencias con respecto a los percentiles más ricos debido, principalmente, a una incorporación masiva de los sectores de menores ingresos que, junto con el cambio demográfico explicitado anteriormente, producen importantes cambios en la composición socio-económica de la matrícula secundaria ${ }^{38}$ (ver Tabla 1 ).

En síntesis, a lo largo de todo el periodo la segregación escolar de los alumnos más pobres en la educación primaria se incrementó producto de una enorme migración de todos los estratos sociales restantes a las escuelas privadas y un aumento de la participación de alumnos pobres de la matrícula escolar. Como se verá más adelante en el análisis de sub-periodos, este proceso es fruto de dos olas migratorias producidas en los últimos 18 años. La primera de ellas se dio durante el periodo 1992 a 1998 y afectó a los estratos de mayores ingresos, mientras la segunda tuvo lugar durante la década de los dos mil. En 1992 la secundaria presentaba bajos niveles de segregación de los alumnos pobres, muy lejos de los valores del nivel primario en ese año. Sin embargo, la vigorosa migración selectiva desde las escuelas públicas a las privadas del resto de los sectores durante los noventa y los dos mil, sumado a los cambios en la composición socio-económica de la matrícula secundaria no sólo incrementaron la segregación de los alumnos pobres respecto a la todos los grupos restantes sino

CSPDV se da en el grupo 48-67, que no se hubiera observado correctamente de considerar sólo los 4 grupos de quintiles restantes.

${ }^{38}$ Notar que la pendiente negativa en partes de las CSPAV y CSPDV resulta llamativa, ya que indica que los alumnos pobres se encuentran menos segregados respecto de percentiles medios de la distribución que respecto a percentiles medios - bajos. Lo anterior parece deberse a la baja relación entre el percentil del ingreso y la probabilidad de asistir a cada tipo de establecimiento en percentiles menores al 50 (ver Figura 6). De hecho, al calcular intervalos de confianza de estas curvas, no puede descartarse que la CSPAV no sea en realidad una línea horizontal recta (con valor 0.52) para todos los grupos, ni que la CSPDV no sea también una línea recta hasta el grupo formado por los percentiles 51-70 (con valor 0.08) para luego sí pasar a tener pendiente positiva. . 
que ésta aumentó más que en el nivel primario cerrando de esta manera parte de la brecha inicial entre ambos niveles.

Si bien es claro el incremento de la segregación escolar en el periodo 1992- 2010, cabe preguntarse si estos patrones se deben a cambios en las características de las familias tomadoras de decisiones o a otros factores. Esta pregunta es válida si se considera que la segregación escolar en Argentina se origina a través de decisiones familiares, como se indicó anteriormente. Es posible realizar una estimación de este efecto utilizando el modelo descripto en la sección 3, calculando cual hubiese sido el nivel de segregación en el año 1992 si las familias hubiesen tenido las características del año 2010. Se consideran las mismas características del alumno y la familia utilizada en las estimaciones de probabilidades de la Figura 6. De esta manera, se simulan decisiones de las familias del año 2010, pero cada característica impactando como en el año 1992. Luego se calculan los índices de segregación estimados ${ }^{39} \mathrm{y}$ al valor de cada índice resultante menos al que estima el modelo para 1992 se le llama efecto característica (EC). ${ }^{40}$

La Figura 12 muestra el valor del EC y de los índices estimados de 1992 y 2010 al considerar como pobre al $20 \%$ de las familias más carenciadas. Se observa que este efecto da cuenta de prácticamente todo el cambio en el nivel primario, pero muy poco del incremento de la segregación escolar por estrato socio-económico que tuvo lugar en el nivel secundario. Este resultado sugiere que en el nivel primario era esperable en aumento de la segregación escolar debido a los cambios en el ingreso, el nivel educativo de los padres y demás características de las familias de la población analizada, que influye en la toma de decisiones respecto al tipo de colegio primario al que asisten los miembros en edad escolar, contribuyendo a la migración selectiva detallada anteriormente desde los colegios públicos hacia las escuelas privadas ${ }^{41}$. Por el contrario, en el nivel secundario los cambios en características no aportan una explicación válida del incremento de la segregación escolar durante este periodo, debido principalmente a los cambios en la tasa de asistencia que tuvo lugar en los quintiles de menores ingresos no atribuible a variaciones en las características de las familias.

\footnotetext{
${ }^{39}$ Notar que tanto el índice de 1992 como el de 2010 utilizados en el análisis no representan su verdadero valor sino el estimado por el modelo. En la sección 3 se explica en detalle por qué se utiliza esta aproximación.

40 Una aproximación alternativa consiste en considerar el año 2010 como base, simulando las decisiones escolares de las familias en 1992 si sus características impactaran cono en el 2010. La literatura de descomposiciones define al efecto calculado de esta manera como "efecto parámetros". Los resultados obtenidos son similares y están disponibles al lector que los requiera.

${ }^{41}$ La relación entre el logaritmo del ingreso y la probabilidad de asistir a un colegio privado varía poco entre estos años, a diferencia de lo que sucede para cada percentil expuesto en la figura 6. Por lo tanto, el incremento en el nivel de ingreso entre 1992 y 2010 da cuenta de gran parte de la migración hacia los colegios privados explicitada anteriormente. Notar que la diferencia entre ambos tipos de análisis radica en que en 2010 prácticamente todos los percentiles registran un ingreso superior al de 1992.
} 
Figura 12: Efecto características entre 1992 y 2010. GBA.

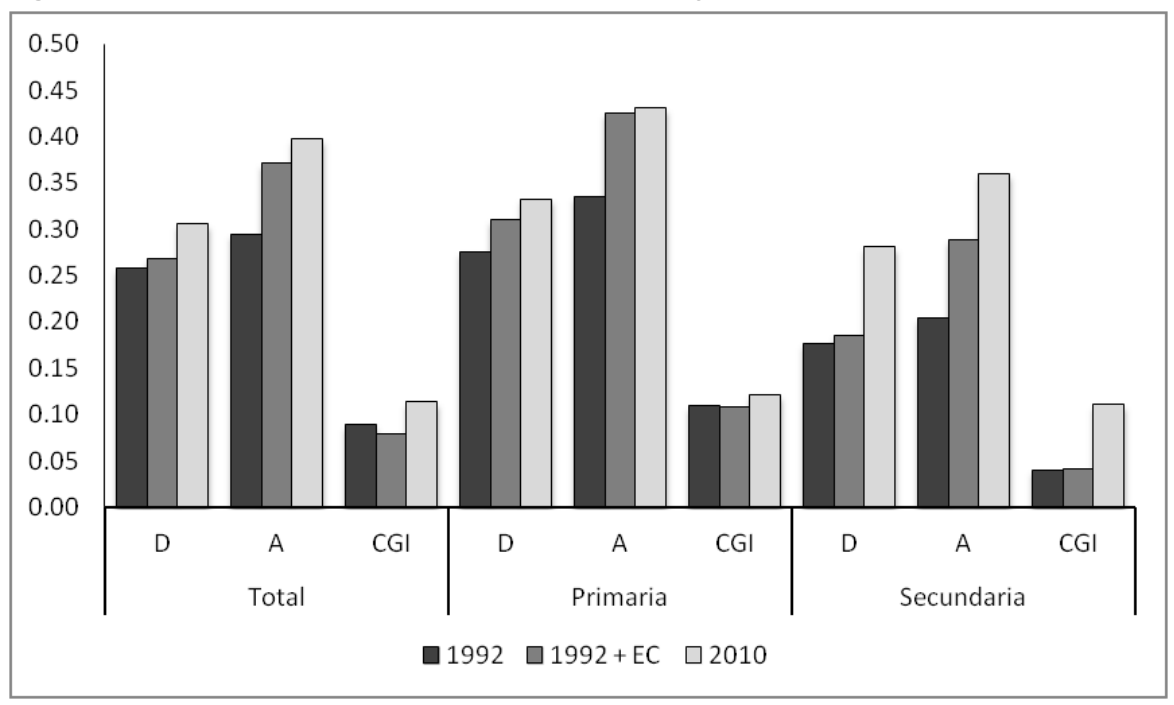

Fuente: Elaboración propia en base a las EPH de 1992 y 2010.

La Tabla 2 muestra, por quintil, la tasa de asistencia y el porcentaje de los asistentes a colegios públicos real y simulada (por medio del modelo de decisión escolar explicitado anteriormente) del año 2010 en el Gran Buenos Aires. Mientras que el modelo estima de forma acertada la tasa de asistencia de cada quintil en el nivel primario (con diferencias menores a 1 punto porcentual), son notorias las discrepancias entre la tasa de asistencia real y la simulada en el nivel secundario, en especial para los quintiles de menores ingresos. Lo anterior es equivalente a pensar que si las familias de 2010 tomaran decisiones basadas en sus características como en 1992, la tasa de asistencia sería muy inferior a la actual, especialmente en los quintiles de menores ingresos. Por lo tanto, gran parte de la masiva incorporación al nivel secundario de los jóvenes de menores ingresos que tuvo lugar durante los años 1992 y 2010 no fue producida por variaciones en las características familiares, sino por cambios en la manera que afectan estas características u otras variables que no se incluyen en el modelo, como políticas educativas dirigidas especialmente a universalizar la educación secundaria. ${ }^{42}$

Como se explicitó en la sección anterior, mayores tasas de asistencias repercuten directa e indirectamente en los índices de segregación, por lo que al no ser correctamente captadas por el efecto características una gran parte del incremento en estos índices queda sin ser explicado. Un claro ejemplo de este efecto se observa en la Tabla 2, donde en el nivel secundario la simulación predice que sólo el $75 \%$ de los asistentes del primer quintil van a un colegio público, mientras que la realidad muestra que este porcentaje asciende a $91 \%$. Esta diferencia se debe principalmente a la alta tasa de asistencia a los colegios públicos del $23.4 \%$ de los alumnos que la simulación considera que no van al colegio pero que en realidad sí lo hacen.

\footnotetext{
${ }^{42}$ Durante gran parte del periodo analizado se realizó una política de expansión de la educación secundaria a los estratos de menores ingresos. Este tipo de política se intensificó en los últimos años donde la aparición de importantes transferencias condicionadas al final del periodo analizado (principalmente la asignación universal por hijo) parecen haber tenido un impacto sustancial en las decisiones escolares y en su relación con las características familiares, ya que produjeron un aumento en la tasa bruta de asistencia escolar de los sectores de menores ingresos que además, debido a la condicionalidad del programa, deben matricularse obligatoriamente en un colegio público.
} 
Tabla 2: Tasa de asistencia y porcentaje de asistentes a escuelas públicas de la base real y la base simulada tomando el efecto caractrística de 1992. Gran Buenos Aires.

\begin{tabular}{|c|c|c|c|c|c|c|}
\hline & \multicolumn{3}{|c|}{ Tasa de asistencia } & \multicolumn{3}{|c|}{ \% de asistentes a escuelas públicas } \\
\hline & Real & Simulada & Diferencia & Real & Simulada & Diferencia \\
\hline \multicolumn{7}{|l|}{ Primaria } \\
\hline 1 & 94.0 & 93.4 & 0.5 & 86.2 & 85.6 & 0.6 \\
\hline 2 & 98.1 & 97.1 & 1.0 & 63.7 & 68.4 & -4.7 \\
\hline 3 & 97.3 & 96.6 & 0.7 & 51.6 & 54.5 & -2.9 \\
\hline 4 & 99.1 & 99.1 & 0.0 & 33.0 & 41.8 & -8.8 \\
\hline 5 & 98.9 & 99.7 & -0.8 & 18.4 & 23.3 & -4.9 \\
\hline Total & 96.6 & 96.1 & 0.5 & 62.6 & 65.5 & -3.0 \\
\hline \multicolumn{7}{|l|}{ Secundaria } \\
\hline 1 & 84.7 & 61.3 & 23.4 & 90.8 & 74.7 & 16.2 \\
\hline 2 & 85.1 & 67.9 & 17.2 & 73.5 & 66.6 & 6.9 \\
\hline 3 & 87.5 & 75.5 & 12.1 & 62.4 & 58.0 & 4.4 \\
\hline 4 & 90.7 & 82.7 & 8.0 & 48.3 & 50.8 & -2.5 \\
\hline 5 & 90.2 & 88.5 & 1.7 & 35.5 & 36.2 & -0.7 \\
\hline Total & 86.7 & 71.2 & 15.5 & 69.5 & 61.1 & 8.3 \\
\hline
\end{tabular}

Fuente: Elaboración propia en base a las EPH de 1992 y 2010.

En lo que sigue de la sección se analizan en profundidad los tres sub-periodos descriptos con anterioridad y que se observan claramente en la Figura 7. En cada uno de ellos se analizarán 4 aspectos: la relación entre el percentil del ingreso familiar per cápita y las decisiones respecto a la escolaridad de los miembros en edad de asistir a la educación básica; la sensibilidad y robustez de los resultados a diferentes definiciones de grupos (CSPD y CSPD); la segregación del grupo de pobres respecto a los demás grupos poblacionales (CSPDV y CSPAV); y la descomposición de la variación del nivel de segregación en efecto característica y otros efectos. Los lectores que no estén interesados en conocer las interesantes dinámicas que operaron en cada unos de estos sub-periodos modificando los niveles de segregación escolar, pueden saltearse esta sección y pasar directamente a las conclusiones.

\subsection{Sub-Periodo 1: 1992- 1998}

El periodo 1992-1998, así como toda la década del 90, se caracterizó por ser una época de grandes cambios en la Argentina. De forma muy resumida, en lo económico el periodo muestra un estancamiento del ingreso per cápita promedio con un marcado aumento de la desigualdad ${ }^{43}$. En lo referido a educación, la descentralización de la misma, así como la mayor flexibilidad posterior a la Ley Federal de Educación de 1993, posibilitaron la existencia de un sector de escuelas privadas más pujantes (Narodowski, 2000). Durante este periodo, la relación entre el ingreso per cápita familiar y las decisiones de no asistir, asistir a un colegio privado o hacerlo a uno público se modificaron drásticamente. La Figura 13 muestra esta relación en el marco del modelo logit multinomial de decisiones escolares de los hogares (ver sección 3).

En el nivel primario, como se dijo anteriormente, ya en el año 1992 es clara la relación entre el percentil del ingreso per cápita familiar y la probabilidad de asistir a cada tipo de colegio, poniendo en manifiesto que mientras mayor es el percentil del ingreso per cápita familiar del alumno, mayor es la probabilidad de asistir a un colegio privado y menor de hacerlo a uno público ${ }^{44}$. En el año 1998

\footnotetext{
${ }^{43}$ Estimación propia en base a la EPH.

${ }^{44}$ Recordar que también se estima la probabilidad de no asistir, pero en el nivel primario ésta es prácticamente cero para todos los percentiles.
} 
la pendiente de las curvas aumenta respecto de 1992, especialmente para percentiles mayores al 40. De esta manera mientras que la probabilidad de asistir a un colegio público (privado) se mantiene constante para percentiles menores al 40 , baja (sube) para los percentiles más altos de la población. Así, a partir del percentil 65 es más probable que un estudiante asista al colegio privado que a una institución pública en el año 1998.

Este mismo análisis se puede realizar en el nivel secundario. Como se analizó anteriormente, en el año 1992, prácticamente no existía relación entre el percentil del ingreso y la probabilidad de asistir a un colegio público, mientras que sí había una fuerte asociación positiva entre el percentil del ingreso y la probabilidad de asistir a un colegio privado. En tan sólo 6 años, el escenario era completamente diferente. La probabilidad de asistir a un colegio público pasa a estar fuerte y negativamente correlacionada con el percentil del ingreso, aumenta también la asociación entre la probabilidad de asistir a una privada y el percentil del ingreso per cápita familiar y disminuye la asociación entre los percentiles de ingreso y la no asistencia al colegio. Durante el periodo analizado, se incorporó un gran porcentaje de la población de menor ingreso a la educación secundaria, especialmente a la escuela pública, mientras que se produjo una migración de los sectores más ricos (por encima del percentil 50) desde las escuelas públicas a las escuelas privadas.

Figura 13: Probabilidad de asistir a una escuela pública, asistir a una escuela privada o no asistir Años 1992 y 1998. GBA.

Prob. de asistir en Nivel Primario

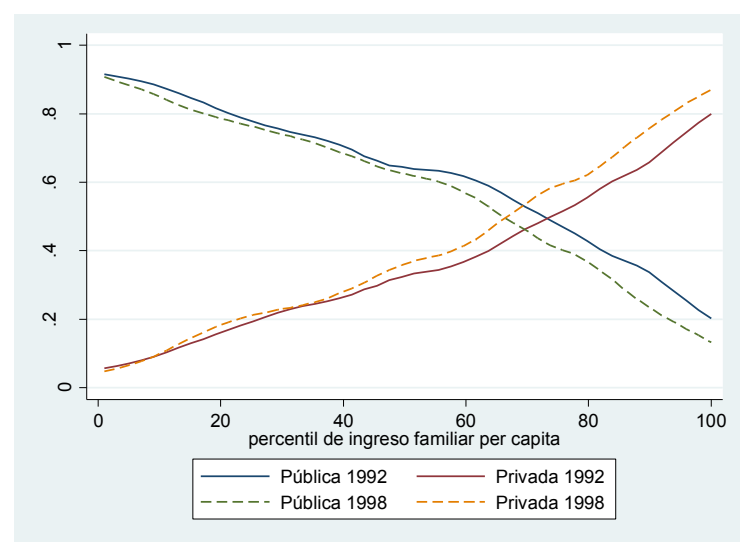

Prob. de asistir en nivel secundario

Prob. de no asistir al nivel secundario

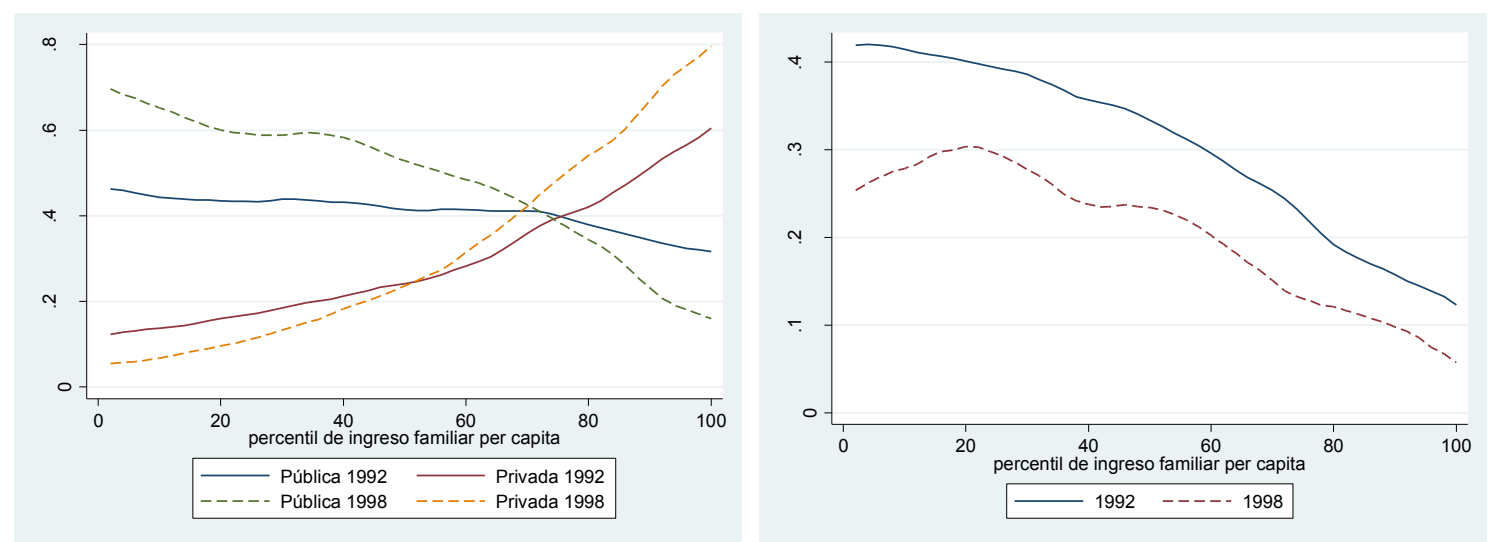

Fuente: Elaboración propia en base a las EPH de 1992 y 1998.

Nota: Los gráficos surgen de predecir la probabilidad de cada evento dadas las características del individuo mediante un modelo Logit Multinomial. Luego se realiza una regresión no paramétrica con kernels de ancho de banda óptimo para graficar la relación de estas probabilidades con el percentil del ingreso per cápita familiar. 
Los cambios descriptos anteriormente están en línea con lo que se observa en la Figura 7 (aunque con leves diferencias debido a que en esta sección el análisis se restringe a GBA), es decir un incremento del nivel de segregación entre 1992 y 1998, especialemente importantes en el nivel secundario. No obstante, es interesante analizar el fenómeno a través de las CSPD y CSPA que permiten verificar la sensibilidad de los resultados en los índices D (Figura 14) y A (Figura 15) para diferentes definiciones de grupos vulnerables.

En el nivel primario en la dimensión de similitud la segregación aumentó sobre todo al incorporar al grupo de vulnerables al sector medio de la población, lo cual refleja lo hallado en la Figura 13, donde se observa que la migración desde las escuelas pública a las privadas parece haber tenido lugar en los percentiles más altos de la población. Por su parte, la dimensión de exposición (índice A) se ha incrementado para todos los grupos debido, principalmente, a los cambios en la composición de la matrícula, donde ha aumentando claramente la participación de los alumnos de estratos sociales más pobres. Los dos primeros quintiles de ingreso pasan de representar el $54 \%$ del total de alumnos de primara en el año 1992 en GBA al 62\% en 1998. Prueba de lo anterior es que la CSPD en el percentil 25 es igual en ambos periodos, mientras que la CSPA es claramente superior en el año 1998. Es decir que este grupo se distribuye de la misma manera en ambos periodos pero es en este último en el que se encuentran más expuestos a encontrarse con individuos de su mismo grupo debido a que ahora son una mayor proporción del total de alumnos. Recordar que este efecto es acumulativo a medida que se expande la población considerada vulnerable.

En el nivel secundario los análisis de robustez y sensibilidad también arrojan resultados interesantes. Por un lado, la CSPD muestra que, independientemente del grupo que se tome, la segregación en su dimensión de similitud ha aumentado entre los años 1992 y 1998. Este es el resultado de una mayor asociación entre el percentil del ingreso de las familias y la asistencia a cada tipo de establecimiento, como se observa en la Figura 13. Por su parte, la CSPA también presenta un incremento de la segregación en la dimensión exposición para todos los grupos posibles, y nuevamente los cambios en la composición de la matrícula tienen un efecto importante: los alumnos de los dos primeros quintiles representaban el 38\% del total de la matrícula secundaria en 1992 y el 50\% en 1998 . Este notable cambio se debe en gran parte al importante incremento en la proporción de jóvenes de estos estratos que asisten al colegio secundario.

Figura 14: Curva de segregación percentílica de disimilitud (CSPD). GBA.

Nivel Primario

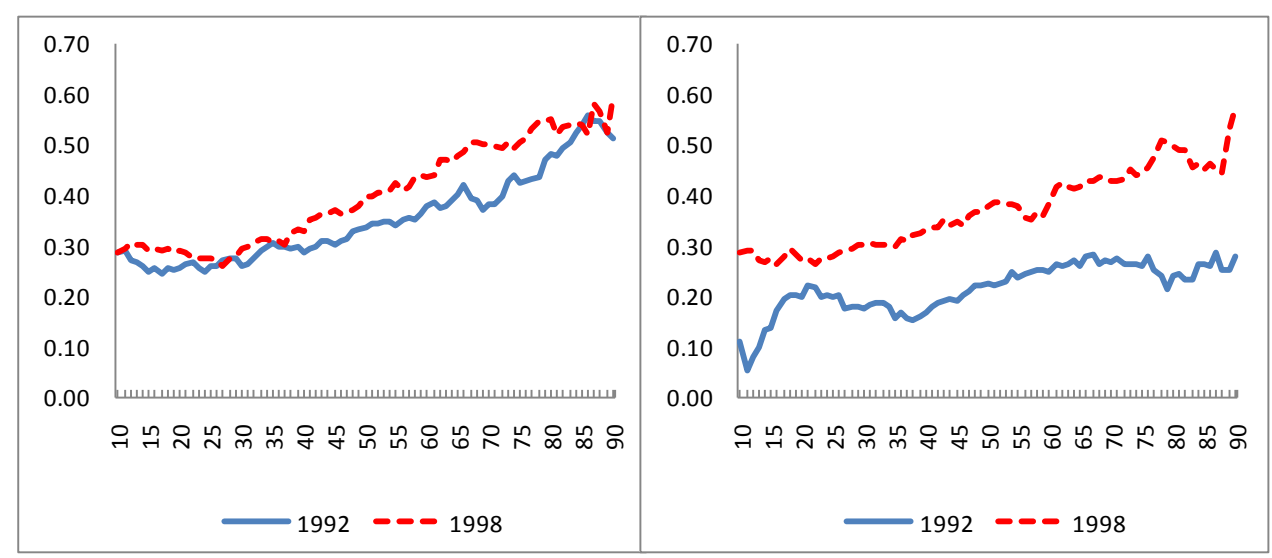

Fuente: Elaboración propia en base a las EPH de 1992 y 1998.

Nivel secundario 
Figura 15: Curva de segregación percentílica de aislamiento (CSPA). GBA.

Nivel Primario

Nivel secundario

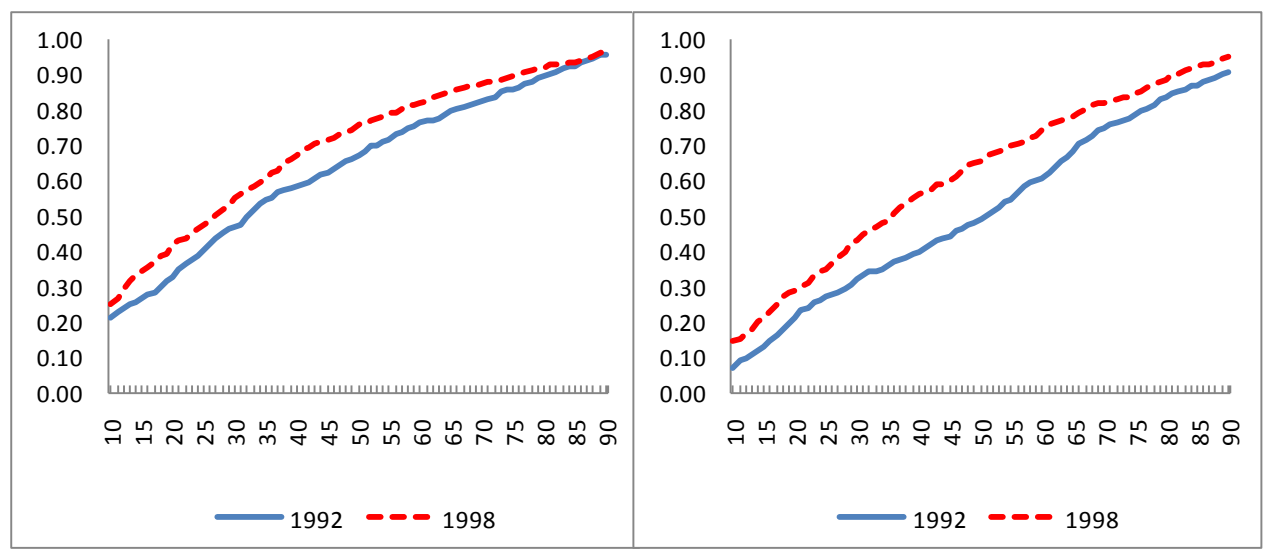

Fuente: Elaboración propia en base a las EPH de 1992 y 1998.

En lo que sigue de la sección se vuelve a poner en el centro del análisis a los alumnos pobres, pertenencientes al 20\% inferior de la distribución. Con este objetivo se presentan las Figuras 16 de CSPDV y 17 de CSPAV. En el nivel primario, el análisis intertemporal del periodo 1992- 1998 aporta principalmente dos resultados: el aumento de la segregación en la dimensión de similitud del grupo de pobres respecto a los grupos de mayores ingresos (del percentil 51 en adelante) y un incremento en la dimensión de exposición respecto de todos los percentiles, pero en especial de los grupos compuestos por personas del percentil 36 en adelante. El primero de estos efectos se debe a la primer ola migratoria en la educación primaria (del periodo bajo estudio) que consistió en una migración selectiva de los estratos con mayores ingresos desde las escuelas públicas hacia la educación privada. El segundo de estos efectos está influido tanto por la primer ola migratoria como por el incremento en la participación del primer quintil en la matrícula total primaria mostrado anteriormente.

Figura 16: Curva de segregación percentílica de disimilitud de vulnerables (CSPDV). GBA.

Nivel Primario

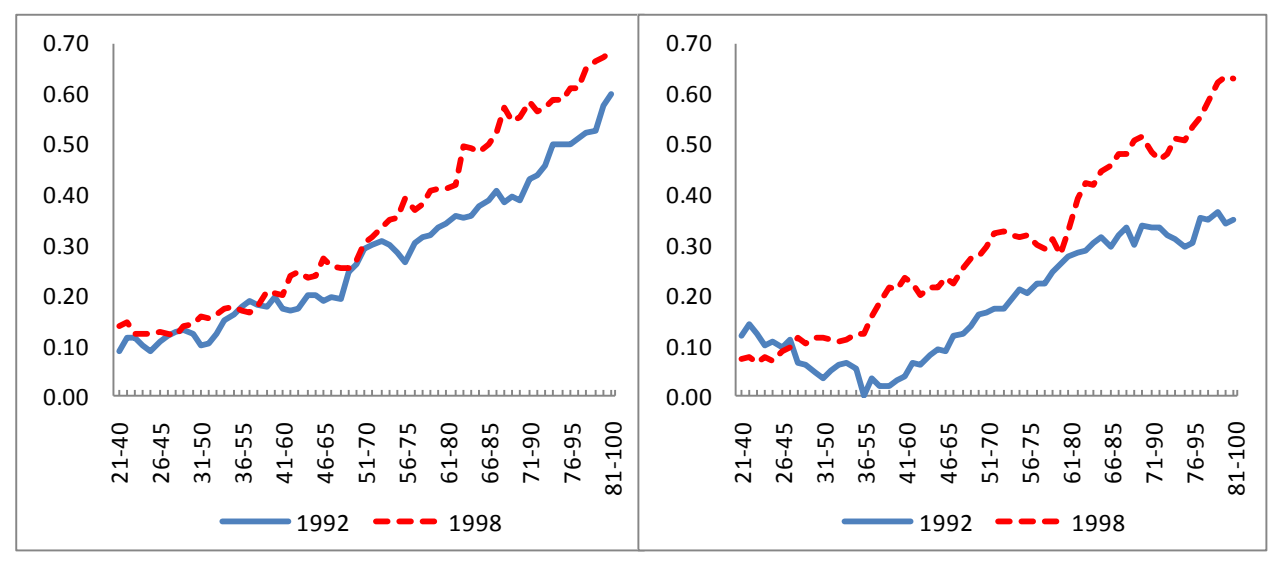

Fuente: Elaboración propia en base a las EPH de 1992 y 1998.

\section{Nivel secundario}


Figura 17: Curva de segregación percentílica de aislamiento de vulnerables (CSPAV). GBA.

Nivel Primario

Nivel secundario

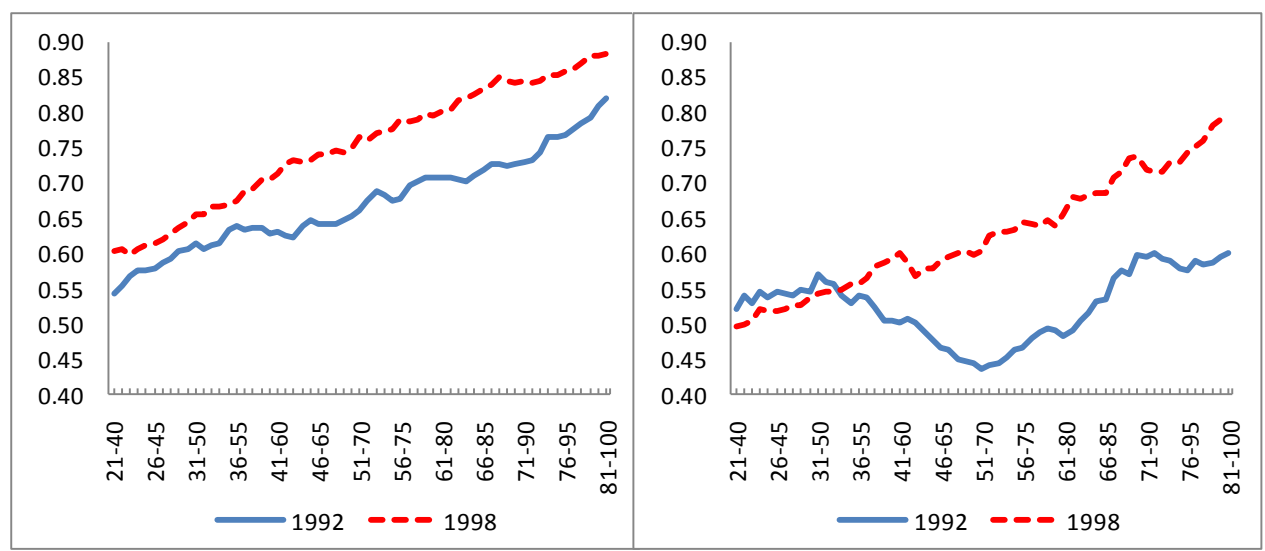

Fuente: Elaboración propia en base a las EPH de 1992 y 1998.

No se observa el mismo patrón en el nivel secundario. Por un lado, las curvas en el año 1992 muestran valores bajos y pendientes levemente positivas, indicando que los sectores más pobres que asistían al colegio secundario se encontraban poco segregados respecto de todos los demás grupos socio-económicos. Esto cambia en forma notable en el año 1998, donde se aprecia tanto un aumento significativo en la pendiente de las curvas como una disminución de la segregacíón en ambas dimensiones respecto a los grupos de ingresos medios bajos (percentiles 21 al 45) pero aumenta significativamente respecto del resto de la población.

En la Figura 18 se muestra el valor del EC y de los índices estimados de 1992 y 1998 al considerar como pobre al $20 \%$ de las familias más carenciadas. Se observa que este efecto nuevamente da cuenta de gran parte de los cambios acontecidos en el nivel primario, pero muy poco del incremento de la segregación escolar por estrato socio-económico que tuvo lugar en el nivel secundario. Este resultado sugiere que en el nivel primario era esperable el aumento de la segregación escolar debido a los cambios en el ingreso y demás características de las familias entre estos años, pero no así del notable incremento registrado en el nivel secundario, debido a razones similares a las explicitadas con anterioridad para el periodo 1992-2010.

Figura 18: Efecto características entre 1992 y 1998. GBA.

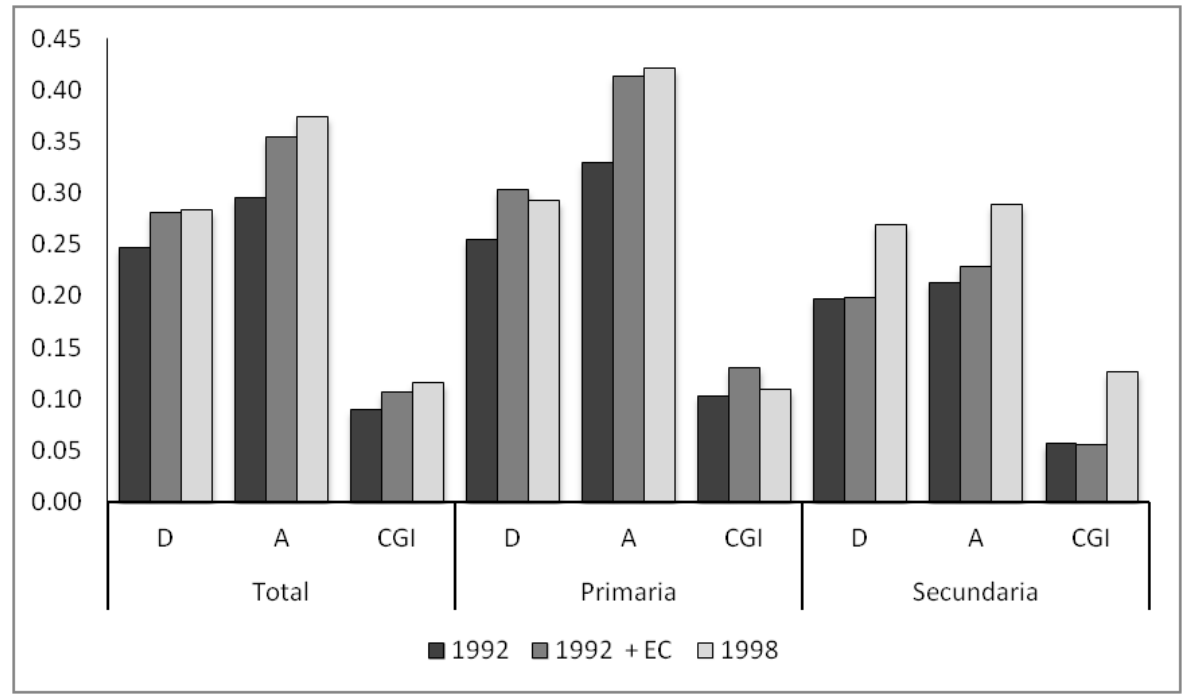

Fuente: Elaboración propia en base a las EPH de 1992 y 1998. 


\subsection{Sub-Periodo 2: 1998- 2003}

El periodo 1998- 2003 se caracteriza por mostrar poca variación en los niveles de segregación escolar con leves aumentos y caidas en algunos indicadores. ${ }^{45}$ En este caso, la EPH de los años 1998 y 2003 permiten ampliar el análisis desde GBA a datos representativos de las áreas urbanas de todo el país. Al igual que en la sección anterior, se analiza primero la relación entre la probabilidad de no asistir y asistir a cada tipo de establecimiento y el percentil de ingreso familiar per cápita. Luego, se realizan las Curvas de segregación percentílica para examinar la sensibilidad de los resultados a la elección del grupo vulnerable (CSPD y CSPA) y para poner en el centro del análisis a los alumnos pobres ( curvas CSPDV y CSPAV). Finalmente se realiza una descomposición parcial del efecto en la variación de las segregación obrado por los cambios en las características de las familias en el periodo analizado.

Figura 19: Probabilidad de asistir a una escuela pública, asistir a una escuela privada o no asistir. Años 1998 y 2003. Total país.

Prob. de asistir en Nivel Primario

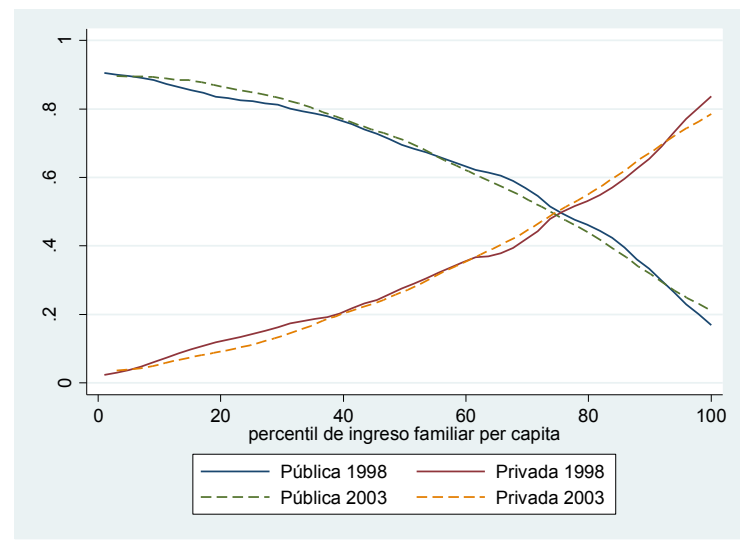

Prob. de asistir en nivel secundario

Prob. de no asistir al nivel secundario
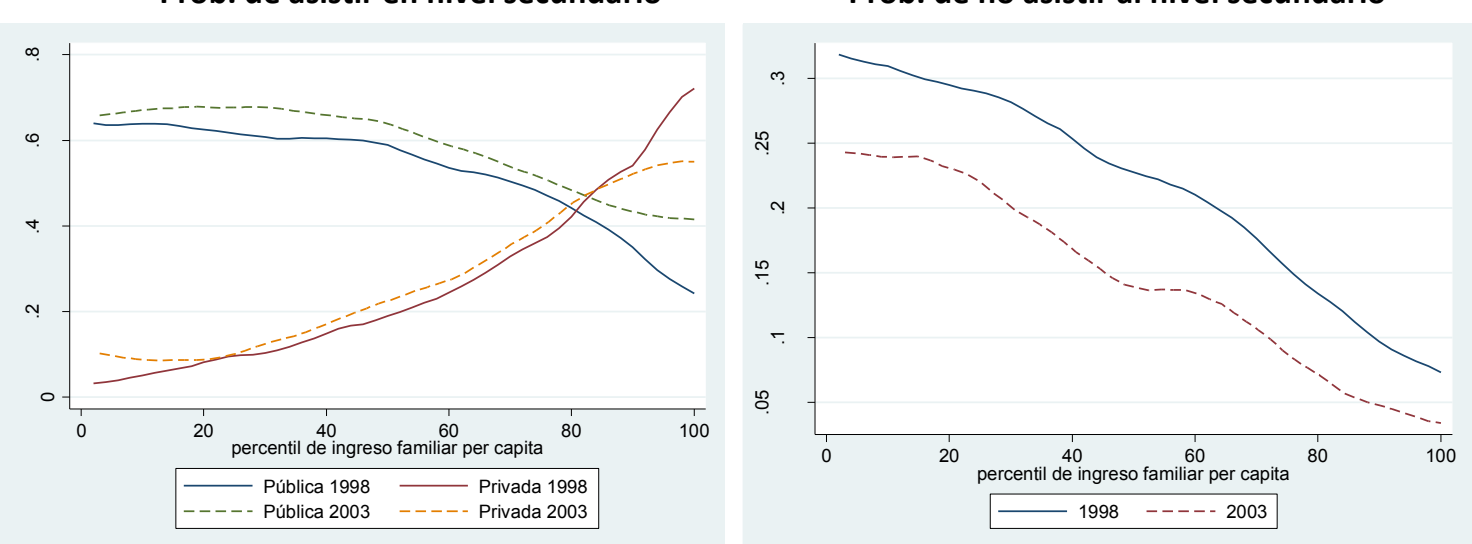

Fuente: Elaboración propia en base a las EPH de 1998 y 2003.

Nota: Los gráficos surgen de predecir la probabilidad de cada evento dadas las características del individuo mediante un modelo Logit Multinomial. Luego se realiza una regresión no paramétrica con kernels con ancho de banda óptimo para graficar la relación de estas probabilidades con el percentil del ingreso per cápita familiar.

La relación entre el percentil del ingreso familiar y la probabilidad de no asistir, asistir a un colegio privado, o asistir a un colegio público presentan un comportamiento diferente según el nivel

${ }^{45}$ Ver nota al pie número 29. 
educativo que se analice (ver Figura 19). En el nivel primario se verifica la clara relación negativa (positiva) entre la probabilidad de asistir a un colegio público (privado) y el percentil del ingreso, a la vez que no se observan modificaciones significativas en este patrón entre los años 1998 y 2003 . Por el contrario, el nivel secundario presenta una menor pendiente de las curvas y una notable disminución de la probabilidad de no asistir al colegio para todos los percentiles. Este aumento de la asistencia parece haber incrementado, principalmente, la probabilidad de asistir a una escuela pública, que aumenta prácticamente para todos los percentiles. En ambos niveles, a diferencia del periodo 1992-1998, mediante este análisis no se encuentran evidencias de una migración selectiva hacia las escuelas privadas. Incluso parece haber ocurrido un proceso inverso en el nivel secundario, especialmente en los percentiles más altos.

Con las curvas de segregación percentílicas (Figuras 20 y 21) se verifica parte de lo observado en el análisis anterior. En el nivel primario prácticamente no hay cambios en la segregación escolar en su dimensión de similitud cualquier sea el grupo analizado, aunque si presenta una caída en la dimensión de exposición para percentiles menores al 35, debido a cambios en la composición de la matrícula. Al considerar el nivel secundario, se observa que disminuye significativamente la segregación escolar en la dimensión de similitud para todos los grupos considerados, mostrando que los cambios en la manera en que se distribuyen los jóvenes de cada percentil entre escuelas públicas y privadas observados con anterioridad contribuyen a reducir la segregación en esta dimensión. Es decir que los alumnos de diferentes estratos económicos se distribuyen, en general, de forma más homogénea entre escuelas públicas y privadas en 2003 que en 1998. No obstante esto, la dimensión de exposición permanece invariante debido a que la mayor participación de los alumnos de menores ingresos en la matrícula total compensa el efecto anterior y los diferentes grupos de alumnos continúan físicamente tan aislados en el 2003 como en el año 1998.

Figura 20: Curva de segregación percentílica de disimilitud (CSPD). Total país. Nivel Primario Nivel secundario

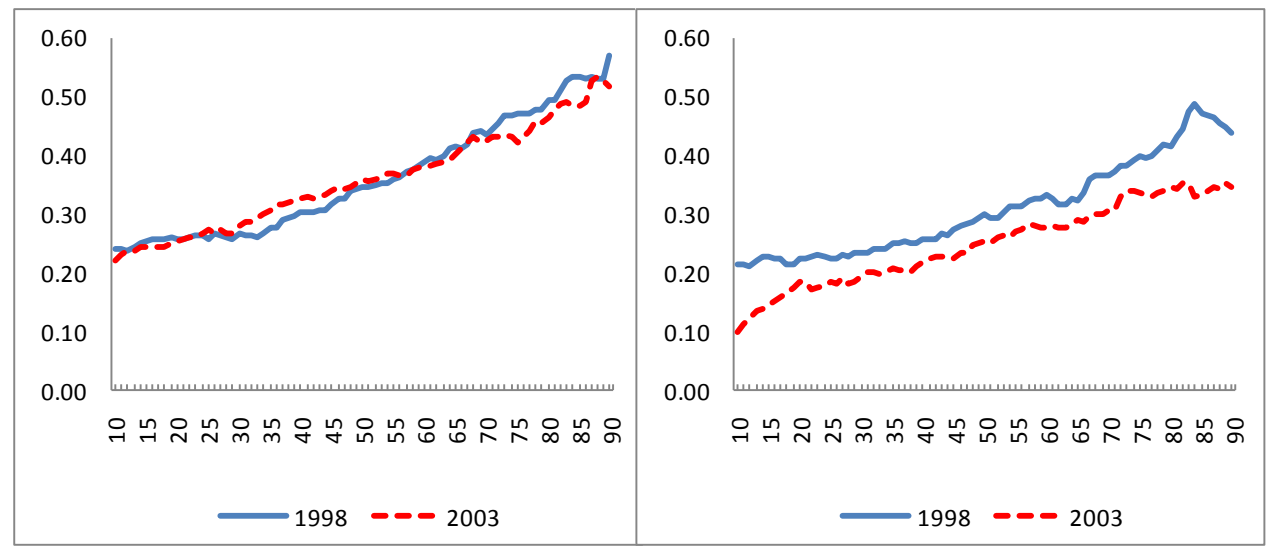

Fuente: Elaboración propia en base a las EPH de 1998 y 2003. 
Figura 21: Curva de segregación percentílica de aislamiento (CSPA). Total país.

Nivel Primario

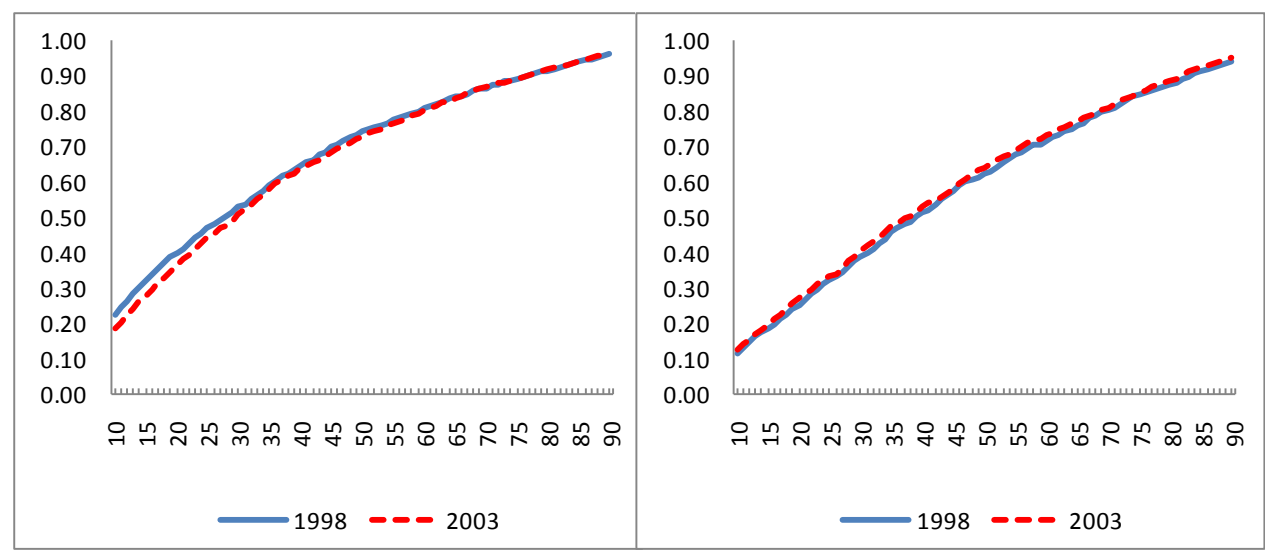

Fuente: Elaboración propia en base a las EPH de 1998 y 2003.

Nuevamente centrando el análisis en la población de alumnos pobres, a través de las CSPDV (Figura 22) y CSPAV (Figura 23), son pocas las variaciones de la segregación escolar por estrato socioeconómico entre escuelas públicas y privadas en este periodo, especialmente en comparación con la que tuvo lugar en la década de los noventa analizada anteriormente y de los dos mil que será analizada a continuación. En el nivel primario operan leves cambios en la dimensión de similitud, donde en general la proporción del grupo de pobres que debería cambiarse de tipo de establecimiento para distribuirse de la misma manera que el grupo de comparación permanece casi sin variantes, mostrando ligeras disminuciones respecto de los grupos de comparación con menor nivel socio-económico y tenues incrementos respecto del sector medio de la población. Si parece haber operado algún efecto en la composición de la matrícula ${ }^{46}$ que disminuye el aislamiento del grupo de alumnos más vulnerables respecto de la mayoría de los grupos de comparación, pero en especial de los de menores recursos.

Figura 22: Curva de segregación percentílica de disimilitud de vulnerables (CSPDV). Total país.

Nivel Primario

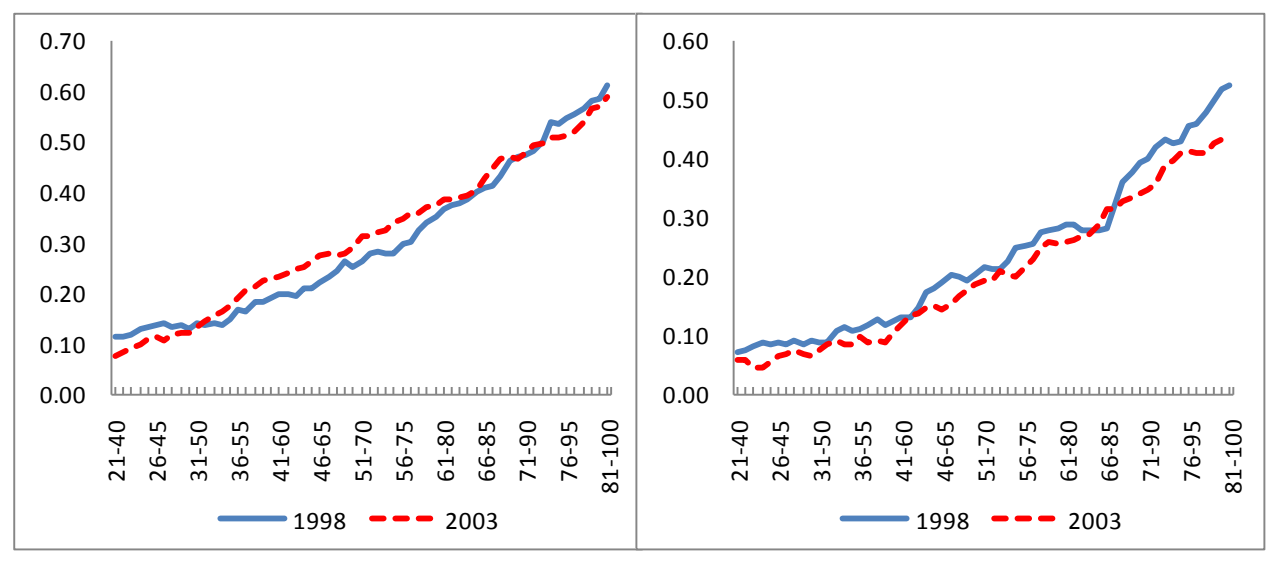

Fuente: Elaboración propia en base a las EPH de 1998 y 2003.

\section{Nivel secundario}

\footnotetext{
${ }^{46}$ Los alumnos pertenecientes al $20 \%$ más pobres de las familias pasan representar el $34.4 \%$ de la matrícula en 1998 al $31.2 \%$ en 2003.
} 
Figura 23: Curva de segregación percentílica de aislamiento de vulnerables (CSPAV). Total país. Nivel Primario Nivel secundario

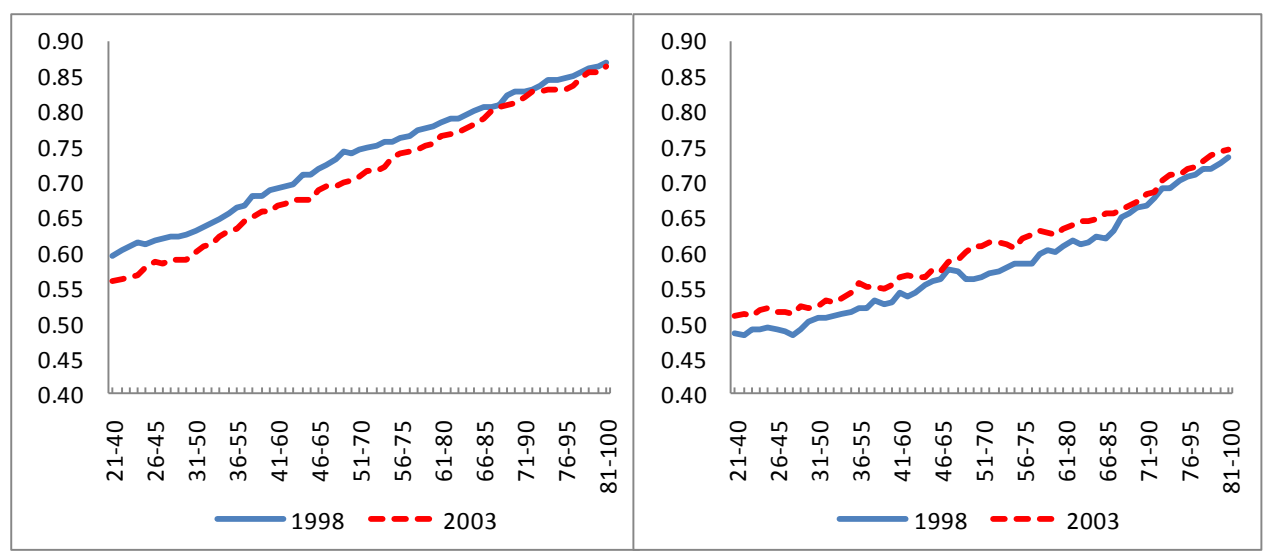

Fuente: Elaboración propia en base a las EPH de 1998 y 2003.

La evolución de los indicadores de segregación del grupo de pobres es diferente en el nivel secundario. La dimensión de similitud ha disminuido en relación a la mayoría de los grupos de comparación, de la misma manera que la dimensión de exposición presenta un incremento. De esta manera, los jóvenes no pobres se distribuyen, en general, de manera más parecida a la población de pobres, a la vez que éstos están más aislados del resto de la población. Lo anterior sólo es posible si el cambio en la composición de la matrícula ${ }^{47}$ produce mayor impacto en el índice A que el efecto de la distribución menos desigual de alumnos entre los diferentes tipos de escuelas. No obstante ambos cambios son relativamente leves en comparación a los demás periodos analizados.

El efecto característica estimado en este periodo muestra que los cambios en los niveles de segregación de 1998 a 2003 se deben en parte a variaciones en las características de las familias (ver Figura 24), pero éstas resultan menos exactas para explicar cambios en el fenómeno que en los demás periodos analizados, especialmente en primaria. De esta manera, debido principalmente a los cambios en el ingreso que tuvo lugar en el periodo (característica que presenta una fuerte variación entre estos años, especialmente al compararla con el resto de los variables consideradas) y la fuerte asociación entre éste y la elección del tipo de establecimiento que imperaba en 1998, era esperable que la segregación disminuyera notoriamente entre ambos periodos analizados: familias con menor ingreso es esperable que se inclinen más por colegios públicos debido a la relación encontrada en la Figura 19, a pesar que el resto de sus características haya permanecido invariante. Sin embargo el efecto de las características explica de manera inexacta los cambios acontecidos en ambos niveles, ya que en primaria era esperable una reducción más notable de la segregación escolar y en secundaria una caída más pequeña que la efectiva en 2003. Durante este periodo otros factores tuvieron incidencia en las decisiones escolares de las familias, ya que si bien la caída en nivel de ingreso de las familias parece haber jugado un papel importante, la segregación escolar disminuyó menos de lo esperado en primaria y más de lo esperado en secundaria (a excepción del índice A).

\footnotetext{
${ }^{47}$ Los alumnos pertenecientes al $20 \%$ más pobre de las familias pasan de representar el $22 \%$ de la matrícula en 1998 al $25 \%$ en 2003.
} 
Figura 24: Estimación del efecto características entre 1998 y 2003. Total país.

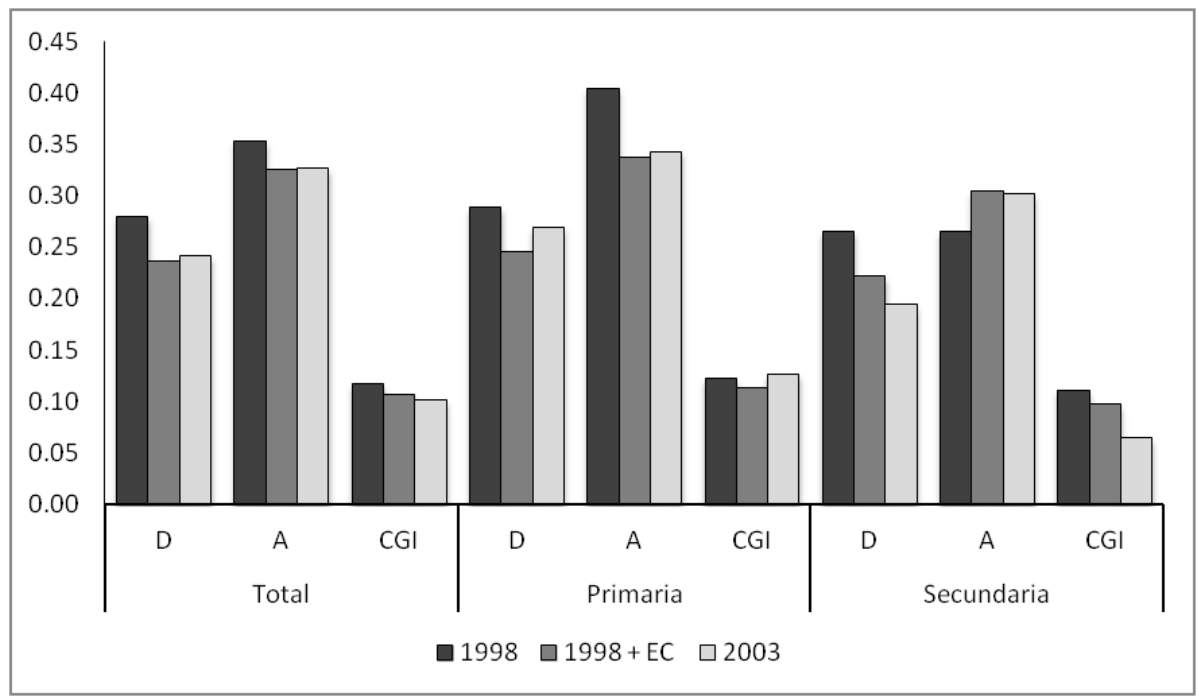

Fuente: Elaboración propia en base a las EPH de 1998 y 2003.

\subsection{Sub-Periodo 3: 2003- 2010}

El último sub- periodo estudiado corresponde a los años 2003- 2010. Los datos de la EPH continua de cada uno de estos años permiten realizar un estudio representativo del casco urbano a nivel país. La segregación escolar muestra un marcado crecimiento en estos años, aún a pesar de la caída en el nivel de desigualdad de ingresos. Los incrementos en la segregación escolar que se observan en la Figura 7, pueden entenderse al observar los cambios en la relación del percentil del ingreso per cápita familiar y las diferentes probabilidades en cada nivel (ver Figura 25).

En el nivel primario es notable el incremento de las pendientes, mostrando que desde el año 2003 al 2010 disminuye la probabilidad de asistir a un colegio público (aumentando por lo tanto la probabilidad de asistir a un colegio privado) para todos los percentiles, pero este cambio es casi imperceptible para percentiles menores al 20 e importante para el sector de medianos ingresos. De esta manera, mientras que en 2003 sólo a partir del percentil 77 era más probable que un alumno asistiera a un colegio privado, en 2010 la misma relación se da en el percentil 60. Estos resultados muestran una clara migración de la población de estratos medios bajos, medios y altos desde los colegios públicos hacia las escuelas privadas.

La educación secundaria presenta una evolución similar al sector primario, donde se da una migración selectiva de la población no pobre hacia los colegios privados, pero con el matiz adicional de una incorporación fuerte del sector de bajos ingresos a la educación pública ${ }^{48}$. De esta manera, el primero de estos efectos parece ocasionar un incremento en las pendientes del extremo derecho del gráfico, mientras que el segundo tiene efecto en el extremo izquierdo del mismo.

\footnotetext{
${ }^{48}$ La probabilidad de no asistir al colegio secundario de los miembros en edad escolar del $20 \%$ más pobre de la población disminuye de $24 \%$ en 2003 a 16\% en 2010 .
} 
Figura 25: Probabilidad de asistir a una escuela pública, asistir a una escuela privada o no asistir. Años 2003 y 2010. Total País.

Prob. de asistir en Nivel Primario

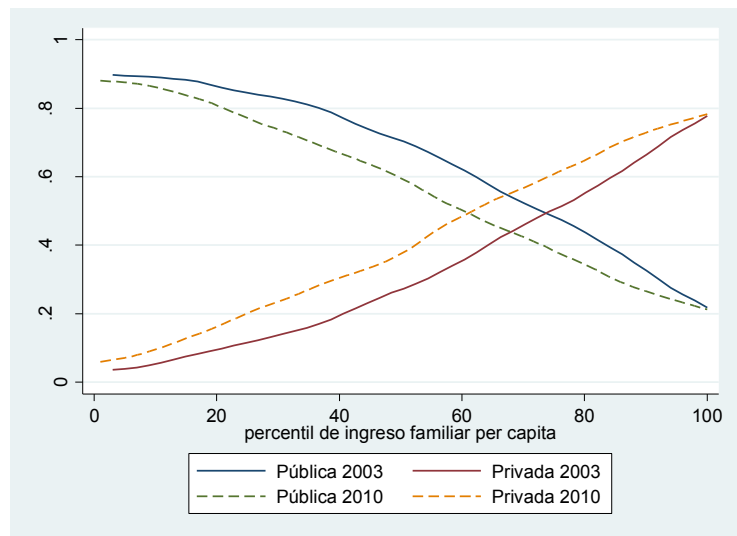

Prob. de asistir en nivel secundario

Prob. de no asistir al nivel secundario
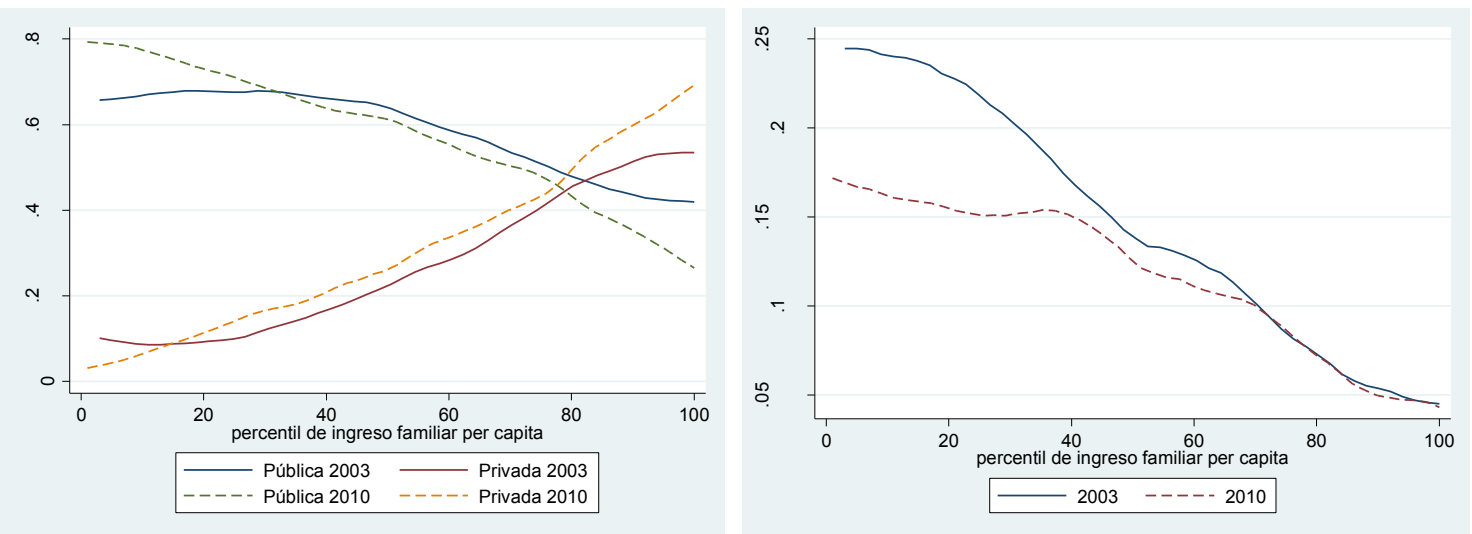

Fuente: Elaboración propia en base a la EPH de 2003 y 2010.

Nota: Los gráficos surgen de predecir la probabilidad de cada evento dadas las características del individuo mediante un modelo Logit Multinomial. Luego se realiza una regresión no paramétrica con kernels con ancho de banda óptimo para graficar la relación de estas probabilidades con el percentil del ingreso per cápita familiar

En el análisis de robustez y sensibilidad a la elección de grupos, la CSPD y CSPA (Figuras 26 y 27 respectivamente) arrojan un claro (pero diferente) patrón en cada nivel educativo. En el nivel primario aumenta el nivel de segregación en ambas dimensiones (similitud y exposición) para cualquier definición de grupos con el punto de corte anterior al percentil 65, mientras que muestra una leve disminución para puntos de cortes superiores a este punto. Que las curvas se crucen de esta manera indica una mayor segregación de los estratos más bajos respecto del resto pero más interacción de los estratos medios con los estratos más ricos de la población. Es por esta razón que el crecimiento del índice CGI no es tan notable como el de los índices D y A durante estos años, como muestra la Figura 7, ya que se trata de una medida general de segregación que se ve disminuida por la mayor interacción de los sectores medios con los sectores altos.

En lo que respecta al nivel secundario, la segregación muestra aún un incremento más sustancial que en el nivel primario para la mayoría de los grupos analizados. Cabe destacar la distancia que toman ambas curvas en sólo 7 años, sobre todo para los percentiles más bajos, indicando que los alumnos de menores recursos se distribuyen de forma más desigual y se encuentran mucho más aislados en el año 2010 que en el año 2003. Por ejemplo, para el grupo de alumnos de percentiles menores al 25 el índice $D$ pasa de 0.18 a 0.28 y el A de 0.33 a 0.42 . 
Figura 26: Curva de segregación percentílica de disimilitud (CSPD). Total país.

Nivel Primario Nivel secundario

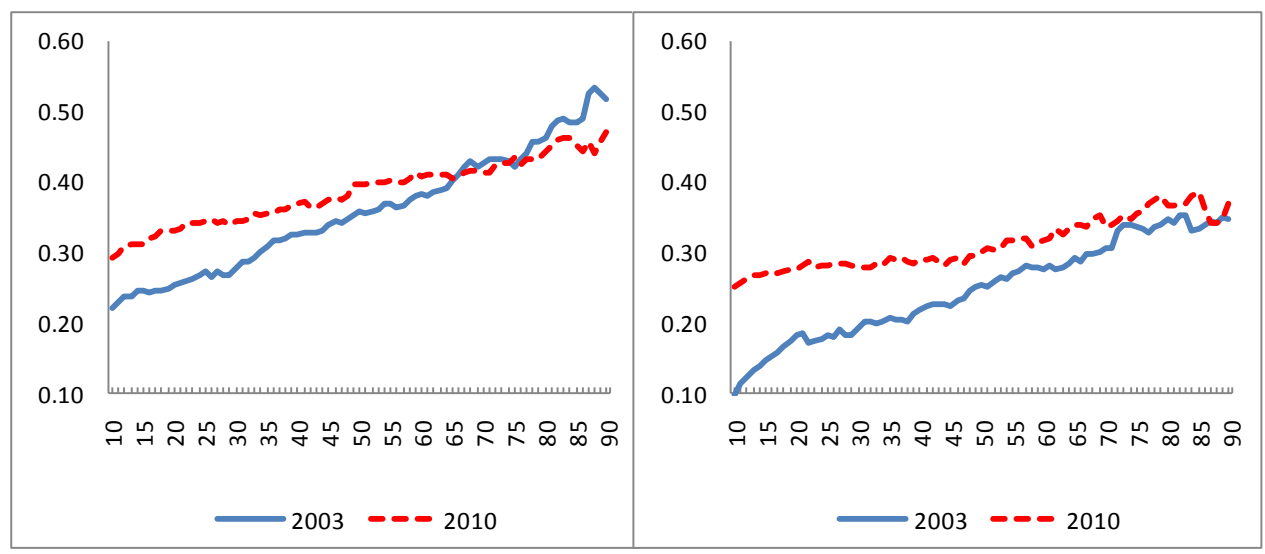

Fuente: Elaboración propia en base a la EPH de 2003 y 2010.

Figura 27: Curva de segregación percentílica de aislamiento (CSPA). Total país. Nivel Primario Nivel secundario

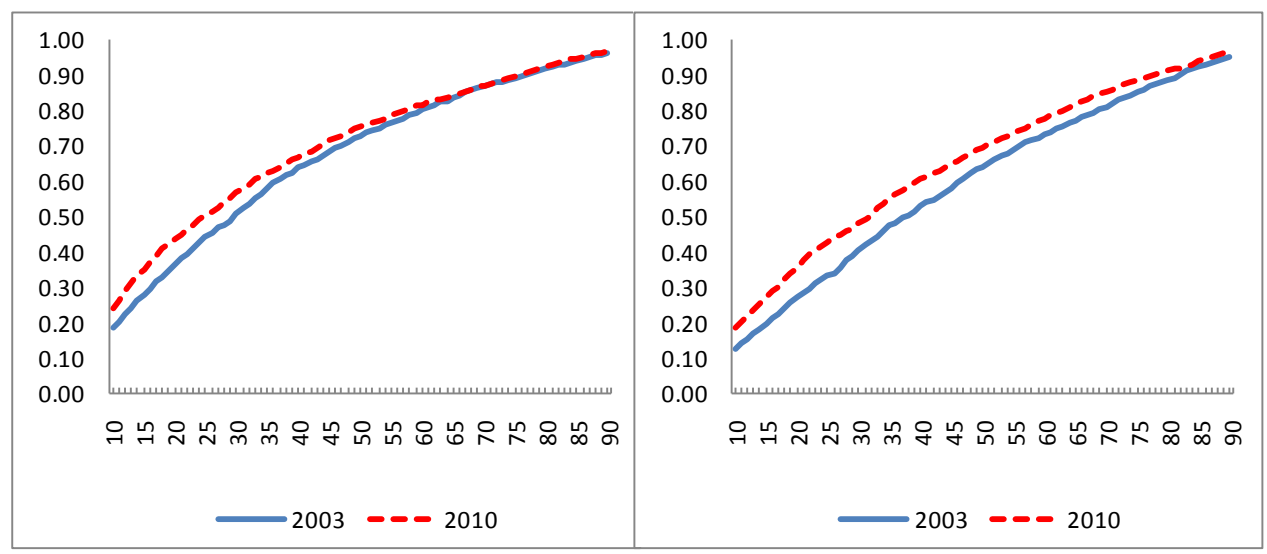

Fuente: Elaboración propia en base a la EPH de 2003 y 2010.

Es interesante el análisis intertemporal del las CSPDV y CSPAV (Figuras 28 y 29) donde en ambos niveles se observa que los estudiantes del nivel primario considerados pobres se encuentran más segregados respecto de todos los grupos de comparación posibles. En la primaria, el incremento más importante se registra del centro a la izquierda de la curva, por lo que el grupo de pobres se separó más en este periodo de los grupos de ingresos medios y medios bajos de la población que de los sectores más ricos. De hecho, del único grupo del cual no se registran aumentos importantes de los niveles de segregación escolar corresponde al quintil más rico (percentiles 81 a 100). Este fenómeno da forma a la segunda ola de migración selectiva en el nivel primario que, a diferencia de la primera que se da en los sectores de mayores ingresos, tiene lugar en los estratos medios y medios bajos de la población.

En el nivel secundario ocurre algo similar pero con algunas particularidades adicionales. El $20 \%$ más pobre de la población se encuentra más segregado respecto a todos los grupos restantes, aunque el cambio es levemente diferente en cada dimensión del fenómeno. Mientras en la dimensión de similitud el aumento fue prácticamente homogéneo para todos los grupos de la población, en la dimensión de exposición los aumentos son algo más grandes a medida que los grupos de comparación corresponden a percentiles más elevados. 
Figura 28: Curva de segregación percentílica de disimilitud de vulnerables (CSPDV). Total país. Nivel Primario Nivel secundario

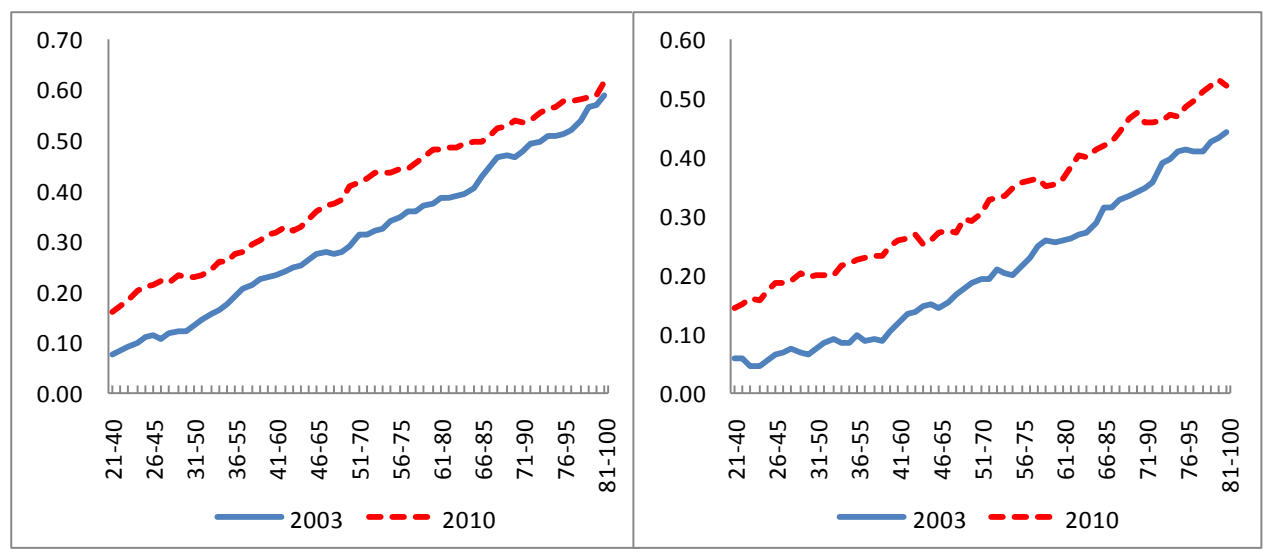

Fuente: Elaboración propia en base a la EPH de 2003 y 2010.

Figura 29: Curva de segregación percentílica de aislamiento de vulnerables (CSPAV). Total país. Nivel Primario Nivel secundario

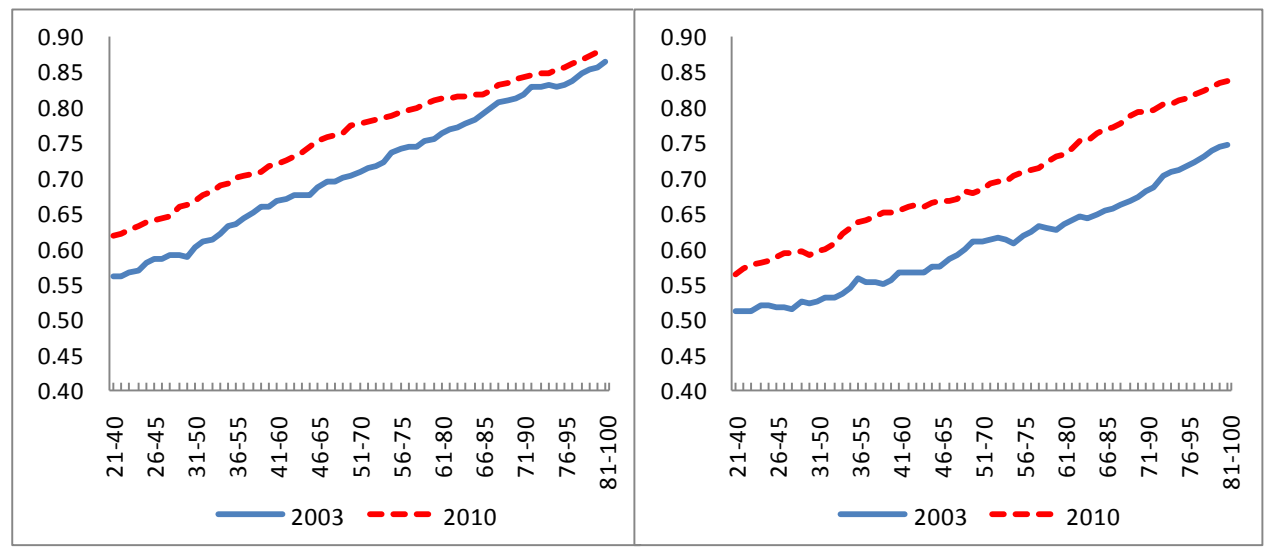

Fuente: Elaboración propia en base a la EPH de 2003 y 2010.

Por último, los cambios en segregación escolar en este periodo están muy relacionados con variaciones en las características de las familias, pero las mismas no son suficientes para explicar la magnitud del incremento en los niveles de segregación, especialmente en el nivel secundario. La Figura 30, muestra que durante el periodo analizado el efecto características resulta más importante en el índice $A$ que en el resto de los índices, probablemente porque ya tiene incorporado el efecto de los cambios en la composición socio-económica de la matrícula, que afectan de manera directa el valor de éste índice. 
Figura 30: Curva Estimación del Efecto Características entre 2003 y 2010. Total país.

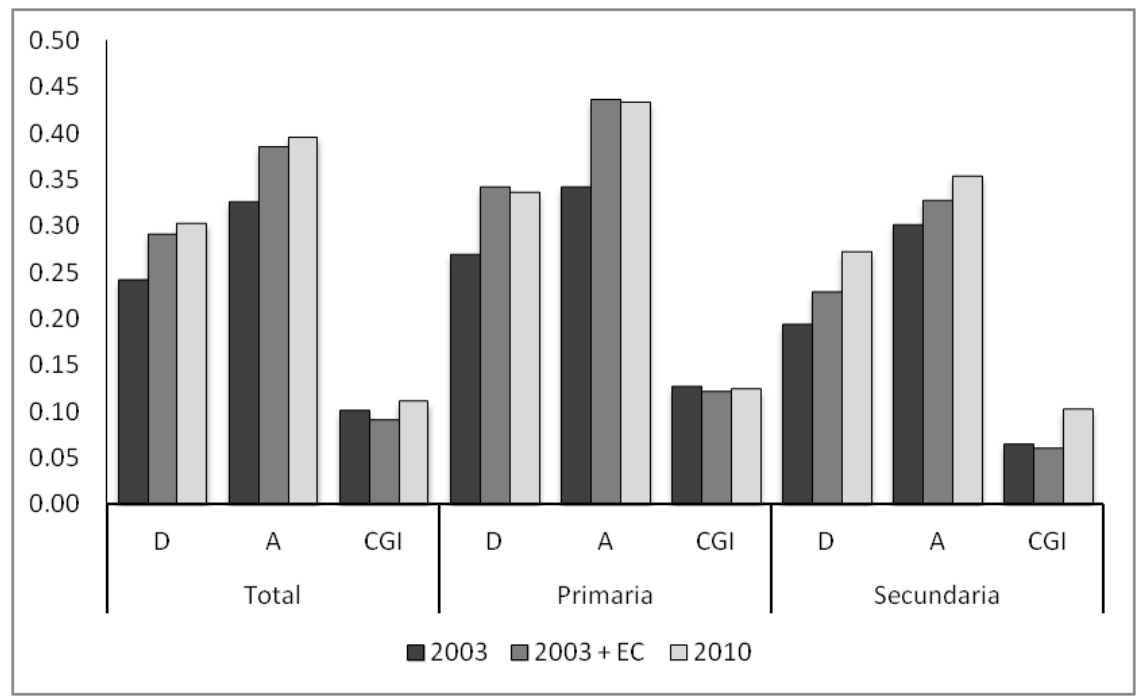

Fuente: Elaboración propia en base a la EPH de 2003 y 2010.

\section{Conclusiones}

El objetivo del trabajo ha sido analizar exhaustivamente la evolución de la segregación escolar por estrato socio-económico entre escuelas públicas y privadas en Argentina, para lo cual se definieron y utilizaron dos nuevas herramientas en el análisis de éste fenómeno: Las curvas de segregación percentílicas y el modelo de decisiones escolares. En particular, el estudio se centró en los alumnos pertenecientes las familias del $20 \%$ más pobre de la población. Para ello se analizaron las Encuestas Permanentes de Hogares del periodo 1992- 2010 que poseen información representativa a nivel país acerca del tipo de colegio al que asiste cada alumno y de los ingresos de sus familias.

Todos los tipos de análisis utilizados proveen fuerte evidencia empírica de un aumento alarmante de la segregación escolar en la Argentina entre los años 1992 y 2010. Tanto en el nivel primario como en el nivel secundario se observa una intensa migración selectiva de los alumnos menos carenciados desde los colegios públicos a los privados, así como cambios en la composición socio-económica de la matrícula escolar. La dirección y magnitud de ambos efectos se encuentra detrás del notable incremento de la segregación escolar en la Argentina.

La proporción de alumnos pobres que debería pasar a escuelas privadas para que éstos se distribuyan de la misma manera al resto de la población (índice D) aumenta un $47 \%$ en el nivel primario y un $74 \%$ en el nivel secundario. Por su parte, la probabilidad de que un alumno pobre se relacione con otros alumnos de su mismo grupo presenta también amplios cambios porcentuales: $40 \%$ en primaria y $90 \%$ en la educación secundaria. Finalmente el CGI se incrementa cerca de un $30 \%$ en primaria y más del $100 \%$ en secundaria. No hay dudas de que la segregación escolar se ha incrementado y esto es particularmente importante en el nivel secundario. No obstante, las variaciones de la segregación no son iguales en todos los años analizados y es posible distinguir tres periodos con comportamientos bien diferenciados.

En primer lugar, la década de los noventa (años 1992 a 1998) presenta un fuerte aumento en la segregación escolar en ambos niveles educativos. En la educación primaria se produce una fuerte ola 
migratoria en los alumnos de sectores de ingresos altos y medios- altos desde la escuela pública a la privada, mientras que en la educación secundaria se combina el efecto anterior con un incremento en la tasa bruta de asistencia de todos los estratos socio-económicos, en particular de aquellos estratos de menores ingresos. En segundo lugar, los años de recesión y crisis en Argentina (periodo 1998- 2003) muestran una leve caída del nivel de segregación en el nivel primario, así como un tenue aumento de la misma en el nivel secundario. En tercer y último lugar, la década de los dos mil (años 2003 a 2010) exhibe nuevamente un importante incremento en los niveles de segregación escolar, y es particularmente notable en los alumnos más pobres. En este último periodo en el nivel primario se produce la segunda ola migratoria hacia las escuelas privadas, esta vez impulsada por los sectores medios y medios- bajos de la población, mientras que en el nivel secundario nuevamente se combina este efecto con el incremento de la tasa bruta de asistencia de los sectores más carenciados.

Los resultados encontrados son robustos a diferentes definiciones de grupos de población vulnerable: aún tomando como vulnerables a los alumnos de familias del $65 \%$ más pobre de la población bajo estudio, la segregación escolar ha aumentado entre 1992 y 2010 . Por otra parte, al centrar el análisis en los alumnos considerados pobres, se observan que éstos están mucho más segregados en 2010 que en 1992 respecto de cualquier otro grupo de alumnos, especialmente de los sectores altos pero también de los sectores medios y medios-bajos.

Finalmente, gran parte de los cambios en los niveles de segregación escolar en el nivel primario se pueden atribuir a las variaciones en las características de las familias tomadoras de decisiones escolares. Tanto el aumento en el ingreso de las familias, en la educación de los hogares, como en otras características han impactado en la segregación escolar de manera tal que explican la mayor parte de las variaciones observadas. Por el contrario, en el nivel secundario el efecto características de poco sirve para explicar las significativas variaciones en segregación escolar debido a que operaron cambios más profundos respecto a la manera en que las familias toman decisiones escolares de sus miembros en edad de asistir a este nivel, por lo que es necesario un análisis causal más profundo en este nivel para determinar que motivó a las familias a modificar sus decisiones escolares.

El trabajo presenta una radiografía de la segregación escolar por estratos socio-económicos entre escuelas públicas y privadas en la Argentina. Los elevados niveles y la tendencia del fenómeno resultan alarmantes, y deben necesariamente llamar la atención de los tomadores de decisiones dadas las consecuencias negativas de la segregación escolar en aspectos tan relevantes como la cohesión social y la igualdad de oportunidades. De esta manera, el trabajo genera un desafío de política escolar, que posiblemente debería enfocarse en remover las desigualdades educativas entre escuelas públicas y privados de manera tal que los colegios públicos vuelvan a ser elegidos por familias de todas las clases sociales Argentinas. 


\section{Referencias}

Blinder, A. (1973). "Wage Discrimination: Reduced Form and Structural Estimate." The Journal of Human Resources VIII (4), 436-453.

Bourguignon, F., Ferreira, F. and Lustig, N. (1998). "The microeconomics of income distribution dynamics in East Asia and Latin America." IDB-World Bank Research Proposal.

Bourguignon, F. and Spadaro, A. (2006). "Micorsimulation as a tool for evaluating redistribution policies." Journal of Economic Inequality, vol 4: 77-106.

Bourguignon, F., Ferreira, F. and Leite, P. (2003). "Conditional Cash Transfers, Schooling, and Child Labor: Micro- Simulating Brazil's Bolsa Escola Program." The World Bank Economic Review, vol 17 Nro 2: 229- 254.

Brock, W. and Durlauf, S. (2001). "Discrete Choice with Social Interactions." Review of Economic Studies 68, pp. 235-260.

Cervini, R. (2003). "Diferencias de resultados cognitivos y no-cognitivos entre estudiantes de escuelas públicas y privadas en la educación secundaria de Argentina: Un análisis multinivel." Education Policy Analysis Archives, Vol. 11, No. 6.

Cowell, F. (2000). Measuring Inequality. Oxford University Press.

Davidson, R. and Mackinnon, J. (2004). Econometric Theory and Methods. New York. Oxford University Press.

Duncan, O. y Duncan, B. (1955). "A Methodological Analysis of Segregation Indexes." American Sociological Review, Vol. 20, No. 2, pág. 210-217.

Durlauf, S. (2006). "Groups, Social Influences, and Inequality: A Memberships Theory Perspective on Poverty Traps." Poverty Traps, eds. S. Bowles, S. Durlauf, and K. Hoff, Princeton, Princeton University Press.

Gasparini, L., Jaume, D., Serio, M. y Vazquez, E. (2010). “Evolución de la Segregación Escolar en la Argentina. Reconstruyendo la Evidencia." Documento de Trabajo Nro. 123. Centro de estudios Distributivos Laborales y Sociales (CEDLAS). Universidad Nacional de La Plata.

Glaeser, E. y Vidgor, J. (2001). "Racial Segregation in the 2000 Census: promising news." Center on Urban and Metropolitana Policy. The Brookings Institution-Survey Series.

Grootaert, C. y Patrinos, H. (1999). "A Four Country Comparative Study of Child Labor." Washington, DC: World Bank.

James, D. y Taeuber, K. (1985). "Measures of Segregation." Sociological Methodology, Vol. 15, pág. 1-32. 
Juhn, C., Murphy, K. and Pierce, B. (1993). "Wage Inequality and the Rise in Returns to Skill." Journal of Political Economy 101.

Llach, J., Montoya, S. y Roldán, F. (1999). Educación para Todos. Instituto de Estudios de la Realidad Argentina y Latinoamericana (IERAL). Buenos Aires.

Marchionni, M., Vazquez, E. y Pinto, F. (2011). "Desigualdad Educativa Argentina. Análisis en base a datos de Pisa 2009." Mimeo. CEDLAS-UNLP.

Massey, D. y Denton, N. (1988). "The Dimensions of Racial Segregation." Social Forces, Vol. 67, No. 2, pág. 281-315.

McFadden, D. (1984). "Econometric Analysis of Qualitative Response Models." Handbook of Econometrics Volumen II, MIT.

Morduchowicz, A. (coord.) (2000). La Educación Privada en la Argentina: Historia, Regulaciones y Asignación de Recursos Públicos. Centro de Estudios para el Desarrollo Institucional (CEDI) de la Fundación Gobierno y Sociedad. Buenos Aires.

Moyi, P. (2010). "Child Labor and School Attendance in Kenya." Educational Research and Reviews, vol 6 Nro 1: 26-35.

Narodowski, M. y Andrada, M. (2000). "Segregación Socioeconómica y Regulaciones en el sistema Educativo Argentino." Documento de trabajo número 37. Universidad de San Andres.

Orfield, G. (2001). "Schools More Separate: Consequences of a decade of resegregation." The Civil Rights Project, Harvard University, Cambridge MA.

Oaxaca, R. (1973). "Male-Female Wage Differentials in Urban Labor Market." International Economic Review 14.

Post, D. (2002). "Children's Work, Schooling, and Welfare in Latin America." Boulder, CO: Westview Press.

Rivas, A., Vera, A. y Bezem, P. (2010). Radiografía de la Educación Argentina. Fundación Centro de Implementación de Políticas Públicas para la Equidad y el Crecimiento (CIPPEC). 1 ed. Buenos Aires.

Schelling, T. (1978) . Micromotives and Macrobehavior, Norton, New York.

Valenzuela, J. (2008). "Evolución de la Segregación Socioeconómica de los Estudiantes Chilenos y su Relación con el Financiamiento Compartido." Proyecto FONIDE, No. 211 - 2006, Ministerio de educación de Chile, Universidad de Chile.

Watson, T. (2009). "Inequality and the Measurement of Residential Segregation by Income in American Neighborhoods." NBER Working Paper, No. 14908. 
www.diniece.me.gov.ar (Resultados Operativos Nacionales de Evaluación. Dirección Nacional de Información y Evaluación de la Calidad Educativa. Ministerio de Educación de la Nación Argentina. Octubre, 2011).

www.indec.gov.ar (Instituto Nacional de Estadísticas y Censos. Octubre, 2011). 